\title{
Control Loop Tuning and Surge Response for Hanford WTP Melter Offgas Systems
}

September 22, 2003

SRTC Immobilization Technology Section

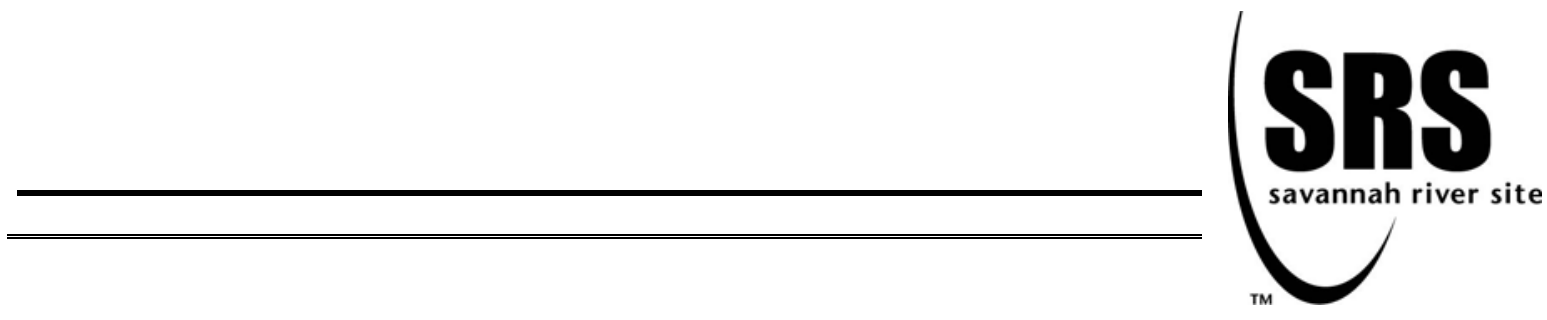


This document was prepared in conjunction with work accomplished under Contract No. DE-AC09-96SR18500 with the U. S. Department of Energy.

\section{DISCLAIMER}

This report was prepared as an account of work sponsored by an agency of the United States Government. Neither the United States Government nor any agency thereof, nor any of their employees, makes any warranty, express or implied, or assumes any legal liability or responsibility for the accuracy, completeness, or usefulness of any information, apparatus, product or process disclosed, or represents that its use would not infringe privately owned rights. Reference herein to any specific commercial product, process or service by trade name, trademark, manufacturer, or otherwise does not necessarily constitute or imply its endorsement, recommendation, or favoring by the United States Government or any agency thereof. The views and opinions of authors expressed herein do not necessarily state or reflect those of the United States Government or any agency thereof.

This report has been reproduced directly from the best available copy.

Available for sale to the public, in paper, from: U.S. Department of Commerce, National Technical Information Service, 5285 Port Royal Road, Springfield, VA 22161, phone: (800) 553-6847, fax: (703) 605-6900

email: orders@ntis.fedworld.gov

online ordering: http://www.ntis.gov/help/index.asp

Available electronically at http://www.osti.gov/bridge

Available for a processing fee to U.S. Department of Energy and its contractors, in paper, from: U.S. Department of Energy, Office of Scientific and Technical Information, P.O. Box 62, Oak Ridge, TN 37831-0062,

phone: (865)576-8401,

fax: (865)576-5728

email: $\underline{\text { reports@ adonis.osti.gov }}$ 
WSRC-TR-2003-00434, Rev. 0

SRT-RPP-2003-00206, Rev. 0

Key Words:

Computer model, Dynamic modeling,

Process Flowsheet

Retention: Permanent

WTP Reference:

Statement of Work -

$H L W$ and LAW Vitrification

Dynamic Pressure

Modeling

\section{Control Loop Tuning and Surge Response for Hanford WTP Melter Offgas Systems}

Frank G. Smith, III

September 22, 2003

Westinghouse Savannah River Company

Savannah River Site

Aiken, SC 29808

Prepared for the U.S. Department of Energy Under Contract Number DE-AC09-96SR18500

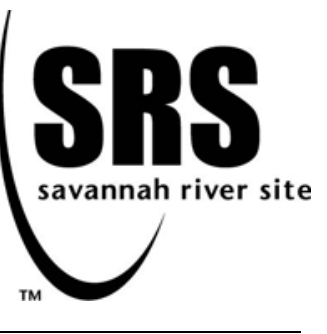


This page was intentionally left blank 


\section{Table of Contents}

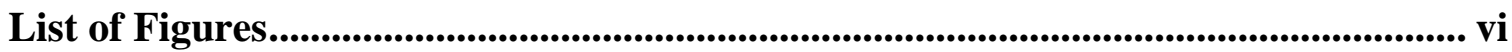

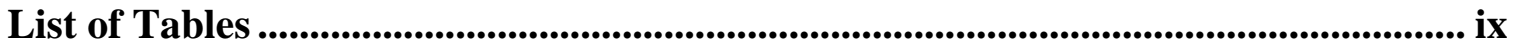

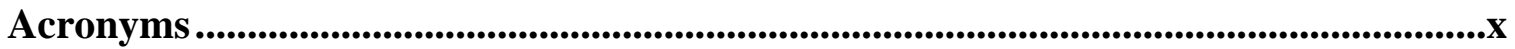

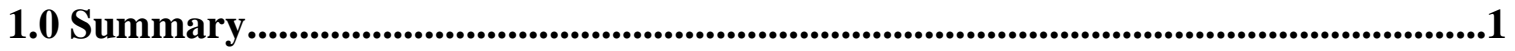

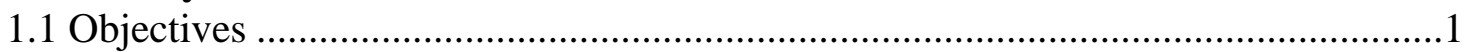

1.2 Conduct of Computer Model Studies ...............................................................2

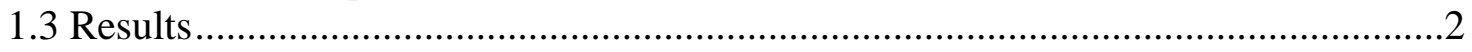

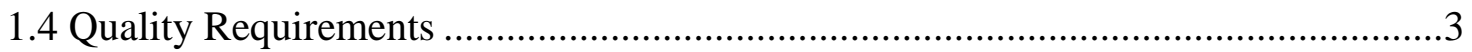

2.0 Control Loop Tuning....................................................................................................4

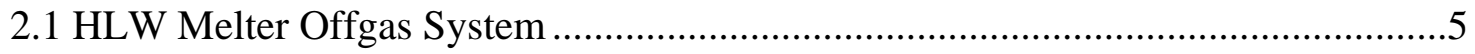

2.1.1 HLW Melter Pressure Control Loop...........................................................8

2.1.2 HLW Vessel Ventilation Control Loop ........................................................12

2.1.3 HLW Fan Speed Control Loop without Signal Averaging ..............................17

2.1.4 HLW Fan Speed Control Loop with 15 Second Signal Averaging ...................21

2.1.5 HLW Fan Speed Control Loop with 30 Second Signal Averaging ..................23

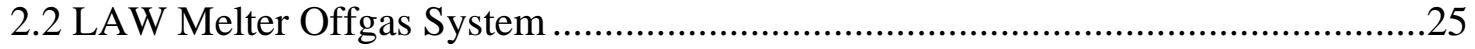

2.2.1 LAW Melter Pressure Control Loop...........................................................28

2.2.2 LAW Vessel Ventilation Control Loop ..........................................................31

2.2.3 LAW Damper Valve Control Loop without Signal Averaging .........................35

2.2.4 LAW Damper Valve Control Loop with 15 second Signal Averaging .............40

2.2.5 LAW Damper Valve Control Loop with 30 second Signal Averaging .............45

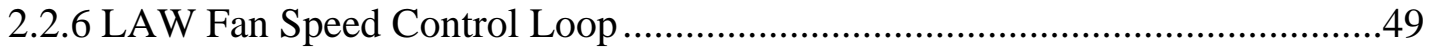

2.3 HLW Pulse Jet Ventilation System ................................................................52

2.3.1 PJV Pressure Control Loop without Signal Averaging ....................................54

2.3.2 PJV Pressure Control Loop with 30 Second Signal Averaging........................57

3.0 Steam Surge Response ...........................................................................................60

3.1 HLW Melter Offgas System .....................................................................60

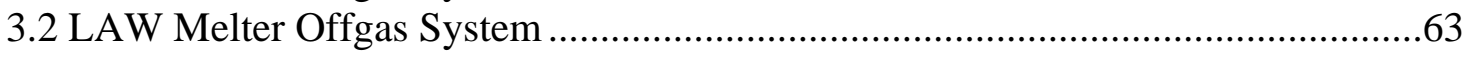

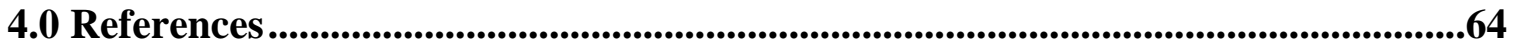

Appendix A: HLW Dynamic Modeling Tuning Procedural Steps.................................65

Appendix B: LAW Dynamic Modeling Tuning Procedural Steps ...............................69

Appendix C: PJV Dynamic Modeling Tuning Procedural Steps ..................................74

Appendix D: Process Flowsheets for Control Loop Tuning. .......................................77 


\section{List of Figures}

Figure 2.1-1 HLW plenum pressure control system response during normal operations and 7X

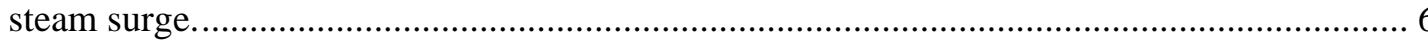

Figure 2.1-2 HLW fan speed control system response during normal operation and 7X steam

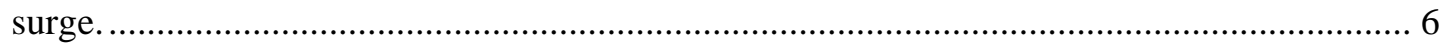

Figure 2.1-3 HLW vessel ventilation pressure control system response during normal operation

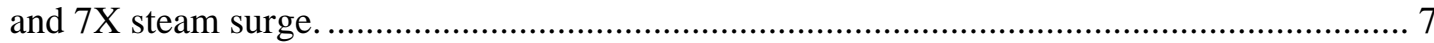

Figure 2.1-4 HEME pressure drop during normal operation and 7X steam surge. ......................... 7

Figure 2.1-5 Determination of ultimate gain for melter pressure control........................................ 8

Figure 2.1-6 Determination of ultimate frequency for melter pressure control............................. 9

Figure 2.1-7 HLW melter pressure control loop response under proportional control. ................ 10

Figure 2.1-8 HLW melter pressure control loop response under PI control................................. 10

Figure 2.1-9 HLW melter pressure control loop response under PID control............................. 11

Figure 2.1-10 HLW melter pressure control loop response using Robbins PI control settings. .. 11

Figure 2.1-11 HLW melter pressure control loop response using PI control settings with

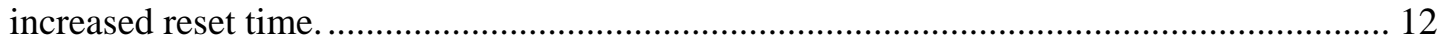

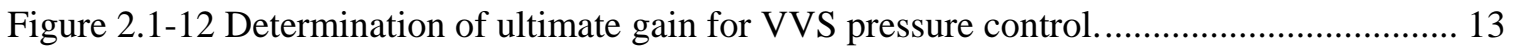

Figure 2.1-13 Determination of ultimate frequency for VVS pressure control.............................. 13

Figure 2.1-14 HLW VVS pressure control loop response under proportional control................. 14

Figure 2.1-15 HLW VVS pressure control loop response under PI control................................. 15

Figure 2.1-16 HLW VVS pressure control loop response under PID control.............................. 15

Figure 2.1-17 HLW VVS pressure control loop response using Robbins PI control settings...... 16

Figure 2.1-18 HLW VVS pressure control loop response using PI control settings with increased

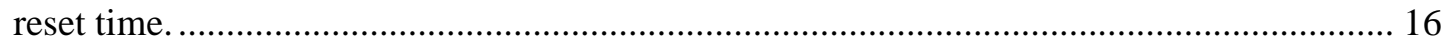

Figure 2.1-19 Determination of ultimate gain for fan speed control........................................... 18

Figure 2.1-20 Determination of ultimate frequency for fan speed control................................... 18

Figure 2.1-21 HLW fan speed control loop response using proportional control. ....................... 19

Figure 2.1-22 HLW fan speed control loop response using PI control. ....................................... 20

Figure 2.1-23 HLW fan speed control loop response using PID control. ................................... 20

Figure 2.1-24 HLW fan speed control loop response using proportional control with 15 second

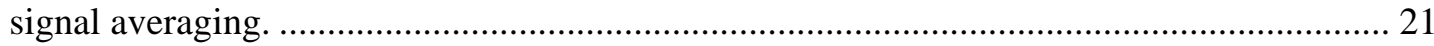

Figure 2.1-25 HLW fan speed control loop response using PI control with 15 second signal

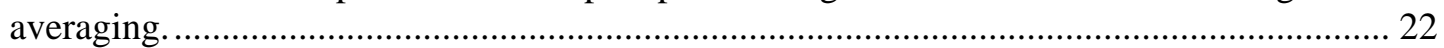

Figure 2.1-26 HLW fan speed control loop response using PID control with 15 second signal

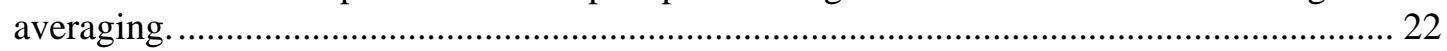

Figure 2.1-27 HLW fan speed control loop response using proportional control with 30 second

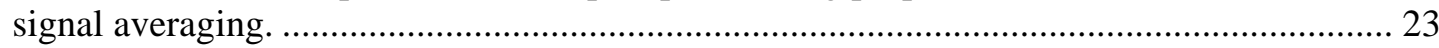

Figure 2.1-28 HLW fan speed control loop response using PI control with 30 second signal

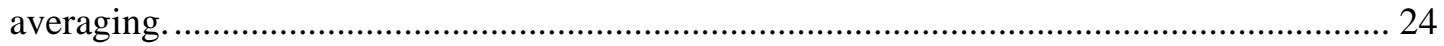

Figure 2.1-29 HLW fan speed control loop response using PID control with 30 second signal

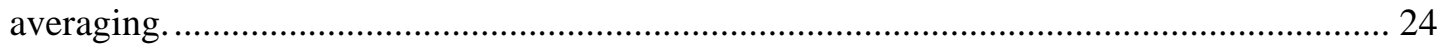

Figure 2.2-1 LAW melter pressure control response during normal operation and 4X steam

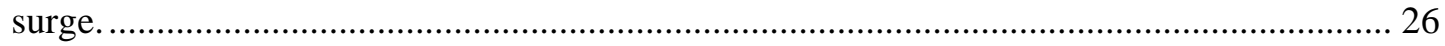

Figure 2.2-2 LAW damper control response during normal operation and 4X steam surge........ 26 Figure 2.2-3 LAW VVS pressure control response during normal operation and 4X steam surge.

Figure 2.2-4 LAW fan speed control response during normal operation and 4X steam surge. ... 27 Figure 2.2-5 LAW SBS pressure drop during normal operation and 4X steam surge. ................ 28 
Figure 2.2-6 LAW melter pressure control loop response under proportional control. ............... 29

Figure 2.2-7 LAW melter pressure control loop response under PI control................................. 29

Figure 2.2-8 LAW melter pressure control loop response under PID control.............................. 30

Figure 2.2-9 LAW melter pressure control loop response using Robbins PI control parameters. 30

Figure 2.2-10 LAW melter pressure control loop response under PI control with increased reset time.

Figure 2.2-11 LAW VVS pressure control loop response using proportional control................. 32

Figure 2.2-12 LAW VVS pressure control loop response using PI control. ................................ 33

Figure 2.2-13 LAW VVS pressure control loop response using PID control. ............................. 33

Figure 2.2-14 LAW VVS pressure control loop response using Robbins PI control parameters. 34

Figure 2.2-15 LAW VVS pressure control loop response using PI control with increased reset time.

Figure 2.2-16 LAW melter pressure and SBS pressure drop response using proportional damper

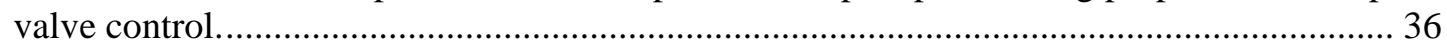

Figure 2.2-17 LAW control airflow and damper valve response using proportional damper valve

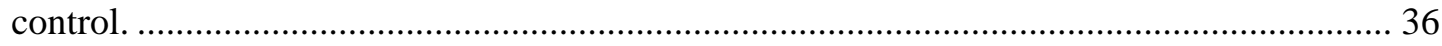

Figure 2.2-18 LAW melter pressure and SBS pressure drop response using PI damper valve

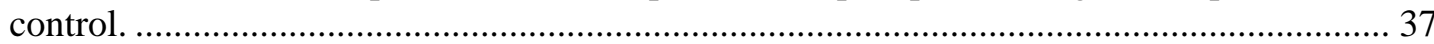

Figure 2.2-19 LAW control airflow and damper valve response using PI damper valve control.37

Figure 2.2-20 LAW melter pressure and SBS pressure drop response using PID damper valve

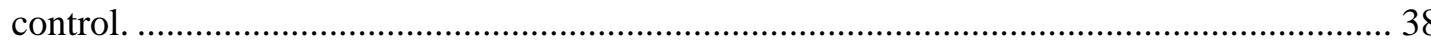

Figure 2.2-21 LAW control airflow and damper valve response using PID damper valve control.

Figure 2.2-22 LAW melter pressure and SBS pressure drop response using Robbins PI damper valve control. 38

Figure 2.2-23 LAW control airflow and damper valve response using Robbins PI damper valve control.

Figure 2.2-24 LAW melter pressure and SBS pressure drop response using proportional damper valve control with 15 second signal averaging. valve response using proportional damper valve

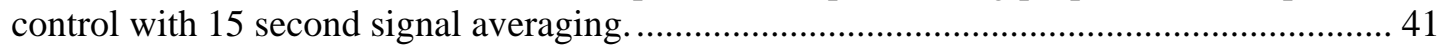

Figure 2.2-26 LAW melter pressure and SBS pressure drop response using PI damper valve

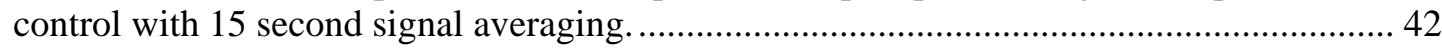

Figure 2.2-27 LAW control airflow and damper valve response using PI damper valve control

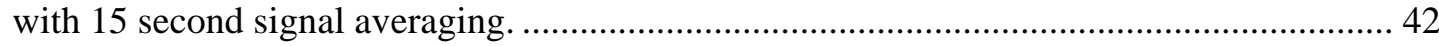

Figure 2.2-28 LAW melter pressure and SBS pressure drop response using PID damper valve control with 15 second signal averaging.

Figure 2.2-29 LAW control airflow and damper valve response using PID damper valve control

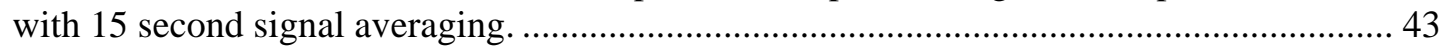

Figure 2.2-30 LAW melter pressure and SBS pressure drop response using Robbins PI damper

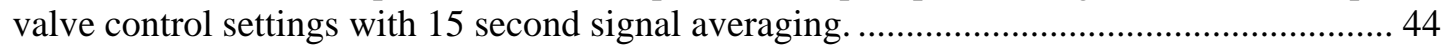

Figure 2.2-31 LAW control airflow and damper valve response using Robbins PI damper valve control settings with 15 second signal averaging..................................................................... 44

Figure 2.2-32 LAW melter pressure and SBS pressure drop response using proportional damper

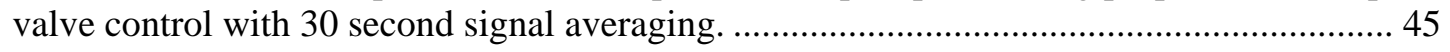

Figure 2.2-33 LAW control airflow and damper valve response using proportional damper valve

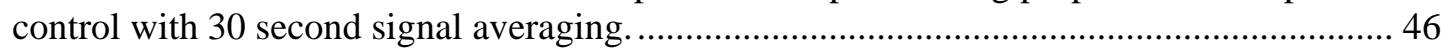

Figure 2.2-34 LAW melter pressure and SBS pressure drop response using PI damper valve

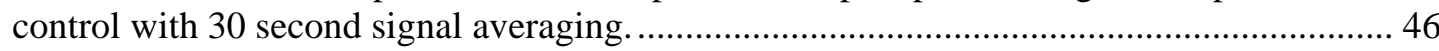


Figure 2.2-35 LAW control airflow and damper valve response using PI damper valve control with 30 second signal averaging.

Figure 2.2-36 LAW melter pressure and SBS pressure drop response using PID damper valve control with 30 second signal averaging.

Figure 2.2-37 LAW control airflow and damper valve response using PID damper valve control with 30 second signal averaging.

Figure 2.2-38 LAW melter pressure and SBS pressure drop response using Robbins PI damper valve control settings with 30 second signal averaging.

Figure 2.2-39 LAW control airflow and damper valve response using Robbins PI damper valve

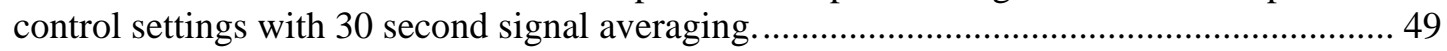

Figure 2.2-40 LAW fan speed control response using proportional control. .............................. 50

Figure 2.2-41 LAW fan speed control response using PI control. ............................................ 51

Figure 2.2-42 LAW fan speed control response using PID control. .......................................... 51

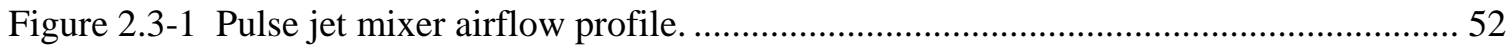

Figure 2.3-2 PJV pressure control loop response using proportional control. ….......................... 54

Figure 2.3-3 PJV pressure control loop response using PI control................................................ 55

Figure 2.3-4 PJV pressure control loop response using PID control........................................... 55

Figure 2.3-5 PJV pressure control loop response using Robbins PI control. ............................... 56

Figure 2.3-6 PJV pressure control loop response using proportional control. ............................... 58

Figure 2.3-7 PJV pressure control loop response using PI control............................................. 58

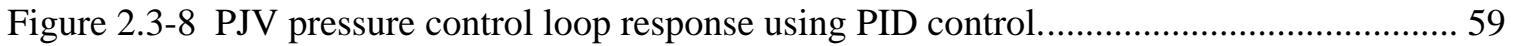

Figure 2.3-9 PJV pressure control loop response using Robbins PI control. .............................. 59

Figure 3-1 HLW melter pressure response to steam surges of different total flow and rate of increase.

Figure 3-2 HLW melter pressure response to steam surges of different total flow and rate of increase.

Figure 3-3 HLW melter pressure response to steam surges of different total flow and rate of increase.

Figure 3-4 LAW melter pressure response to steam surges of different total flow and rate of increase.

Figure D-1 HLW melter offgas system flowsheet. 77

Figure D-2 LAW melter offgas system control loop tuning flowsheet. ....................................... 78

Figure D-3 HLW PJV system control loop tuning flowsheet. 


\section{List of Tables}

Table 1.1 Summary of Optimized Control Settings ................................................................... 3

Table 2.1-1 HLW Melter Offgas System Tuned Control Parameters ............................................ 5

Table 2.1-2 HLW Melter Pressure Control Parameters. ................................................................. 8

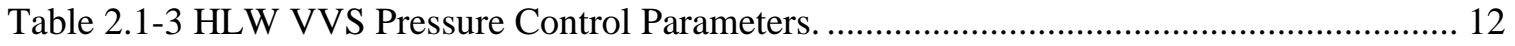

Table 2.1-4 HLW Fan Speed Control Parameters without Averaging.......................................... 17

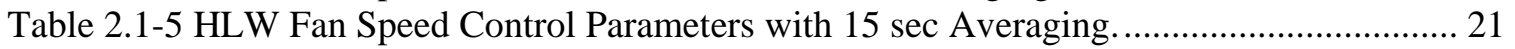

Table 2.1-6 HLW Fan Speed Control Parameters with 30 sec Averaging.................................. 23

Table 2.2-1 LAW Melter Offgas System Tuned Control Parameters ......................................... 25

Table 2.2-2 LAW Melter Pressure Control Parameters. ............................................................. 28

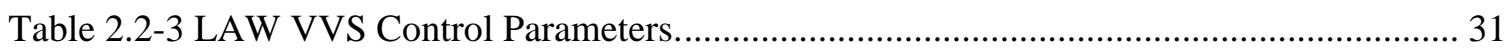

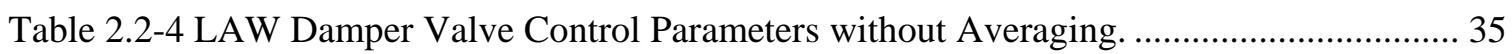

Table 2.2-5 LAW Damper Control Parameters with $15 \mathrm{sec}$ Averaging........................................ 40

Table 2.2-6 LAW Damper Control Parameters with 30 sec Averaging......................................... 45

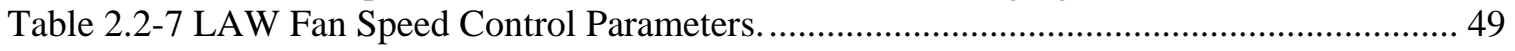

Table 2.3-1 PJV Vessel PJM Flow Sequencing Parameters. ........................................................ 53

Table 2.3-2 HLW PJV Control Parameters without Signal Averaging......................................... 54

Table 2.3-3 HLW PJV Control Parameters with 30 sec Averaging............................................. 57 


\section{Acronyms}

$\begin{array}{ll}\text { ACM } & \text { Aspen Custom Modeler } \\ \text { CFM } & \text { Cubic Feet per Minute } \\ \text { HEME } & \text { High Efficiency Mist Eliminator } \\ \text { HEPA } & \text { High Efficiency Particulate Air (filter) } \\ \text { HLW } & \text { High Level Waste } \\ \text { LAW } & \text { Low Activity Waste } \\ \text { PI } & \text { Proportional-Integral } \\ \text { PID } & \text { Proportional-Integral-Derivative } \\ \text { PJV } & \text { Pulse Jet Ventilation } \\ \text { RPP } & \text { River Protection Project } \\ \text { SBS } & \text { Submerged Bed Scrubber } \\ \text { SRTC } & \text { Savannah River Technology Center } \\ \text { WESP } & \text { Wet Electrostatic Precipitator } \\ \text { WG } & \text { Water Gauge (pressure) } \\ \text { WTP } & \text { Waste Treatment Plant }\end{array}$




\subsection{Summary}

This report describes control loop tuning in models of the HLW melter offgas system, the LAW melter offgas system and the HLW Pulse Jet Ventilation system and an assessment of the response to steam surges in both melter offgas systems. The three offgas systems were modeled using the Aspen Custom Modeler (ACM) software. The ACM models have been recently updated as described by Smith (2003a, 2003b). Flowsheets of the system models used in this study are provided in Appendix D. To facilitate testing, these flowsheets represent somewhat simplified versions of the full models. For example, the HLW and LAW vessel ventilation systems have been represented as fixed air sources that provide a constant gas flow and specified air surges. Similarly, the six tanks and individual pulse-jet air sources in the HLW Pulse Jet Ventilation system are represented as a constant air source for control loop tuning purposes. The second LAW melter system has also been represented as a constant flow air source and several other simplifications such as removing HLW and LAW control interlocks, SBS bypass lines, and pressure relief valves have been made.

The model control study is intended to give some idea of what system response would be expected during initial tuning as part of real plant commissioning. Beyond that point in plant operation, the control systems should be tuned to optimize actual performance. Optimum controller settings were determined using the standard Ziegler-Nichols tuning procedure. The response of the melter offgas systems during normal operations with nominal steam surges was then compared using the proportional, PI and PID controller settings determined in the tuning study. The control strategy that provided the best surge response and smoothest control variable response during normal operation was selected as the optimal control method. The model system responses to control action were consistent with expected behavior with shorter frequencies and not much change in amplitude as one goes from proportional to PI to PID control. Results indicated only a minor benefit from including derivative control action in a few of the controllers. Since derivative control is difficult to maintain and is susceptible to unpredictable behavior in response to other process disturbances, the best control strategy may be to use only proportional or PI control. The model predicted that the controls could easily handle nominal 4X steam surges in the LAW melter and 7X steam surges in the HLW melter.

\subsection{Objectives}

The objective of this work was to determine tuning parameters for eight control loops in the three offgas systems. In each system one loop was tuned both with and without signal averaging. Therefore, the following 11 control loop tunings were performed:

- HLW Melter Offgas System

1. Melter Pressure Control Loop

2. Vessel Ventilation Pressure Control Loop

3. Fan Speed Control Loop (without signal averaging)

4. Fan Speed Control Loop (with signal averaging)

- LAW Melter Offgas System 
1. Melter Pressure Control Loop

2. Vessel Ventilation Pressure Control Loop

3. Damper Flow Control Loop (without signal averaging)

4. Damper Flow Control Loop (with signal averaging)

5. Fan Speed Control Loop

- HLW Pulse Jet Ventilation System

1. Fan Speed Control Loop (without signal averaging)

2. Fan Speed Control Loop (with signal averaging)

In addition, after control loop tuning, the response of the HLW and LAW melter offgas systems to melter steam surges of varying magnitude and rate were determined.

\subsection{Conduct of Computer Model Studies}

Control loop tuning was performed using the procedures provided by WTP Process Engineering. Copies of the tuning procedures are attached as Appendices $\mathrm{A}-\mathrm{C}$ to this report. In cases where the requested tuning procedure could not be followed, details of the method used to obtain controller parameters are provided. In general, WTP requested that the control parameters should be determined using both the quarter-decay (ZieglerNichols) tuning procedure and the method proposed by Robbins. The procedural steps defined in the Appendices are derived from Smith and Corripio, Principals and Practice of Automatic Process Control, Section 6, for Quarter Decay Ratio Response by Ultimate Gain and from Robbins, Tuning Control Loops for Minimum Variability, Chemical Engineering Progress, June 2002.

\subsection{Results}

To facilitate the large number of calculations required for control loop tuning, the flowsheet models were simplified as much as possible. In particular, the vessel ventillation systems were eliminated from the HLW and LAW melter system models and replaced with a single gas source. To tune the HLW PJV system, the individual pulse jets were eliminated and replaced with a single gas source representing the total average flow. Flowsheets of the systems used for control loop tuning are provided in Appendix D. The process flowsheets and models were updated to the latest design configurations provided by WTP Process Engineering before performing the work.

In general, PI control coupled with increased integral reset time provided the best system response. However, in most cases, the improvement of PI control over that obtained with PID or even proportional control alone was relatively small. Proportional control alone is not typically used since the system can reach steady-state operation with an offset between the controlled variable and the setpoint. Signal averaging was found to produce a smoother control loop response. The Robbins tuning method gave relatively small gains which tended to smooth the system response during normal operations but respond poorly to system upsets. Results from the tuning study are summarized in Table 1.1. 
Table 1.1 Summary of Optimized Control Settings

\begin{tabular}{|c||l|l|l|r|r|c|}
\hline \multirow{2}{*}{ System } & Controller & Type & Gain & $\begin{array}{c}\text { Reset } \\
\text { (sec) }\end{array}$ & $\begin{array}{c}\text { Signal } \\
\text { Rate } \\
\text { (sec) }\end{array}$ & $\begin{array}{c}\text { Averaging } \\
\text { (sec) }\end{array}$ \\
\hline \hline \multirow{2}{*}{ HLW } & Melter Pressure & PI & 5.0 & 20.0 & - & - \\
\cline { 2 - 7 } & VVS Pressure & PID & 3.5 & 4.5 & 1.0 & - \\
\cline { 2 - 7 } & Fan Speed & PI & 0.32 & 35.0 & - & 30 \\
\hline \multirow{2}{*}{ LAW } & Melter Pressure & PI & 1.4 & 28.0 & - & - \\
\cline { 2 - 7 } & Damper Valve & PI & 0.4 & 18.0 & - & 15 \\
\cline { 2 - 7 } & VVS Pressure & PID & 2.4 & 8.5 & 2.0 & - \\
\cline { 2 - 7 } & Fan Speed & PID & 5.9 & 14.0 & 0.7 & - \\
\hline \multirow{2}{*}{ PJV } & Fan Speed & PI & 0.45 & 33.0 & - & 30 \\
\hline
\end{tabular}

Surge response modeling indicated that by using the optimal controls nominal and fast $7 \mathrm{X}$ steam surges in the HLW melter and nominal and fast $4 \mathrm{X}$ steam surges in the LAW melter would not cause plenum pressures to become positive relative to the local cell. Large 10X steam surges in the LAW melter and 20X steam surges in the HLW melter did pressurize the plenum. This testing was conducted without activating the standby offgas lines to the Submerged Bed Scrubbers.

\subsection{Quality Requirements}

This work was conducted in accordance with the RPP-WTP QA requirements specified for work conducted by SRTC as identified in DOE IWO MOSRLE60. SRTC has provided matrices to WTP demonstrating compliance of the SRTC QA program with the requirements specified by WTP. Specific information regarding the compliance of the SRTC QA program with RW-0333P, Revision 10, NQA-1 1989, Part 1, Basic and Supplementary Requirements and NQA-2a 1990, Subpart 2.7 is contained in these matrices. 


\subsection{Control Loop Tuning}

In addition to the controller gain, rate, and reset time, several other parameters in the control loops influence the system behavior. These are the response time of the device (fan or valve) that the controller is acting on, the dead time in the transmission of the process signal to the controller and the linear range of the controller. The following parameters were fixed in all of the system simulations:

Fan time constant .5 seconds

Control valve time constant .5 seconds

Melter pressure control dead time. .0 .5 second

Dead time in other controllers. 0.1 second

The fan and valve time constants represent the time it takes the device to respond to a change in control signal. With no other action, the controlled variable will be able to make $62.3 \%$ of a requested change in value in one time constant. The dead time represents a lag between the time a signal is sent to and received by the controller. WTP Engineering estimated that the actual lag times in the melter pressure controller and other controllers were only 0.1 and zero seconds, respectively. However, the model does not account for the time lag between when a pressure or flow is changed and when it is detected downstream. That is, the pipe models will instantaneously transmit a change in pressure. To partially account for this additional signal lag that is not modeled, the controller dead times were increased. Since this lag is expected to be most important in sensing pressure control loop changes, the dead time in this loop was increased to 0.5 second and all other controller dead times given the smaller 0.1 second delay. We note that control loop tuning results are a function of the dead times and equipment response constants. Therefore, the control parameters derived in this study can only provide initial guidance for actual plant operation. Once the plant is operational, the dynamic models can be adjusted to match actual operating performance providing accurate models of the true system behavior.

The controller model calculates the error as the difference between the control variable position and the set point divided by the linear range of the controller. For pressure control the linear range was set to $\pm 1500 \mathrm{~Pa}$ ( \pm 6 inches WG) around the set point while for flow control a linear range of $\pm 0.1 \mathrm{~m}^{3} / \mathrm{s}( \pm 212 \mathrm{CFM})$ was used. If the input signal falls outside this linear response range, the control signal is set to 0 or 1 when the input is below or above the range, respectively. Exhaust fan and control valve specifications used in these control tuning calculations are unchanged from those used in the most recent sets of model calculations reported in Smith (2003a) for the LAW system and Smith (2003b) for the HLW system. 


\subsection{HLW Melter Offgas System}

The HLW system was modeled using the flowsheet shown in Fig. D-1. For simulation purposes, the model was initialized to steady-state operation with the control loops in manual. In this mode, the bias values listed in Table 2.1-1 serve as the fixed output from each controller. The pressure control valve settings are the fraction open and the fan speed setting is the fraction of full speed. These values operated the system within 0.25 inch WG of the pressure set points and 1\% of the control airflow. Note that fan speed is controlled from the air flow through the pressure control valve and not from the valve stem position. Numerical values above the bold line in Table 2.1-1 are fixed parameters in each controller while values below the bold line are the optimal controller tuning parameters based on the results of this study. In some cases, the controller gains and rates have been rounded off slightly from the values found by the optimization study. The integral reset times have typically been increased by a factor of about six to smooth the controller response without sacrificing significant control action.

Table 2.1-1 HLW Melter Offgas System Tuned Control Parameters

\begin{tabular}{|c|c|c|c|}
\hline Controller & $\begin{array}{c}\text { Melter } \\
\text { Pressure }\end{array}$ & $\begin{array}{c}\text { VVS } \\
\text { Pressure }\end{array}$ & Fan Speed \\
\hline \hline Type & PI & PID & PI \\
\hline Action & -1 & +1 & -1 \\
\hline Setpoint & $98500 \mathrm{~Pa}$ & $98900 \mathrm{~Pa}$ & $0.1 \mathrm{~m}^{3} / \mathrm{s}$ \\
\hline Dead Time & $0.5 \mathrm{~s}$ & $0.1 \mathrm{~s}$ & $0.1 \mathrm{~s}$ \\
\hline Linear Range & $\pm 1500 \mathrm{~Pa}$ & $\pm 1500 \mathrm{~Pa}$ & $\pm 0.1 \mathrm{~m}^{3} / \mathrm{s}$ \\
\hline Bias & 0.699 & 0.149 & 0.654 \\
\hline \hline Gain & 5.0 & 3.5 & 0.32 \\
\hline Rate (s) & - & 1.0 & - \\
\hline Reset (s) & 20 & 4.5 & 35 \\
\hline Signal Averaging (s) & - & - & 30 \\
\hline
\end{tabular}

Figures 2.1-1 through 2.1-3 show the response of the HLW system during normal melter feeding and a 7X steam surge using the tuned control parameters in Table 2.1-1. During normal operation, melter plenum pressure and fan speed fluctuate in response to cyclic ADS feeding. Starting at 5 minutes, the $7 \mathrm{X}$ steam surge linearly ramps up to maximum flow over 18.5 seconds and then linearly ramps down to zero during the next 74 seconds. Figure 2.1-1 shows that the melter plenum pressure is normally controlled between -4 inches WG and -5.5 inches WG and that the control air valve normally operates at about $70 \%$ open. The $7 \mathrm{X}$ steam surge has only a small impact on plenum pressure. As shown in Fig. 2.1-2, control air flow on average operates close to the desired rate of 200 CFM although it varies between 150 CFM and 225 CFM from ADS feed cycling. The exhauster speed normally operates at about $66 \%$ increasing to a maximum of $72 \%$ in response to the steam surge. Figure 2.1-3 shows that the VVS header pressure and valve position remain nearly constant during normal operation and the steam surge transient. The pressure drop across the HEME plotted in Fig. 2.1-4 is nominally 13.5 inches WG and varies by about \pm 1 inch WG in response to the change in fan speed during the $7 \mathrm{X}$ steam surge. 


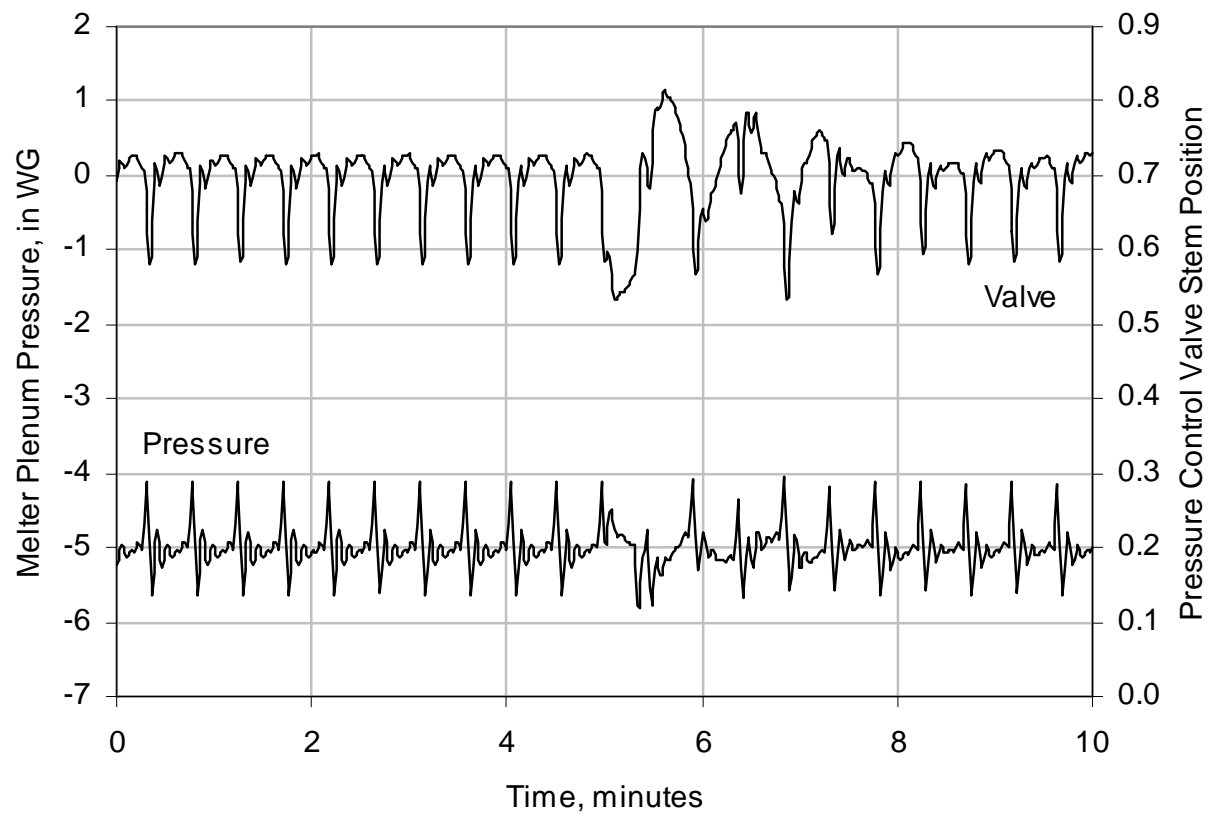

Figure 2.1-1 HLW plenum pressure control system response during normal operations and $7 \mathrm{X}$ steam surge.

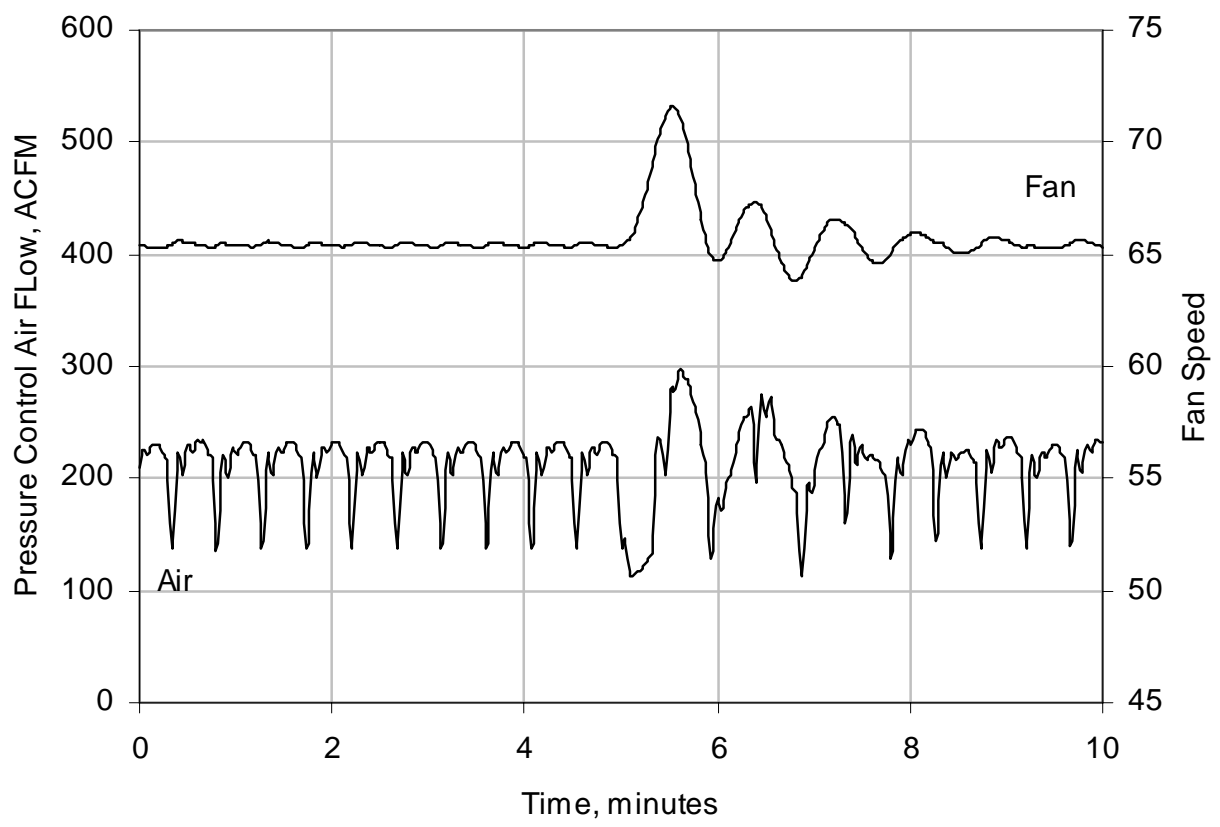

Figure 2.1-2 HLW fan speed control system response during normal operation and 7X steam surge. 


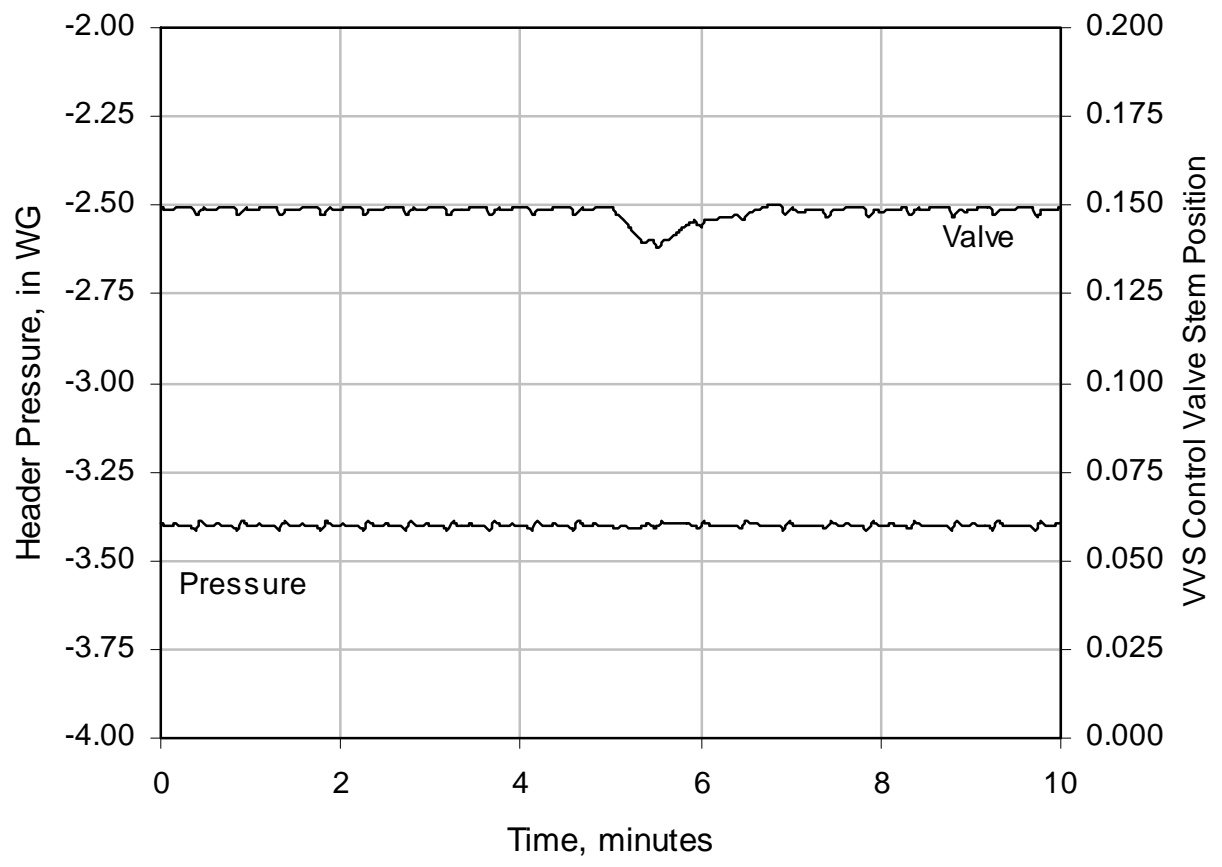

Figure 2.1-3 HLW vessel ventilation pressure control system response during normal operation and $7 \mathrm{X}$ steam surge.

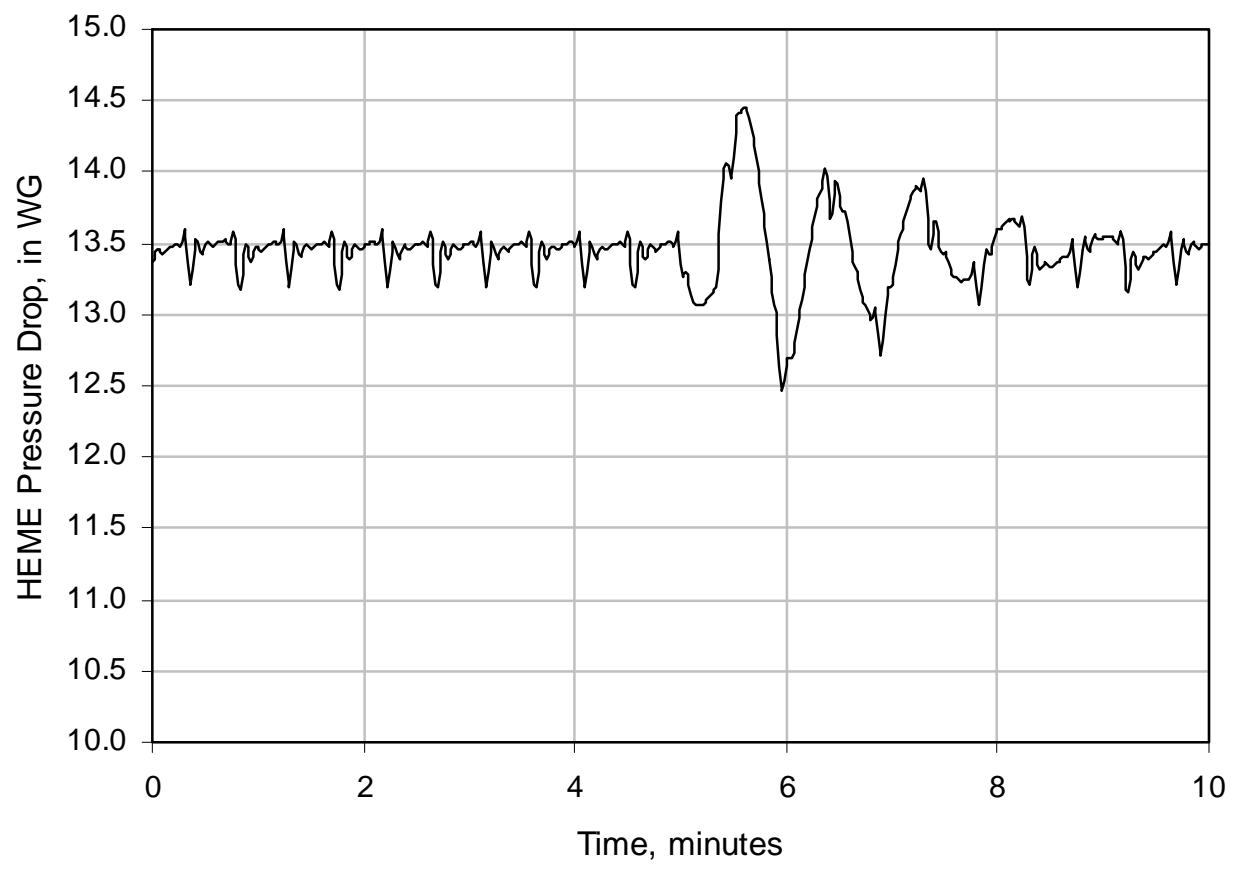

Figure 2.1-4 HEME pressure drop during normal operation and 7X steam surge. 


\subsubsection{HLW Melter Pressure Control Loop}

Table 2.1-2 lists the ultimate gain and time constant for the HLW melter pressure control loop and the calculated parameters for the controller modes. Determination of the ultimate gain and time constant (or frequency) is illustrated in Figs. 2.1-5 and 2.1-6. The system was first brought to steady-state operation with melter pressure control in automatic mode and VVS pressure and fan speed controllers in manual mode. Using proportional control only, every two minutes, step changes were made in the melter pressure control set point at various gains. The results are plotted in Fig. 2.1-5 where the controller gain labels the segments of the pressure response curve. As shown in Fig. 2.15 , sustained oscillations were obtained at a gain of 12 . The ultimate frequency was calculated as shown in Fig. 2.1-6. At a gain of 11, there is still a slow decay in the pressure fluctuations; however, to be slightly conservative, 11 was used as the ultimate system gain.

Table 2.1-2 HLW Melter Pressure Control Parameters.

[Ultimate gain $\mathrm{K}_{\mathrm{u}}=11.0$, Ultimate time constant $\tau_{\mathrm{u}}=4.3(\mathrm{~s})$ ]

\begin{tabular}{|c||c|c|c|}
\hline Control Method & Gain, $\mathbf{K}_{\mathbf{c}}$ & Reset, $\boldsymbol{\tau}_{\mathbf{i}}(\mathbf{s})$ & Rate, $\boldsymbol{\tau}_{\mathbf{d}}(\mathbf{s})$ \\
\hline \hline P & 5.5 & - & - \\
\hline PI & 5.0 & 3.6 & - \\
\hline PID & 6.5 & 2.1 & 0.5 \\
\hline Robbins (PI) & 1.0 & 8.0 & - \\
\hline PI/Increased Reset & 5.0 & 21.5 & - \\
\hline
\end{tabular}

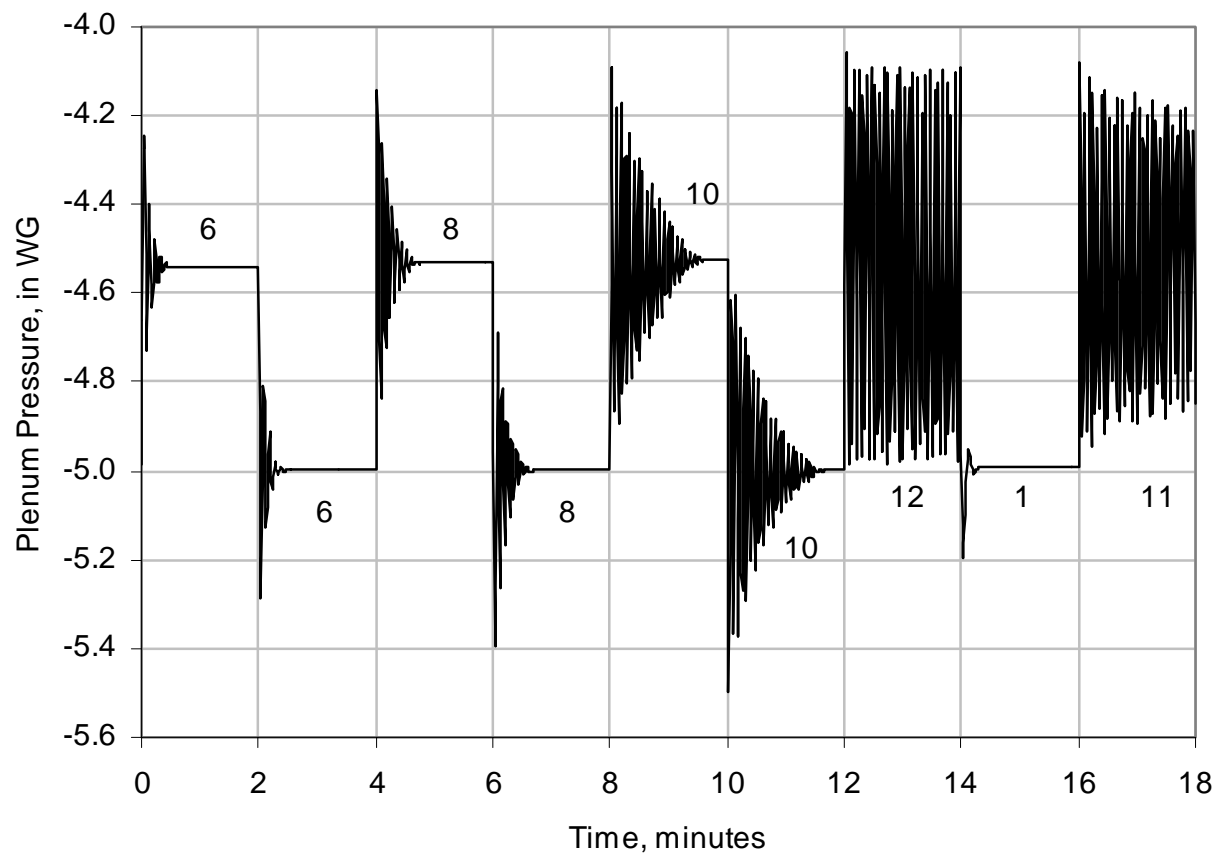

Figure 2.1-5 Determination of ultimate gain for melter pressure control. 


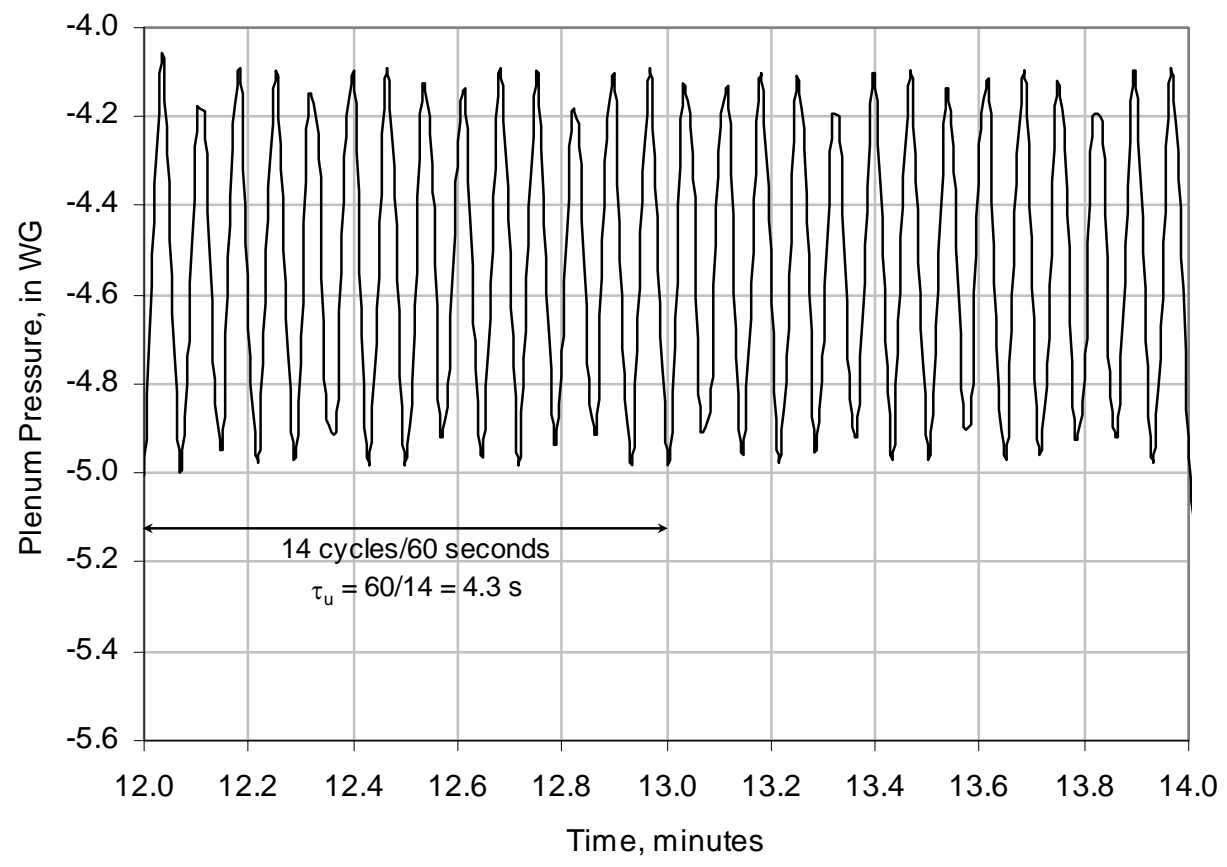

Figure 2.1-6 Determination of ultimate frequency for melter pressure control.

Figures 2.1-7 through 2.1-11 show the melter plenum pressure and control air flow during melter feeding and a nominal $7 \mathrm{X}$ steam surge using the five control methods listed in Table 2.1-2. The 7X surge occurs at 5 minutes on the plots. Proportional, PI and PID control were able to maintain the melter pressure within \pm 1 inch WG during normal operation and effectively limited the pressure increase during the steam surge. Comparing Figs. 2.1-7 through 2.1-9, of the three basic control modes, proportional control showed the tightest control with the least noise. The Robbins tuning method gave a much smaller gain, which significantly smoothed the system response but produced poor pressure control during both normal operation and the steam surge. Robbins also suggests increasing the integral reset time by a factor of six based on the observed pattern that the controlled variable (melter pressure) typically crossed the set point when the control variable (valve stem position) reached a maximum or minimum. System response using PI control with increased integral reset is shown in Fig. 2.1-11. Comparing Fig. 2.1-8 with Fig. 2.1-11 shows that increasing the reset time significantly smoothed the signal without adversely impacting pressure control. Therefore, PI control with increased reset was judged to be the preferred method for melter pressure control. 


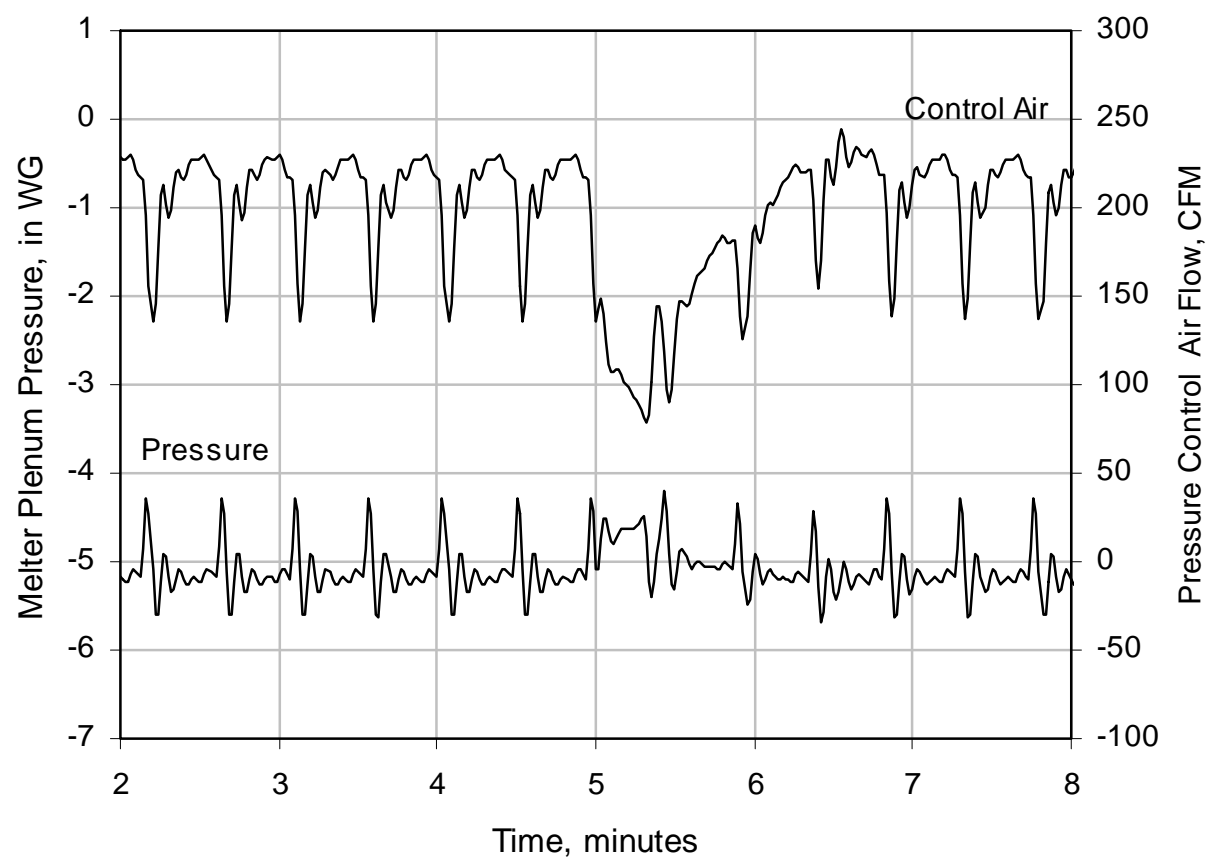

Figure 2.1-7 HLW melter pressure control loop response under proportional control.

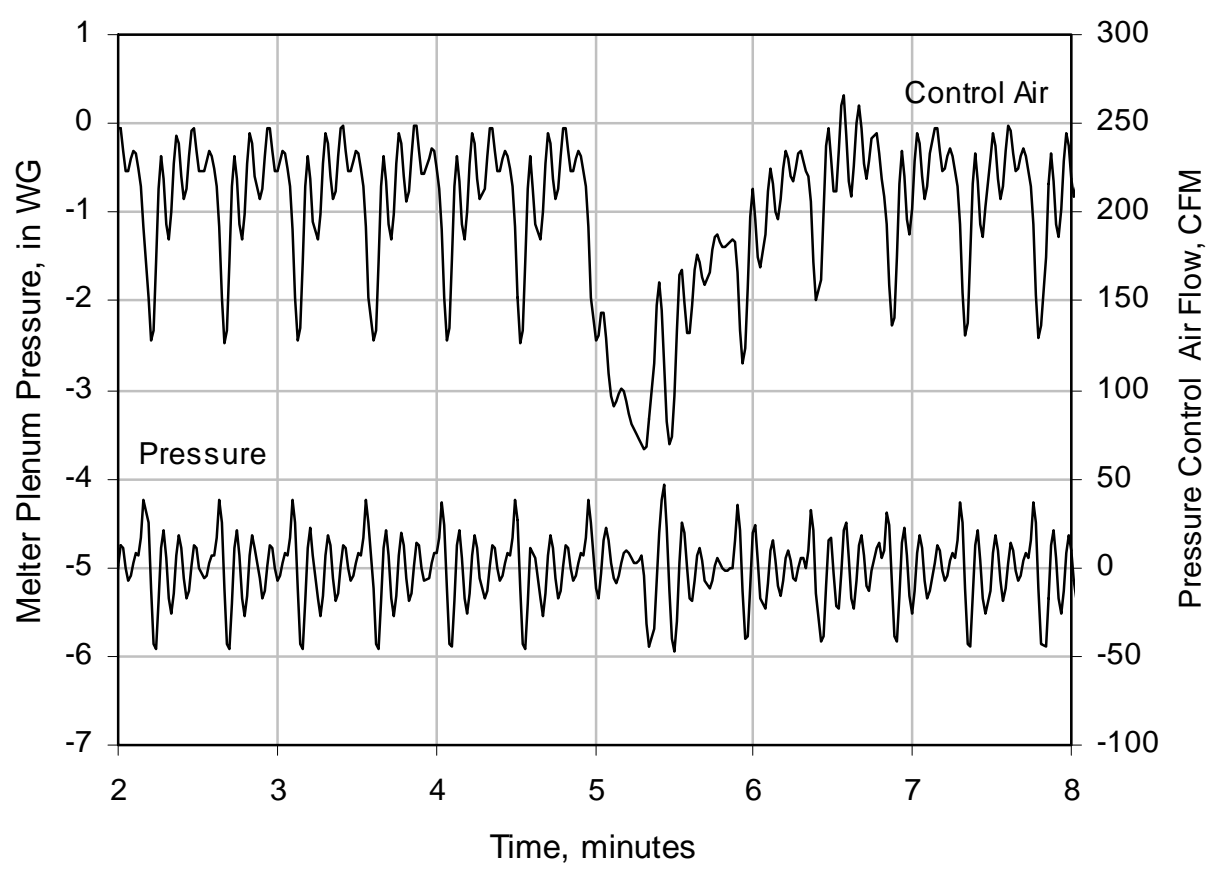

Figure 2.1-8 HLW melter pressure control loop response under PI control. 


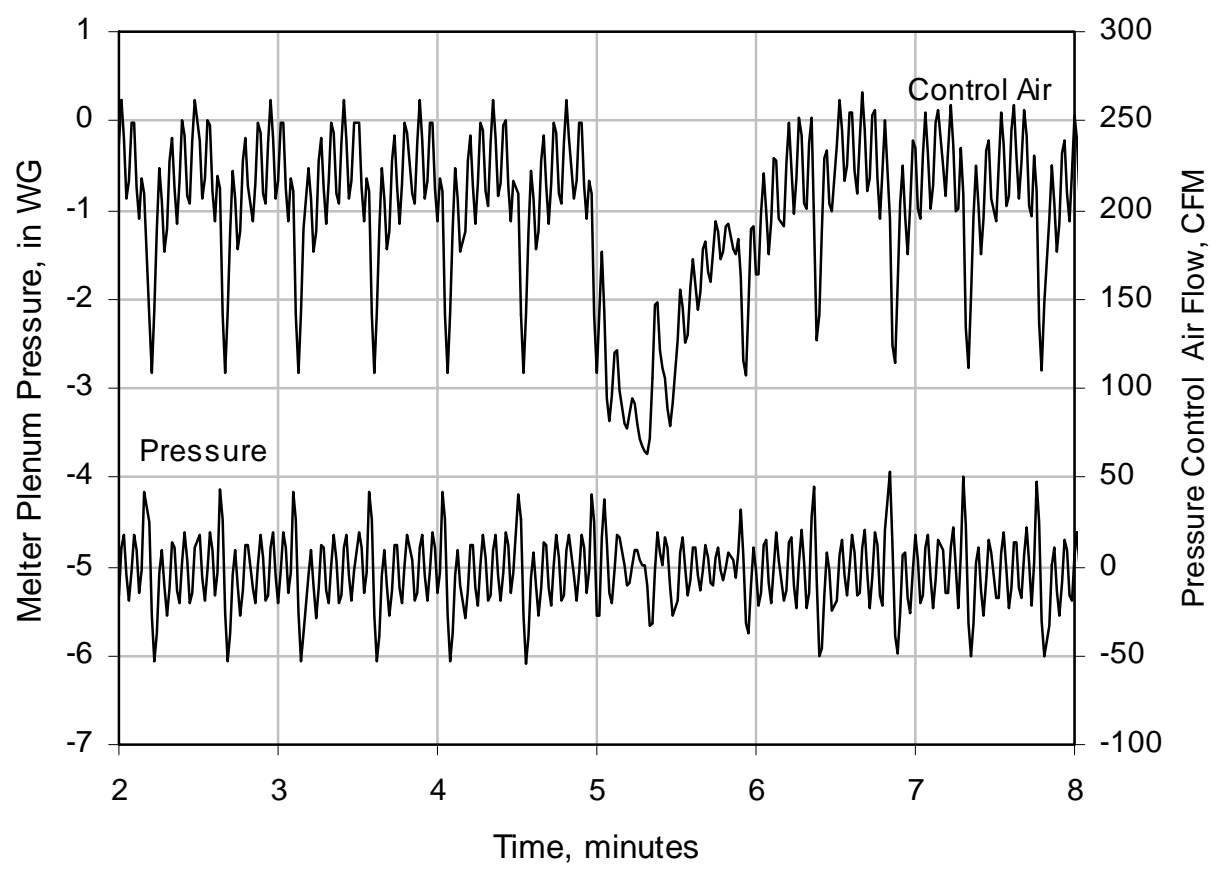

Figure 2.1-9 HLW melter pressure control loop response under PID control.

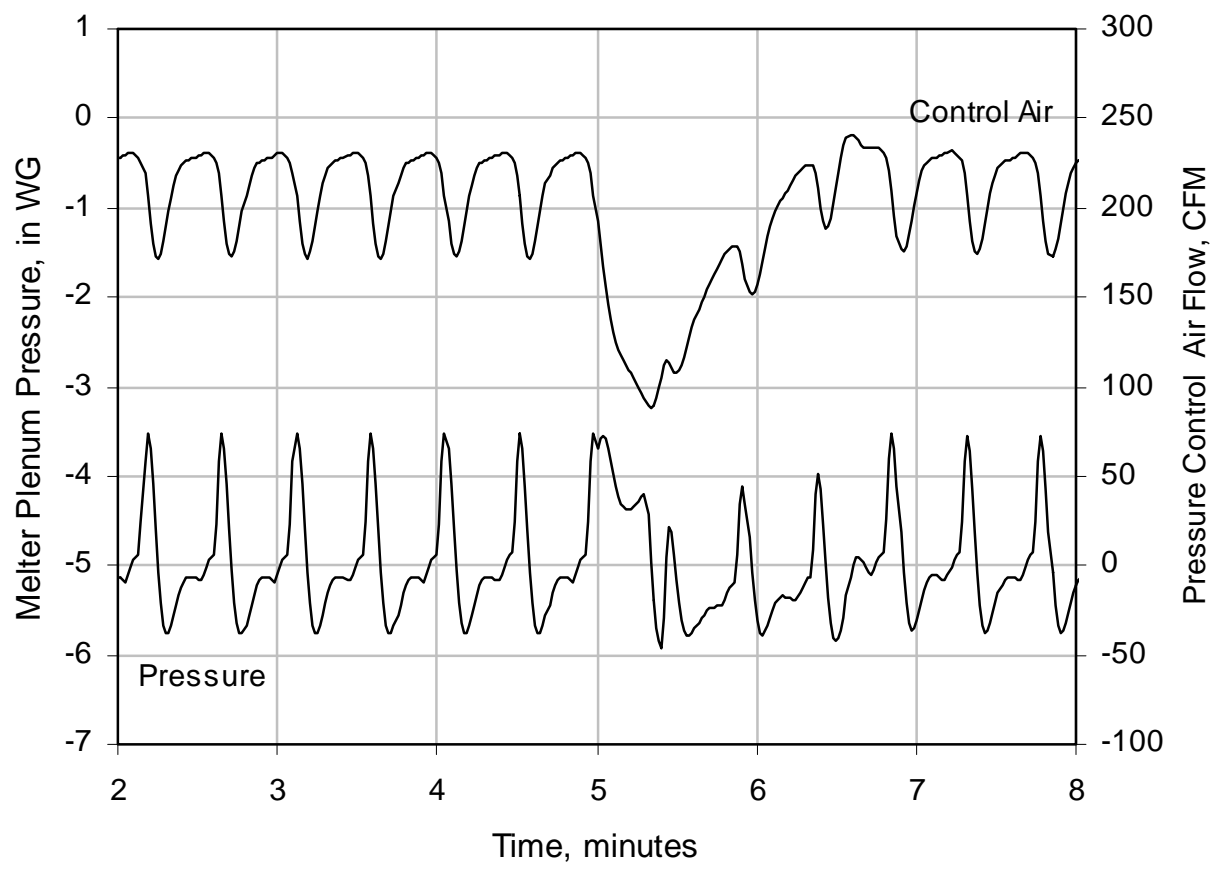

Figure 2.1-10 HLW melter pressure control loop response using Robbins PI control settings. 


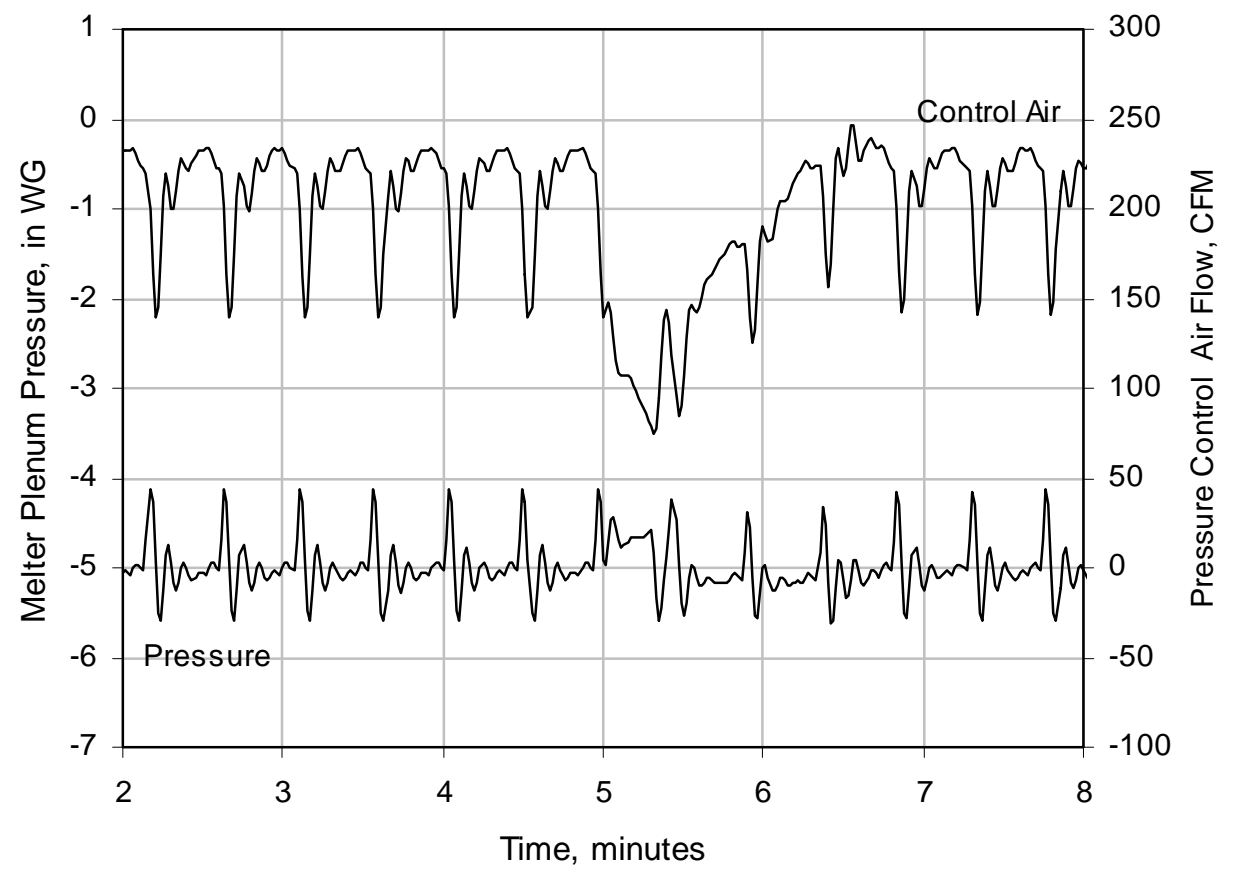

Figure 2.1-11 HLW melter pressure control loop response using PI control settings with increased reset time.

\subsubsection{HLW Vessel Ventilation Control Loop}

Table 2.1-3 shows the ultimate gain and frequency for the VVS pressure control loop and the corresponding controller parameters. The ultimate gain and frequency were determined from the results plotted in Fig. 2.1-12 and 2.1-13. The system was brought to steady-state operation with the VVS pressure control in automatic mode and the melter pressure and fan speed controllers in manual mode. Using proportional control only, every two minutes, step changes were made in the VVS pressure control set point using various controller gains. The results are plotted in Fig. 2.1-12 with the gains labeling the segments of the pressure response curve. As shown in Fig. 2.1-12, sustained pressure oscillations were obtained at a controller gain of 6 with the frequency calculated as demonstrated in Fig. 2.1-13.

Table 2.1-3 HLW VVS Pressure Control Parameters.

[Ultimate gain $\mathrm{K}_{\mathrm{u}}=6.0$, Ultimate time constant $\tau_{\mathrm{u}}=8.7(\mathrm{~s})$ ]

\begin{tabular}{|c||c|c|c|}
\hline Control Method & Gain, $\mathbf{K}_{\mathbf{c}}$ & Reset, $\boldsymbol{\tau}_{\mathbf{i}} \mathbf{( s )}$ & Rate, $\boldsymbol{\tau}_{\mathbf{d}} \mathbf{( s )}$ \\
\hline \hline P & 3.0 & - & - \\
\hline PI & 2.7 & 7.0 & - \\
\hline PID & 3.5 & 4.4 & 1.1 \\
\hline Robbins (PI) & 0.5 & 15.0 & - \\
\hline PI/Increased Reset & 2.7 & 40.0 & - \\
\hline
\end{tabular}




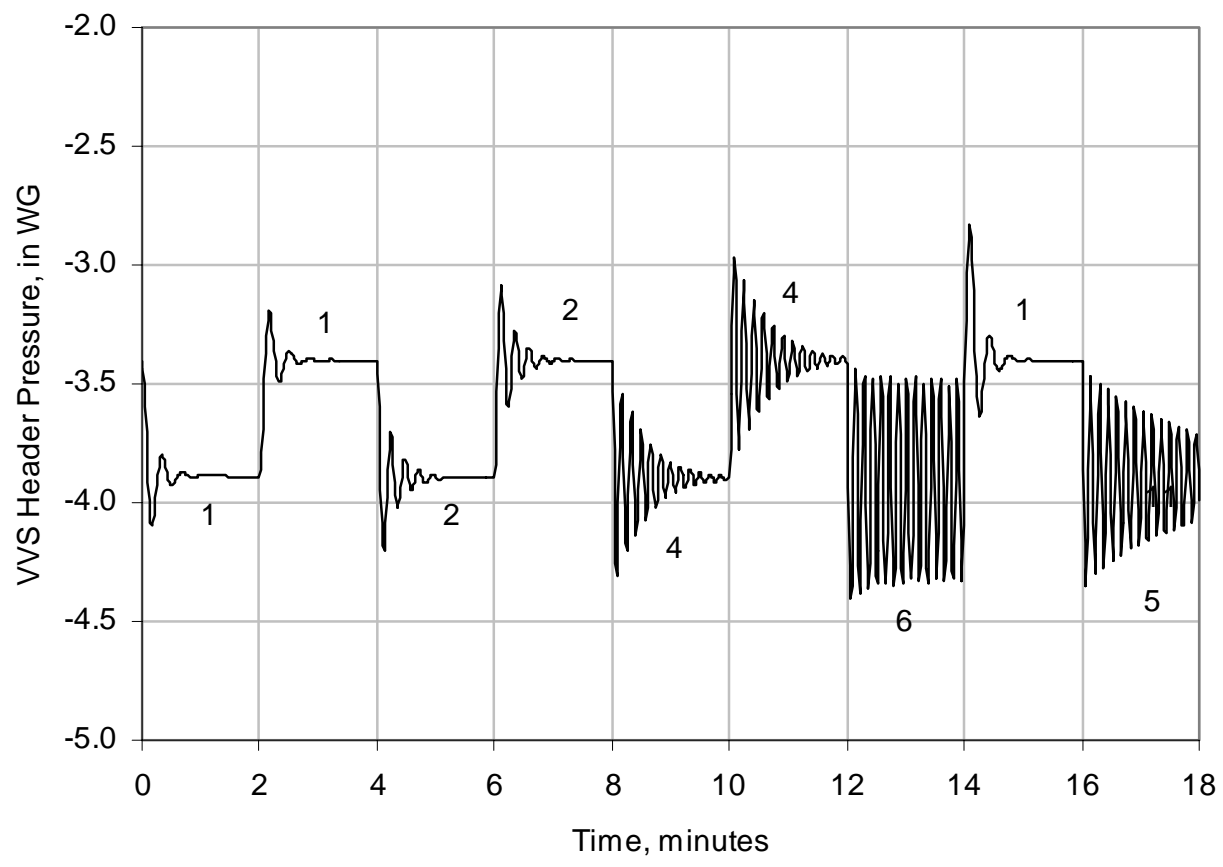

Figure 2.1-12 Determination of ultimate gain for VVS pressure control.

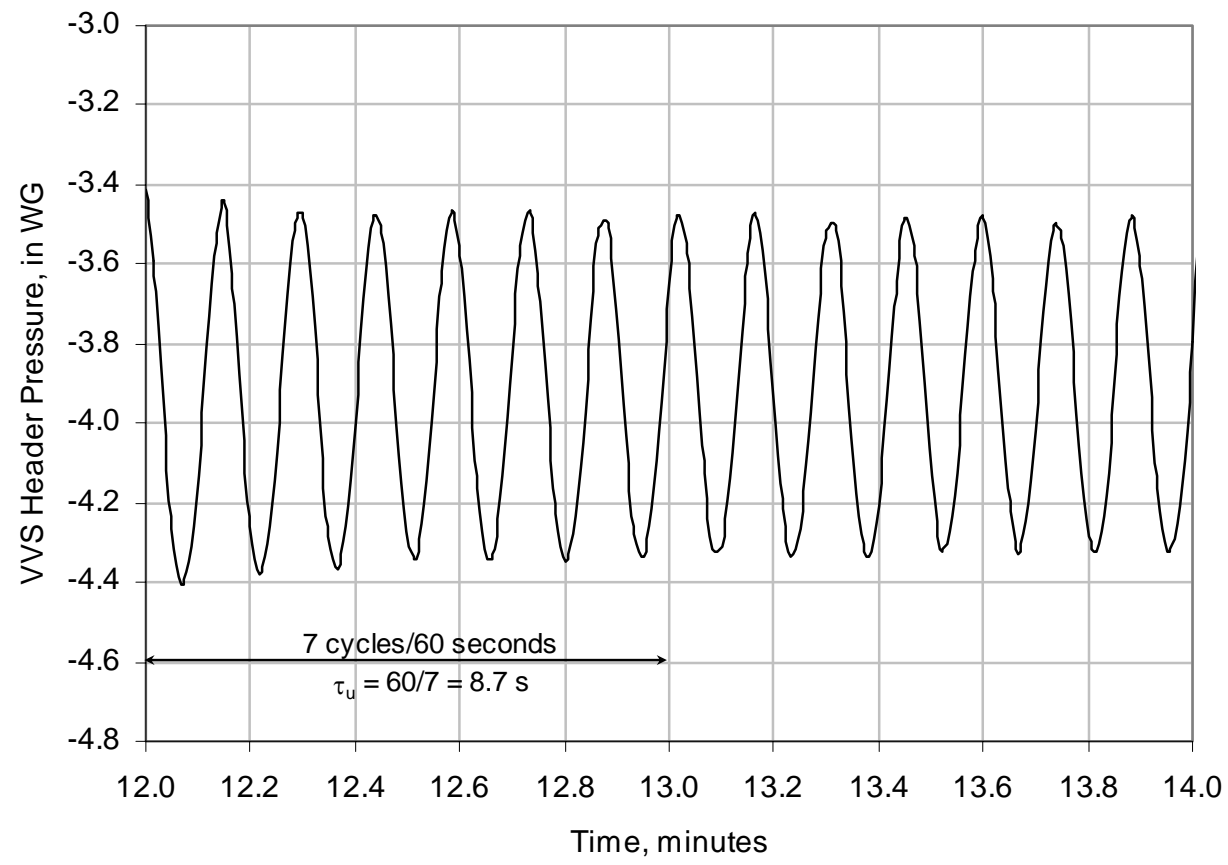

Figure 2.1-13 Determination of ultimate frequency for VVS pressure control. 
Figures 2.1-14 through 2.1-18 show VVS system response during $2 \mathrm{X}$ and $4 \mathrm{X}$ flow surges using the five control methods listed in Table 2.1-3. The flow surges were instantaneously turned on at 5 and 10 minutes in the simulation, the higher gas flow was kept on for 30 seconds, and the flows then instantaneously returned to normal. In all cases, the control action is able to return the header pressure to the set point after an initial pressure spike. PID control performed the best in limiting the header pressure fluctuations. The Robbins tuning method gave a much smaller gain, which smoothed the system response but produced very poor pressure control. Robbins suggests increasing the integral reset time by a factor of 6 based on the observed pattern that the controlled variable (header pressure) typically crossed the set point when the control variable (valve stem position) reached a maximum or minimum. The system response with increased controller reset is plotted in Fig. 2.1-18. Comparing Fig. 2.1-15 with Fig. 2.1-18 shows that increasing the reset time smoothed the signal and gave about the same pressure control. For this system, PID control was selected as the method of choice providing the best response. We note that, except for the low gain Robbins control scheme, the $2 \mathrm{X}$ surge did not cause the header pressure to exceed that of the local cell whereas the $4 \mathrm{X}$ surge always caused the header pressure to become positive ( $>0$ inches WG). The vessel vent vacuum set point may need to be increased to maintain the system under vacuum during a $4 \mathrm{X}$ flow spike.

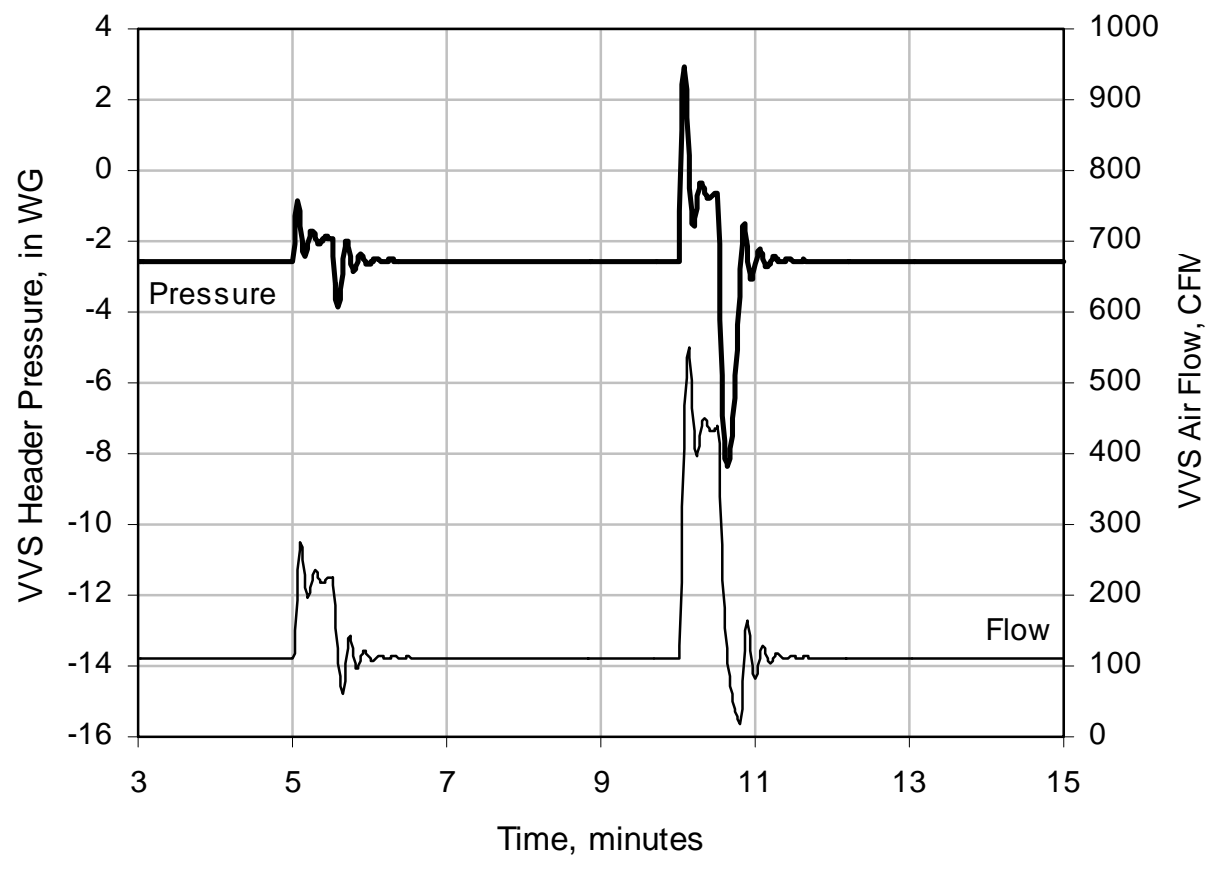

Figure 2.1-14 HLW VVS pressure control loop response under proportional control. 


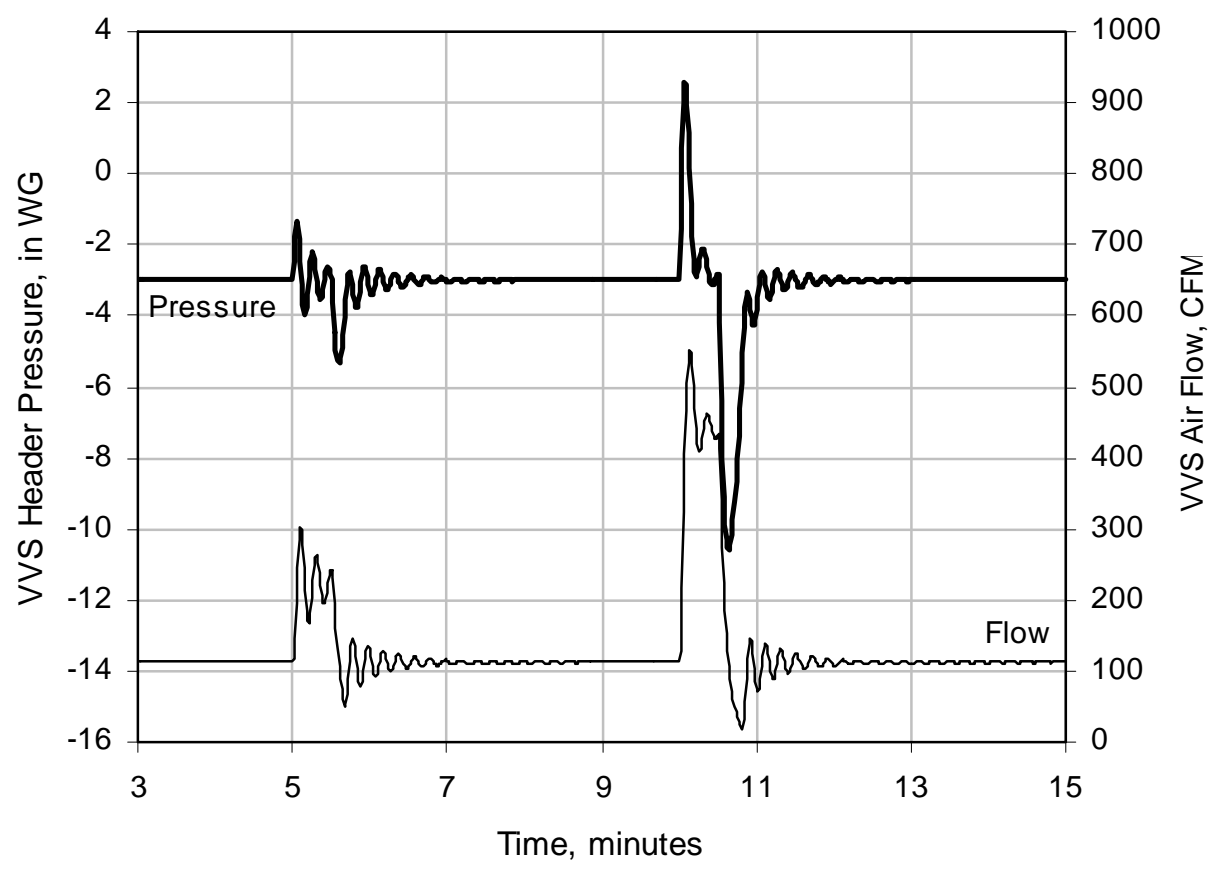

Figure 2.1-15 HLW VVS pressure control loop response under PI control.

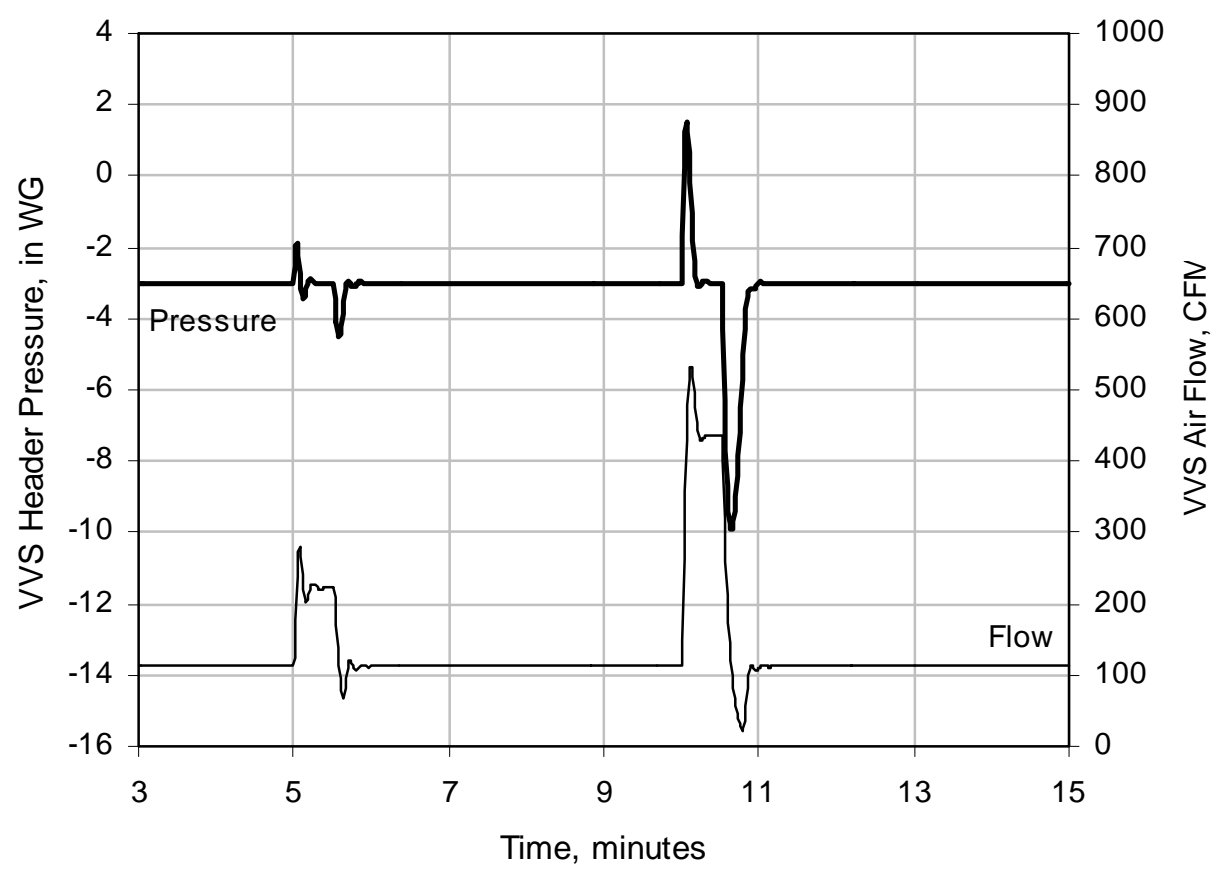

Figure 2.1-16 HLW VVS pressure control loop response under PID control. 


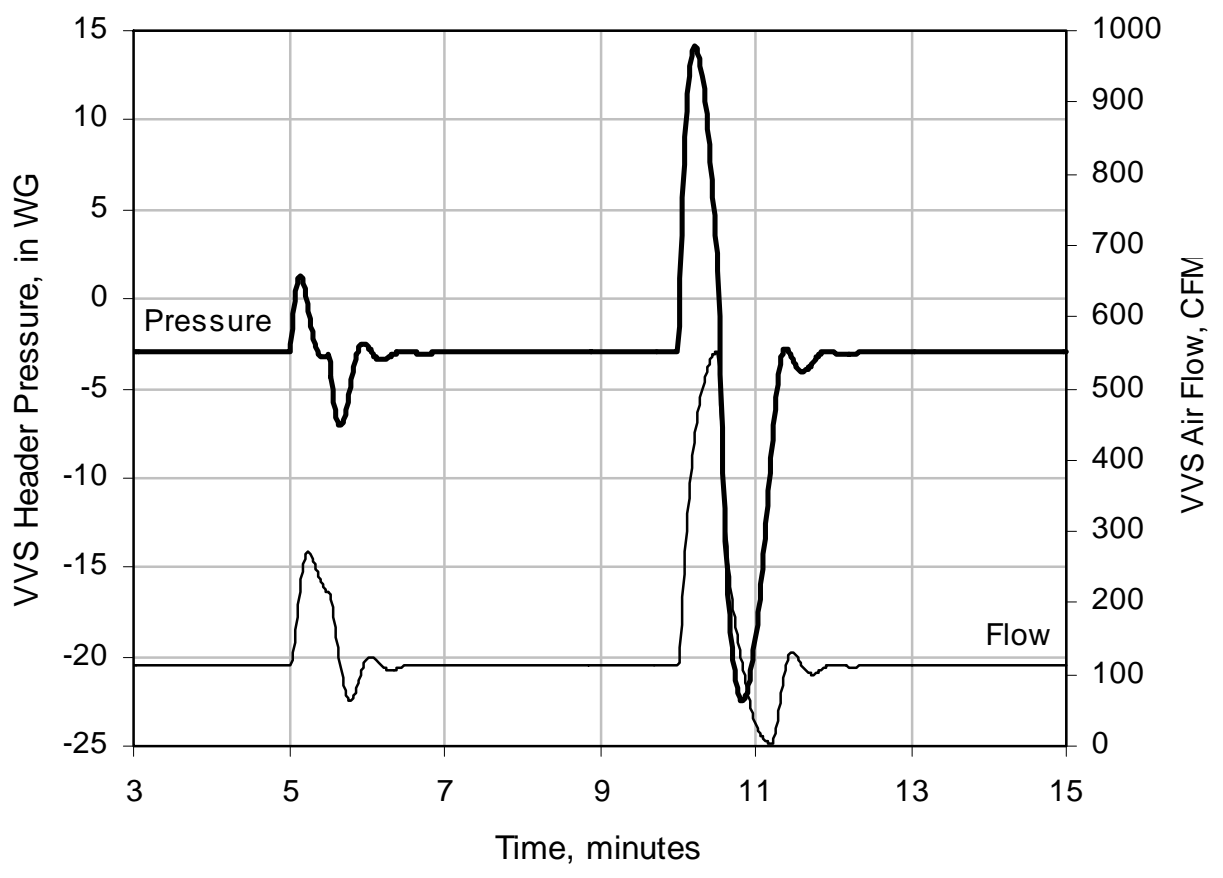

Figure 2.1-17 HLW VVS pressure control loop response using Robbins PI control settings.

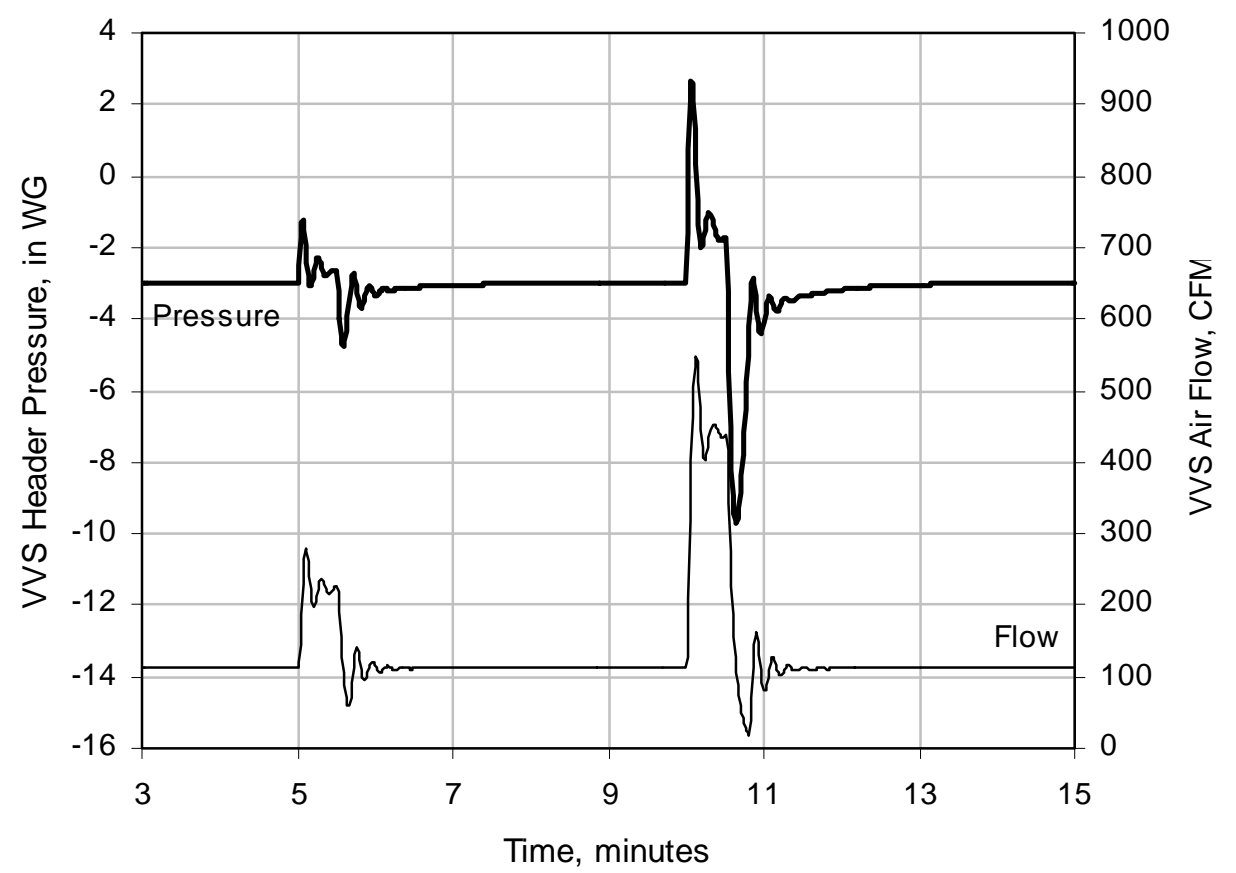

Figure 2.1-18 HLW VVS pressure control loop response using PI control settings with increased reset time. 


\subsubsection{HLW Fan Speed Control Loop without Signal Averaging}

It is not possible to tune the fan speed control loop as an isolated system as requested in the work scope given in Part C of Appendix A. The extraction fan does not directly regulate the flow of pressure control air. If the pressure control loop is in manual and the control valve position held fixed, the flow of control air $(Q)$ will only respond to changes in pressure across the control valve $(\Delta p)$ according to the relationship:

$$
Q=K \sqrt{\Delta p}
$$

Taking the ratio of two flow conditions cancels out the valve constant $(K)$ and gives:

$$
\Delta p_{2}=\Delta p_{1} \frac{Q_{2}^{2}}{Q_{1}^{2}}
$$

Therefore, to change the flow by $5 \%$, the pressure difference across the control valve must change by about $10 \%$. Since the control air supply pressure is fixed at 19.5 psia and the offgas system operates at about 14.5 psia the nominal pressure drop across the melter pressure control valve is approximately 5 psi. A $10 \%$ change is then 0.5 psi or almost 14 inches WG, which implies that the pressure at the control point would have to change by \pm 14 inches WG through changes in fan speed to significantly perturb the air flow. Since this is not feasible, an alternative approach of tuning the fan speed control with active melter pressure control was used.

Table 2.1-4 shows the ultimate gain and frequency for the fan speed control loop and the corresponding controller parameters. Since the quarter decay tuning procedure already produced very small gains, the Robbins method was not tried in this case. Figures 2.1-19 and 2.1-20 illustrate the determination of the ultimate gain and frequency for this system. As explained above, both the melter pressure control and fan speed control were operating in automatic mode during the calculation. As shown in Fig. 2-1.19, every two minutes the set point for control air flow was perturbed using increasing gains in the fan speed controller. At a gain of 0.56 , fan speed oscillated uniformly.

Table 2.1-4 HLW Fan Speed Control Parameters without Averaging.

[Ultimate gain $\mathrm{K}_{\mathrm{u}}=0.56$, Ultimate time constant $\tau_{\mathrm{u}}=7.5(\mathrm{~s})$ ]

\begin{tabular}{|c||c|c|c|}
\hline Control Method & Gain, $\mathbf{K}_{\mathbf{c}}$ & Reset, $\boldsymbol{\tau}_{\mathbf{i}} \mathbf{( s )}$ & Rate, $\boldsymbol{\tau}_{\mathbf{d}}(\mathbf{s})$ \\
\hline \hline P & 0.28 & - & - \\
\hline PI & 0.25 & 6.2 & - \\
\hline PID & 0.33 & 3.8 & 1.0 \\
\hline
\end{tabular}




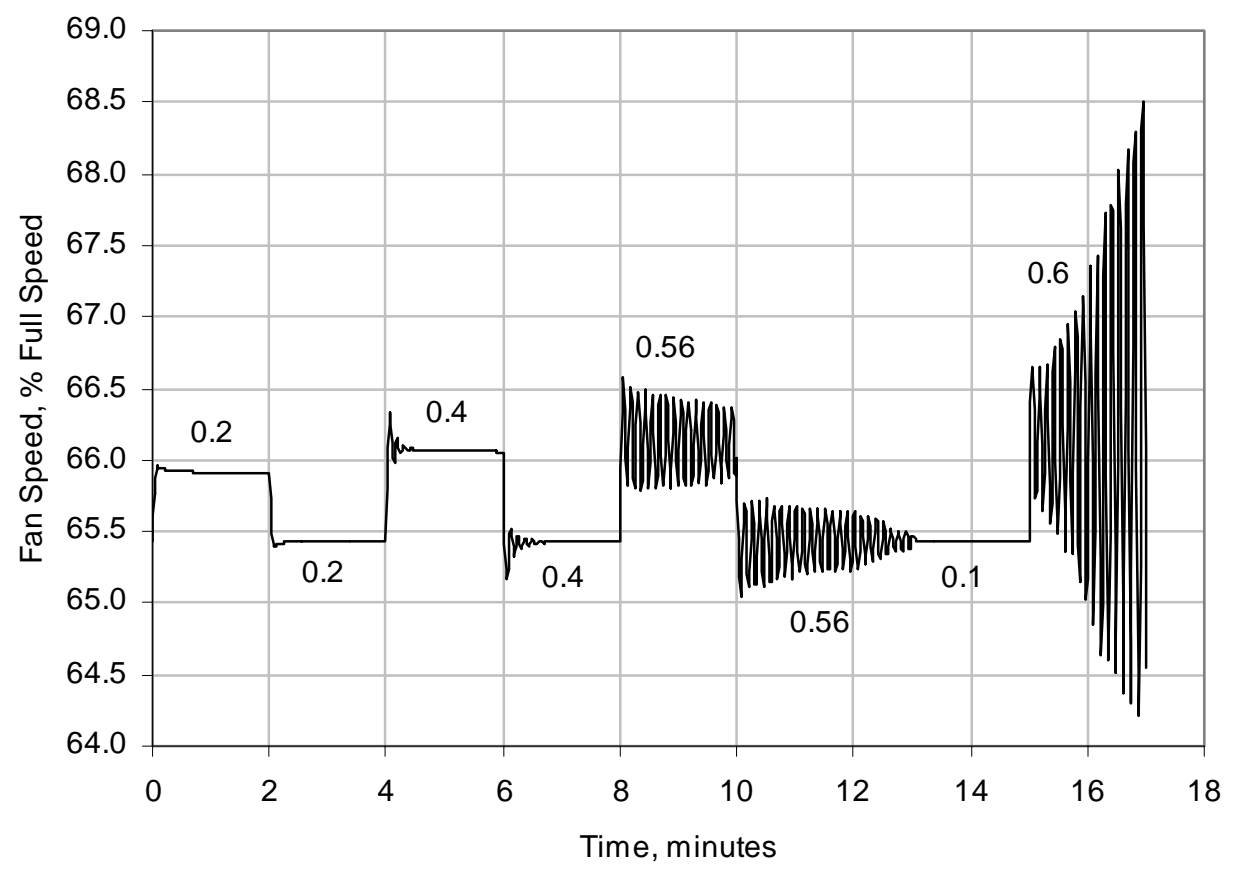

Figure 2.1-19 Determination of ultimate gain for fan speed control.

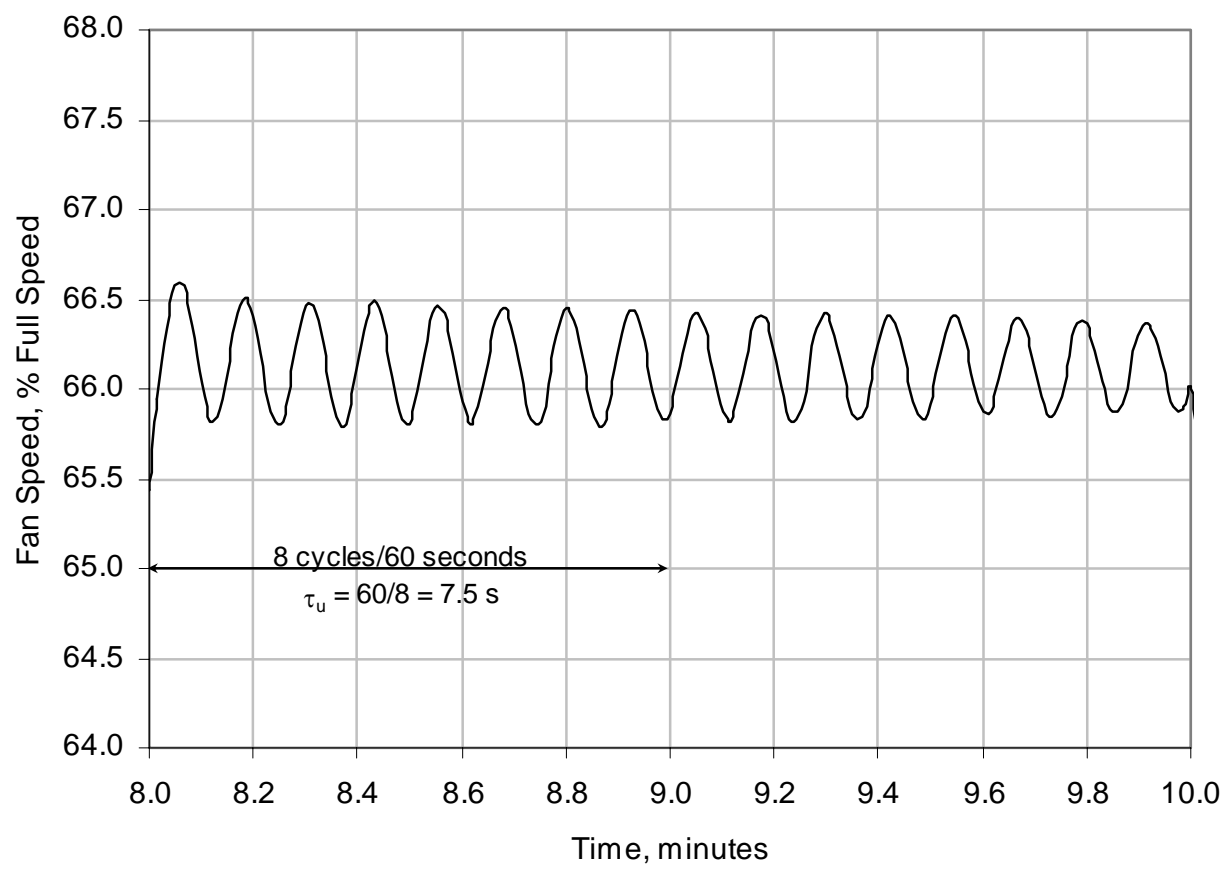

Figure 2.1-20 Determination of ultimate frequency for fan speed control. 
Figures 2.1-21 through 2.1-23 show the fan system response during melter feeding and a $7 \mathrm{X}$ steam surge using the three control methods listed in Table 2.1-4. Proportional control resulted in the least variation in fan speed during both normal operation and the $7 \mathrm{X}$ steam surge. PI control maintained the average control airflow as close to the set point as proportional control while reducing fluctuations in control air flow. As can be seen in Fig. 2.1-23, PID control resulted in a very noisy response in both fan speed and control air flow. PI control with increased reset time was also tested but gave essentially the identical response as PI control using the reset time determined directly from quarterdecay tuning. Pressure control during the $7 \mathrm{X}$ surge was slightly improved with fan speed control but the melter pressure response was actually better during normal operation with a constant fan speed.

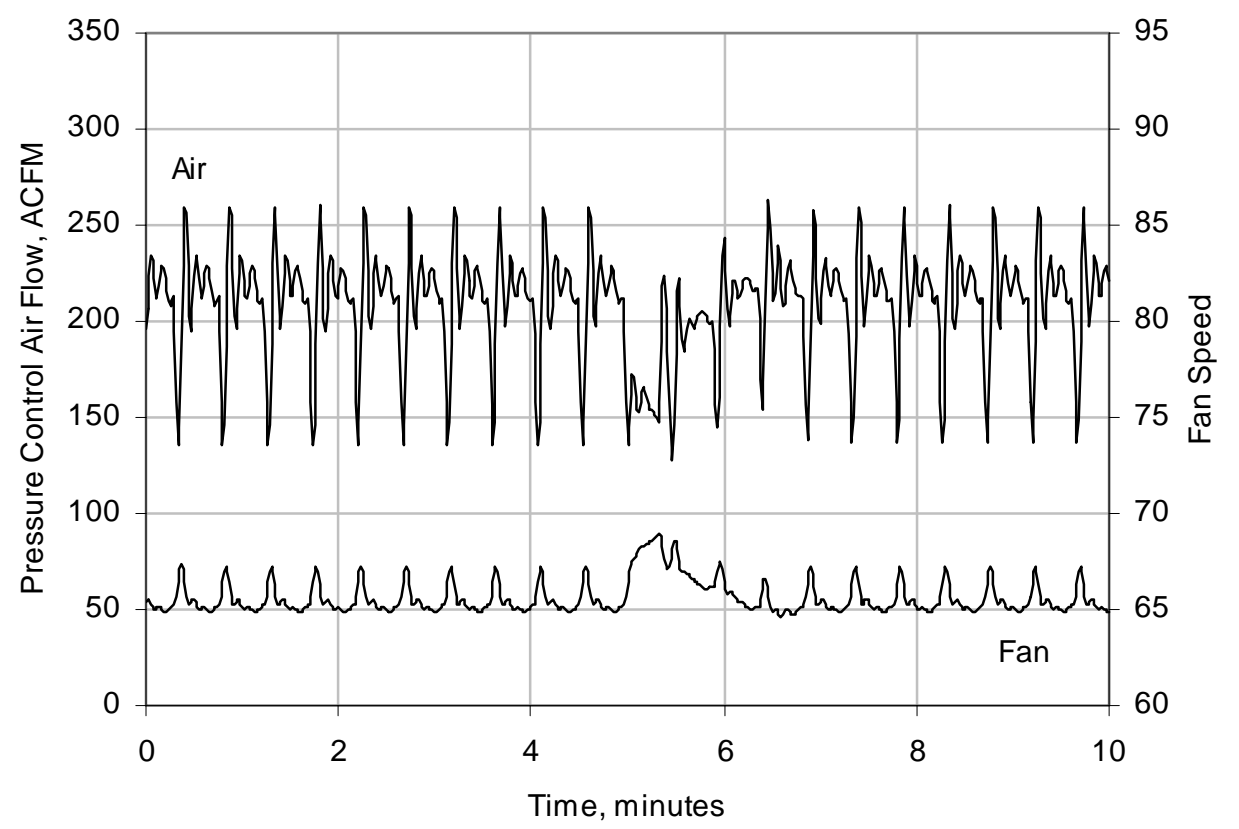

Figure 2.1-21 HLW fan speed control loop response using proportional control. 


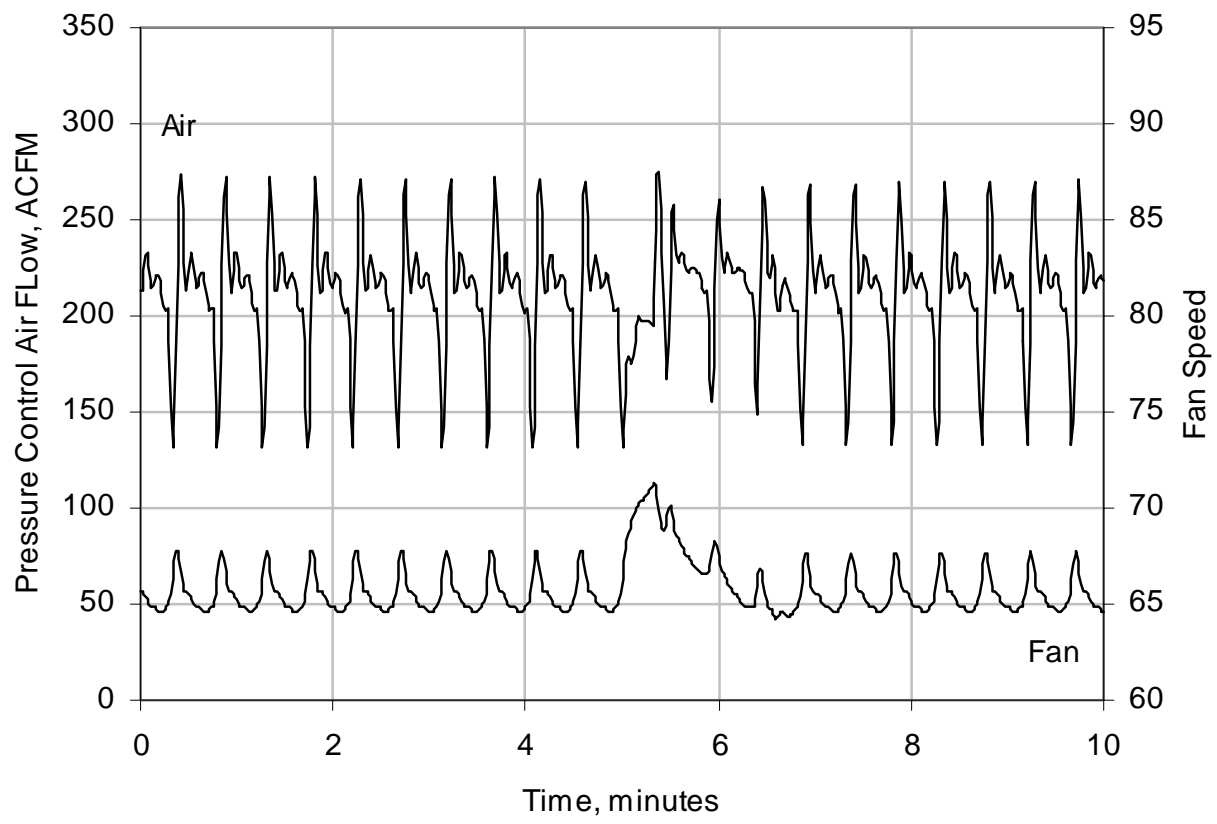

Figure 2.1-22 HLW fan speed control loop response using PI control.

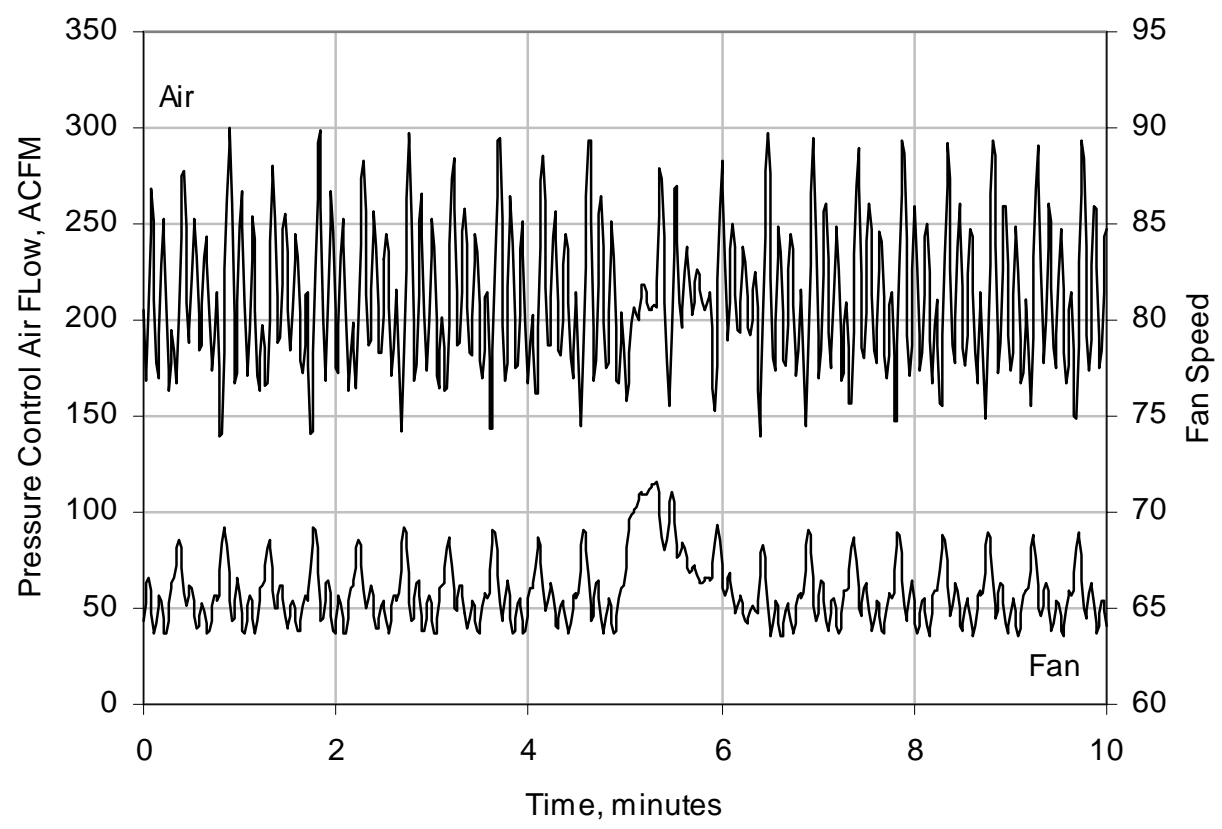

Figure 2.1-23 HLW fan speed control loop response using PID control. 


\subsubsection{HLW Fan Speed Control Loop with 15 Second Signal Averaging}

The results in the preceding section are relatively noisy which suggests that filtering the input signal to the controller could smooth the fan response without substantially degrading performance. Therefore, the tuning process was repeated with the input signal to the fan filtered using both 15 second and 30 second averaging times.

Table 2.1-5 shows the ultimate gain and frequency for the fan speed control loop and the corresponding controller parameters when the input signal to the controller is averaged over a 15-second time interval. Figures 2.1-24 through 2.1-26 show the fan system response during normal melter feeding and during a $7 \mathrm{X}$ steam surge using the control parameters listed in Table 2.1-5. With signal averaging, all three control methods gave very smooth response. A comparison with Figs. 2.1-21 through 2.1-23 shows that the control air flow is significantly smoother using signal averaging although the deviation from the control point is greater. PI control performed slightly better than proportional or PID control in maintaining the control airflow close to the set point.

Table 2.1-5 HLW Fan Speed Control Parameters with 15 sec Averaging.

[Ultimate gain $\mathrm{K}_{\mathrm{u}}=0.60$, Ultimate time constant $\tau_{\mathrm{u}}=27.5$ (s)]

\begin{tabular}{|c||c|c|c|}
\hline Control Method & Gain, $\mathbf{K}_{\mathbf{c}}$ & Reset, $\boldsymbol{\tau}_{\mathbf{i}} \mathbf{( s )}$ & Rate, $\boldsymbol{\tau}_{\mathbf{d}}(\mathbf{s})$ \\
\hline \hline P & 0.30 & - & - \\
\hline PI & 0.27 & 23 & - \\
\hline PID & 0.35 & 14 & 3.4 \\
\hline
\end{tabular}

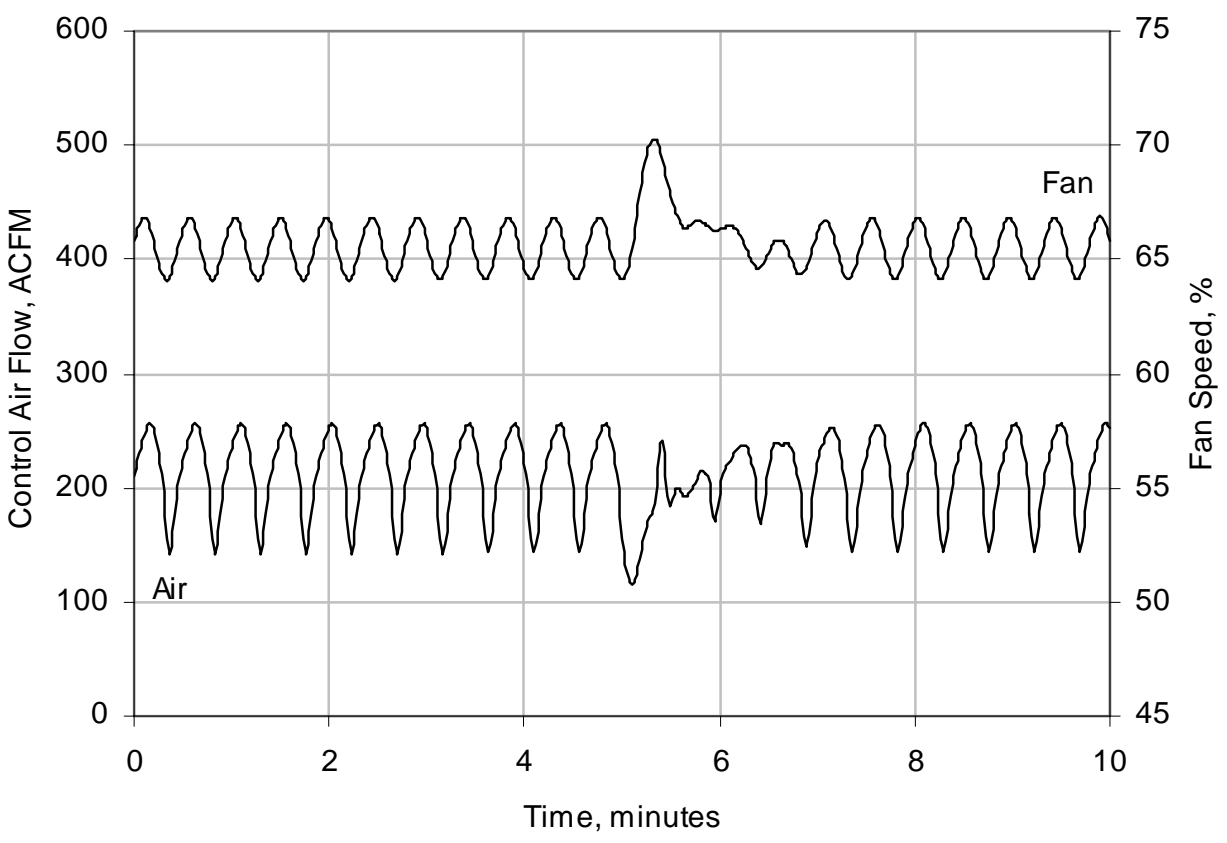

Figure 2.1-24 HLW fan speed control loop response using proportional control with 15 second signal averaging. 


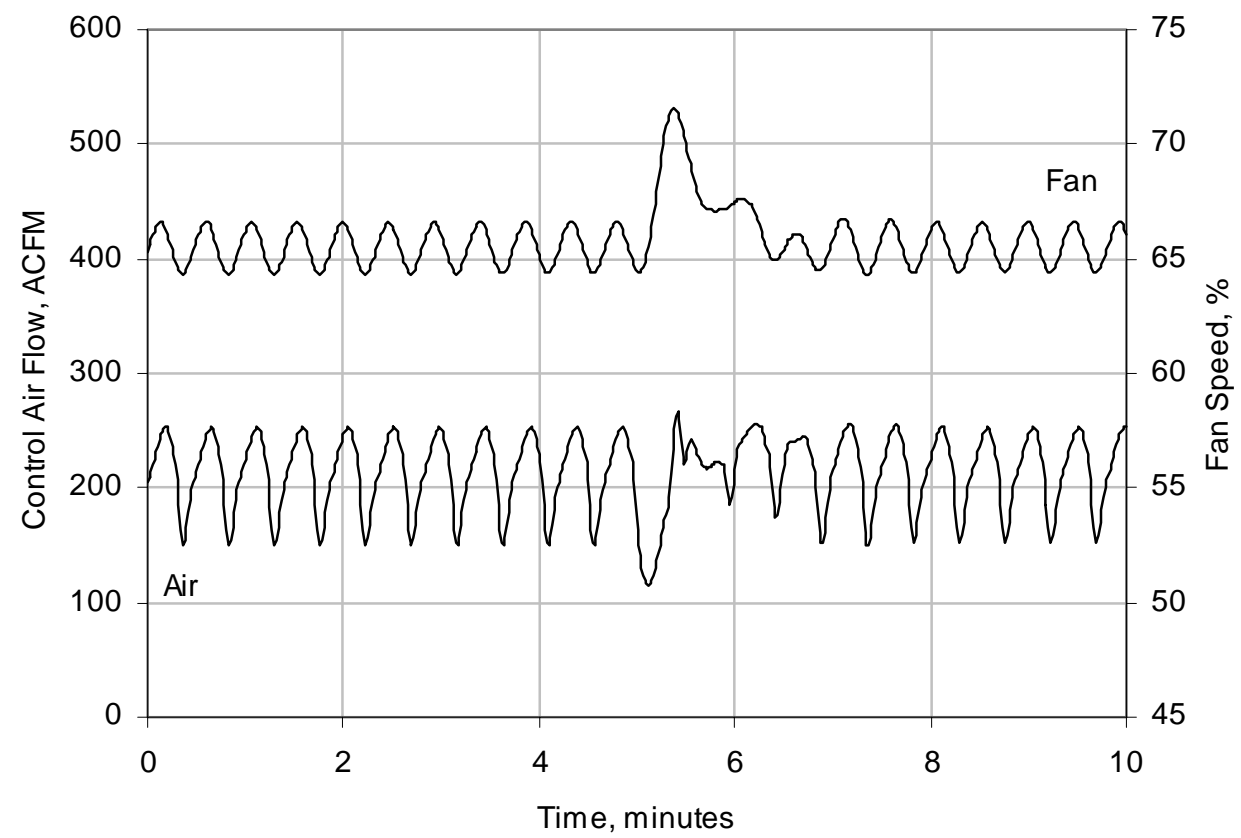

Figure 2.1-25 HLW fan speed control loop response using PI control with 15 second signal averaging.

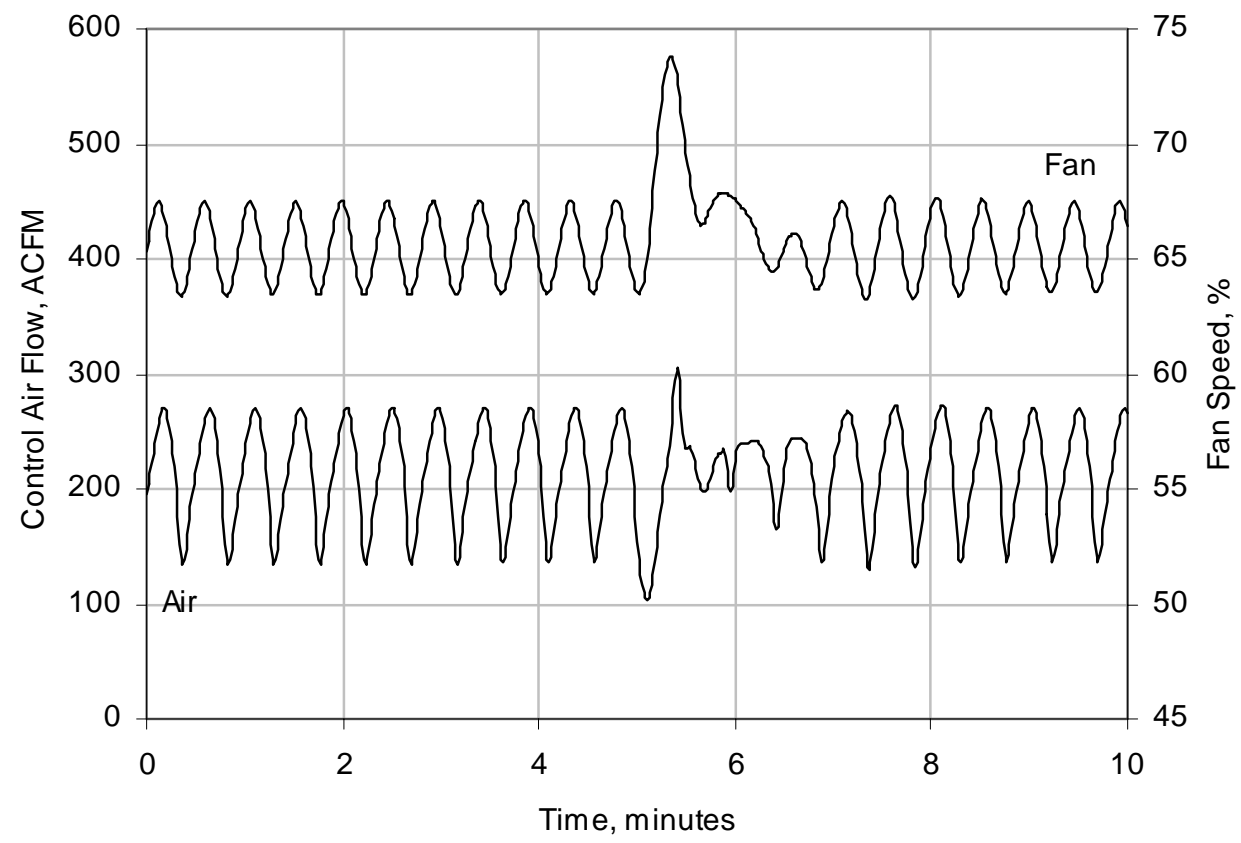

Figure 2.1-26 HLW fan speed control loop response using PID control with 15 second signal averaging. 


\subsubsection{HLW Fan Speed Control Loop with 30 Second Signal Averaging}

Table 2.1-6 shows the ultimate gain and frequency for the fan speed control loop and the corresponding controller parameters when the input signal to the controller is averaged over a 30-second time interval. Figures 2.1-27 through 2.1-29 show the fan system response during normal melter feeding and during a $7 \mathrm{X}$ steam surge using the three control methods listed in Table 2.1-6. When compared to the corresponding results with 15-second signal averaging, 30-second averaging gives a relatively constant fan speed which takes longer to recover normal operation following the steam surge. However 30 second averaging reduces the variation in control airflow and maintains the control air nearer to the set point. Of the three control methods, PID control produced the largest fluctuations in response to the steam surge while proportional control gave the smallest. However, PI control produced results nearly identical to those obtained with proportional control. Since proportional control alone can result in operation at an offset from the set point, PI control with 30 second signal averaging was judged to provide the best results and was selected as the optimum control settings reported in Section 2.1.

Table 2.1-6 HLW Fan Speed Control Parameters with 30 sec Averaging.

[Ultimate gain $\mathrm{K}_{\mathrm{u}}=0.70$, Ultimate time constant $\tau_{\mathrm{u}}=44.0$ (s)]

\begin{tabular}{|c||c|c|c|}
\hline Control Method & Gain, $\mathbf{K}_{\mathbf{c}}$ & Reset, $\boldsymbol{\tau}_{\mathbf{i}}(\mathbf{s})$ & Rate, $\boldsymbol{\tau}_{\mathbf{d}}(\mathbf{s})$ \\
\hline \hline P & 0.35 & - & - \\
\hline PI & 0.32 & 37 & - \\
\hline PID & 0.41 & 22 & 5.5 \\
\hline
\end{tabular}

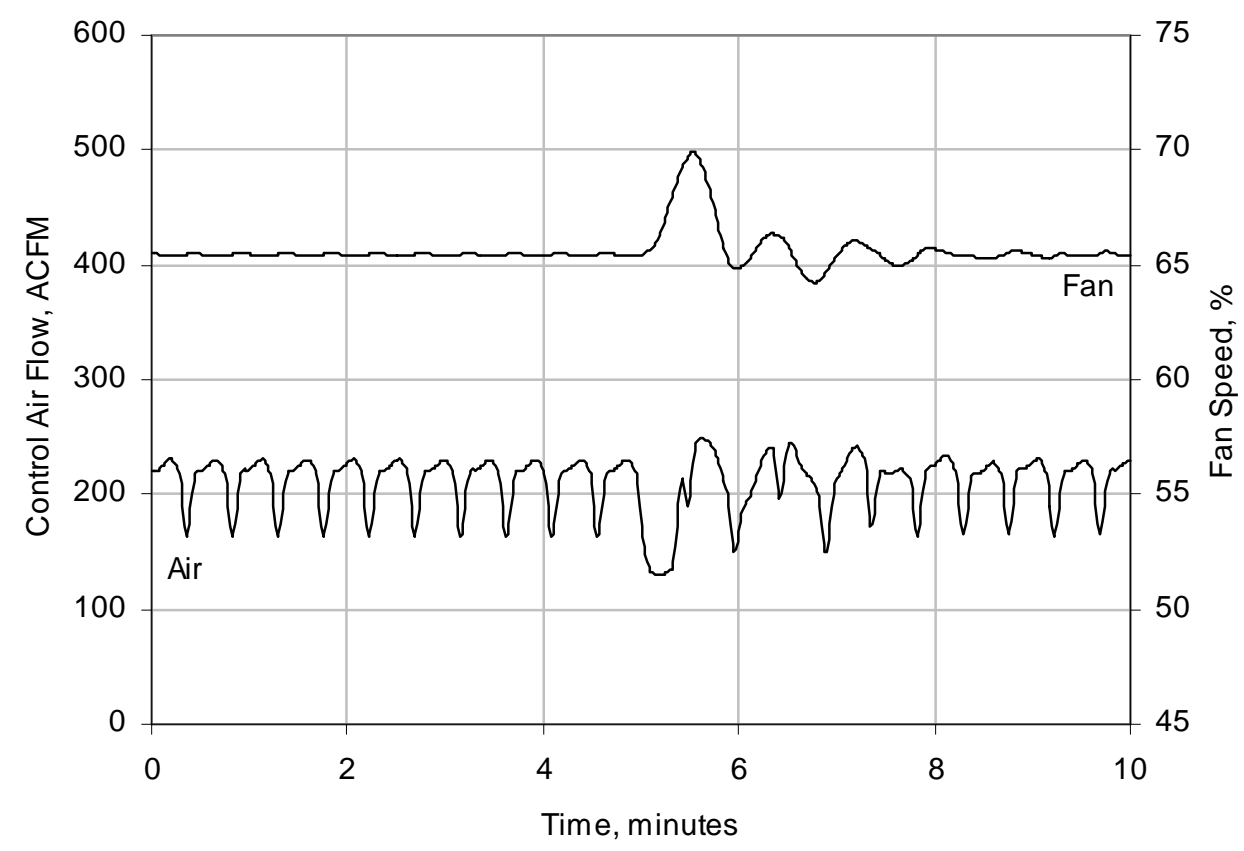

Figure 2.1-27 HLW fan speed control loop response using proportional control with 30 second signal averaging. 


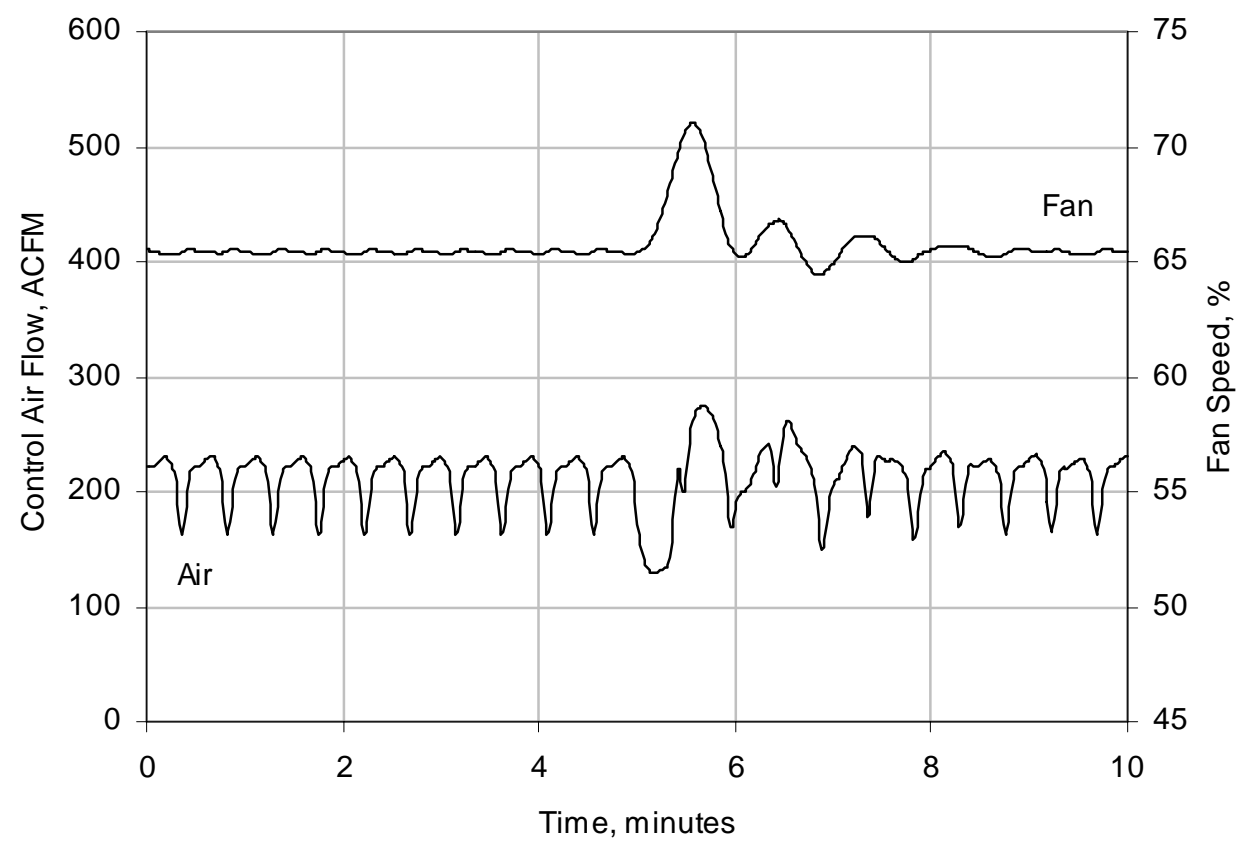

Figure 2.1-28 HLW fan speed control loop response using PI control with 30 second signal averaging.

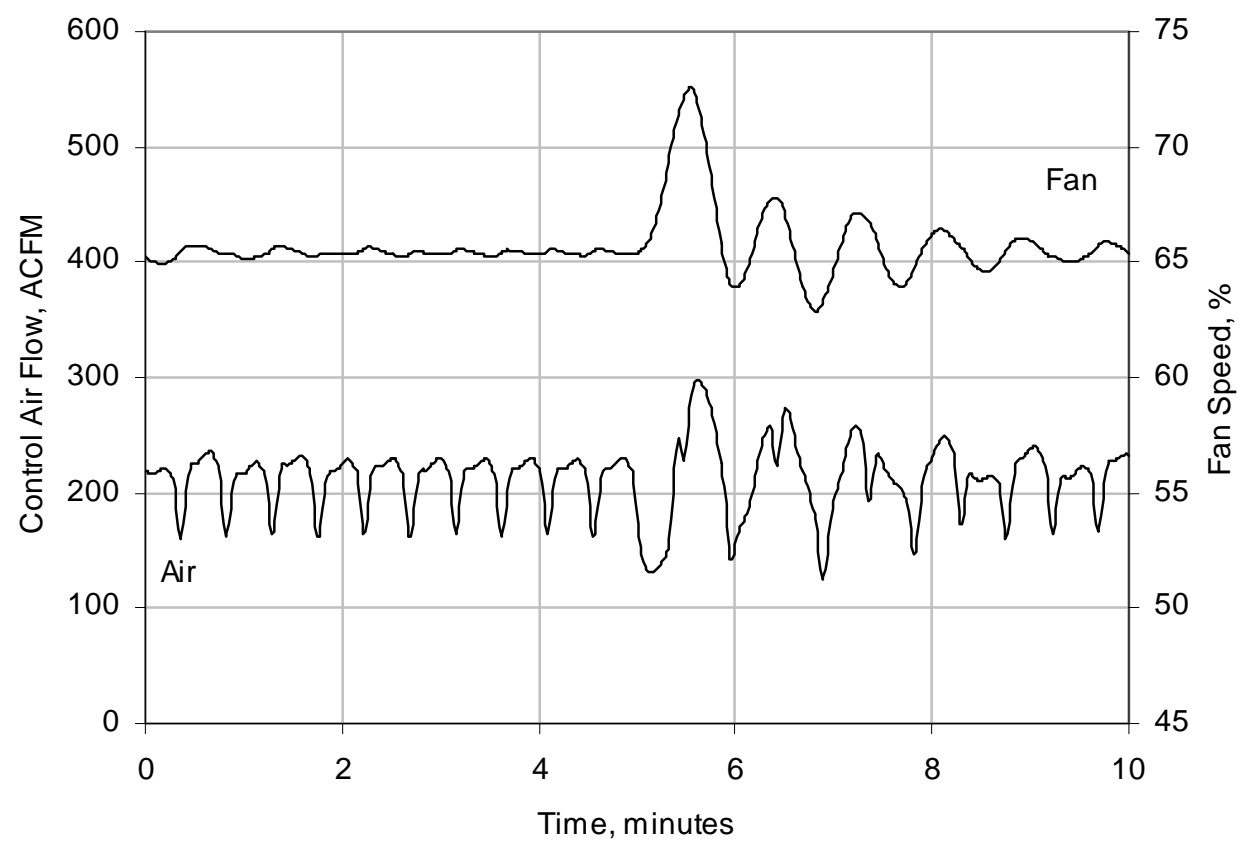

Figure 2.1-29 HLW fan speed control loop response using PID control with 30 second signal averaging. 


\subsection{LAW Melter Offgas System}

The LAW system was modeled using the flowsheet shown in Fig. D-2. The system was initialized to steady-state operation with the control loops in manual. In this mode, the bias values shown in Table 2.2-1 are fixed outputs from the controllers. The pressure control valve settings are the fractional openings and the fan speed setting is the fraction of full speed. These values operated the system within 0.25 inches of the pressure set points and $1 \%$ of the control airflow. Note that the damper valve position is controlled from the air flow through the pressure control valve and not from the valve position.

Numerical values above the bold line in Table 2.2-1 are fixed parameters in each controller while values below the bold line in Table 2.2-1 are recommended controller tuning parameters based on the results from this study. In some cases, the controller gains and rate constants have been slightly rounded off from the values found by the optimization study. As recommended by Robbins, integral rate constants have typically been increased by a factor of six to smooth the controller response without sacrificing significant control action.

Table 2.2-1 LAW Melter Offgas System Tuned Control Parameters

\begin{tabular}{|c||c|c|c|c|}
\hline Controller & $\begin{array}{c}\text { Melter } \\
\text { Pressure }\end{array}$ & $\begin{array}{c}\text { Damper } \\
\text { Flow }\end{array}$ & $\begin{array}{c}\text { VVS } \\
\text { Pressure }\end{array}$ & Fan Speed \\
\hline \hline Type & PI & PI & PID & PID \\
\hline Action & -1 & -1 & +1 & +1 \\
\hline Setpoint & $97875 \mathrm{~Pa}$ & 0.15 & $99250 \mathrm{~Pa}$ & $87500 \mathrm{~Pa}$ \\
\hline Dead Time & $0.5 \mathrm{~s}$ & $0.1 \mathrm{~s}$ & $0.1 \mathrm{~s}$ & $0.1 \mathrm{~s}$ \\
\hline Linear Range & $\pm 1500 \mathrm{~Pa}$ & $\pm 0.1 \mathrm{~m}^{3} / \mathrm{s}$ & $\pm 1500 \mathrm{~Pa}$ & $\pm 1500 \mathrm{~Pa}$ \\
\hline Bias & 0.300 & 0.430 & 0.445 & 0.902 \\
\hline \hline Gain & 1.4 & 0.4 & 2.4 & 5.9 \\
\hline Rate (s) & - & - & 2.0 & 0.7 \\
\hline Reset (s) & 28.0 & 18.0 & 8.5 & 14.0 \\
\hline Signal Averaging (s) & - & 15.0 & - & - \\
\hline
\end{tabular}

Figures 2.2-1 through 2.2-5 show the responses of the LAW systems using the tuned control parameters listed in Table 2.2-1 during normal melter feeding and a $4 \mathrm{X}$ steam surge. During normal operation, the pressures and fan speed fluctuate in response to the cyclic ADS feeding. Starting at 900 seconds, the $4 \mathrm{X}$ steam surge linearly ramps up to its maximum flow in 22 seconds and then linearly ramps down to zero during the next 89 seconds. As can be seen in Fig. 2.2-5, between 700 and 800 seconds the SBS pressure drop was increased by $10 \%$. The control scheme is able to maintain the plenum pressure between +0.7 and -0.3 inches WG of the set point during normal operation. During the steam surge, the pressure increases by about +1.2 inch WG. Control air flow fluctuates between 280 and 340 CFM during normal operation and falls to about 225 CFM during the steam surge. The VVS header pressure remains essentially constant during normal operation and during the steam surge. As shown in Fig. 2.2-4, the exhauster is operating at about $90 \%$ of full capacity. 


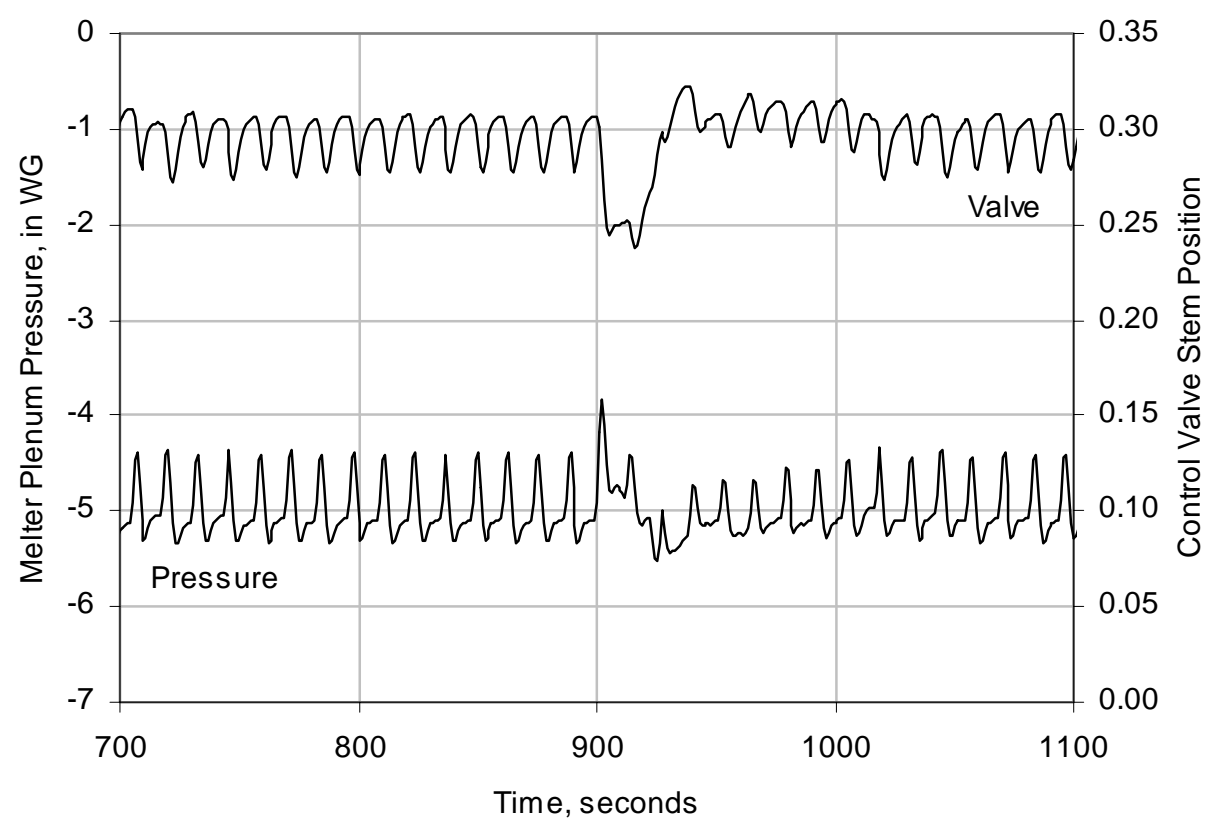

Figure 2.2-1 LAW melter pressure control response during normal operation and 4X steam surge.

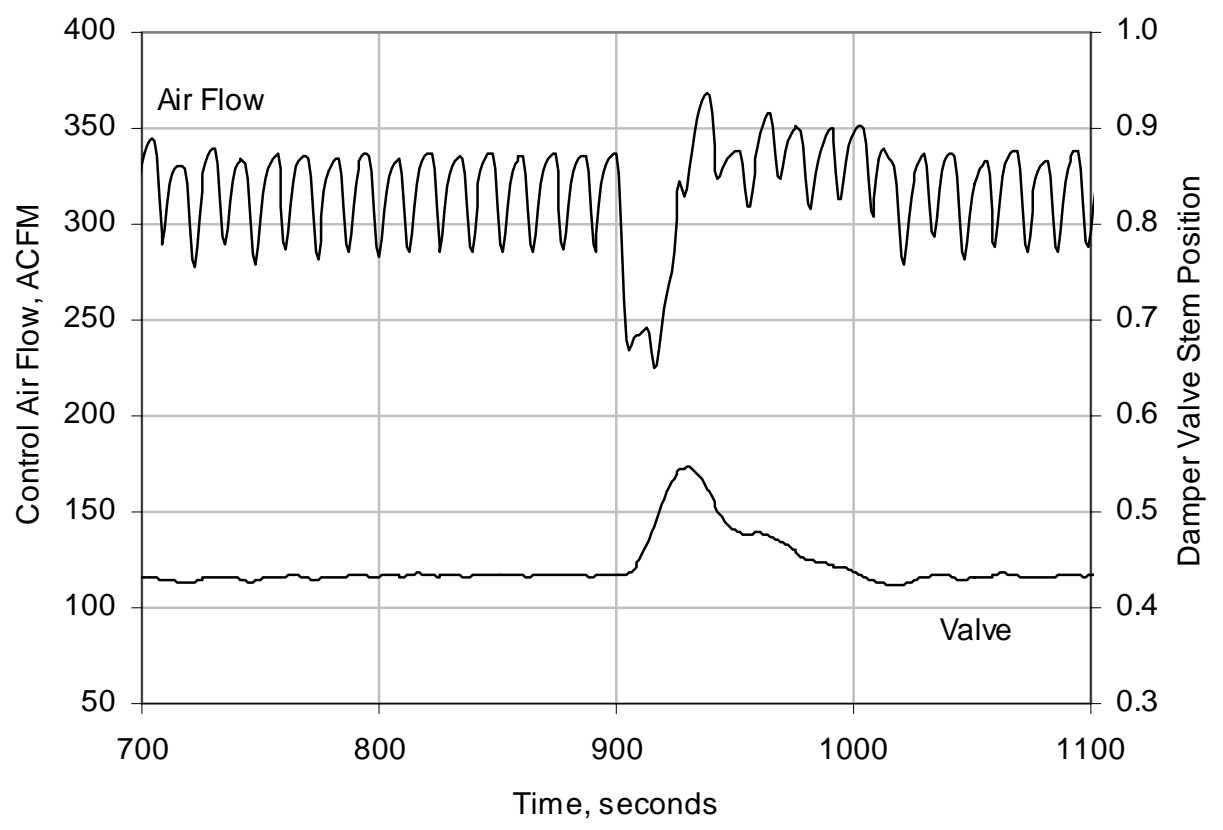

Figure 2.2-2 LAW damper control response during normal operation and 4X steam surge. 


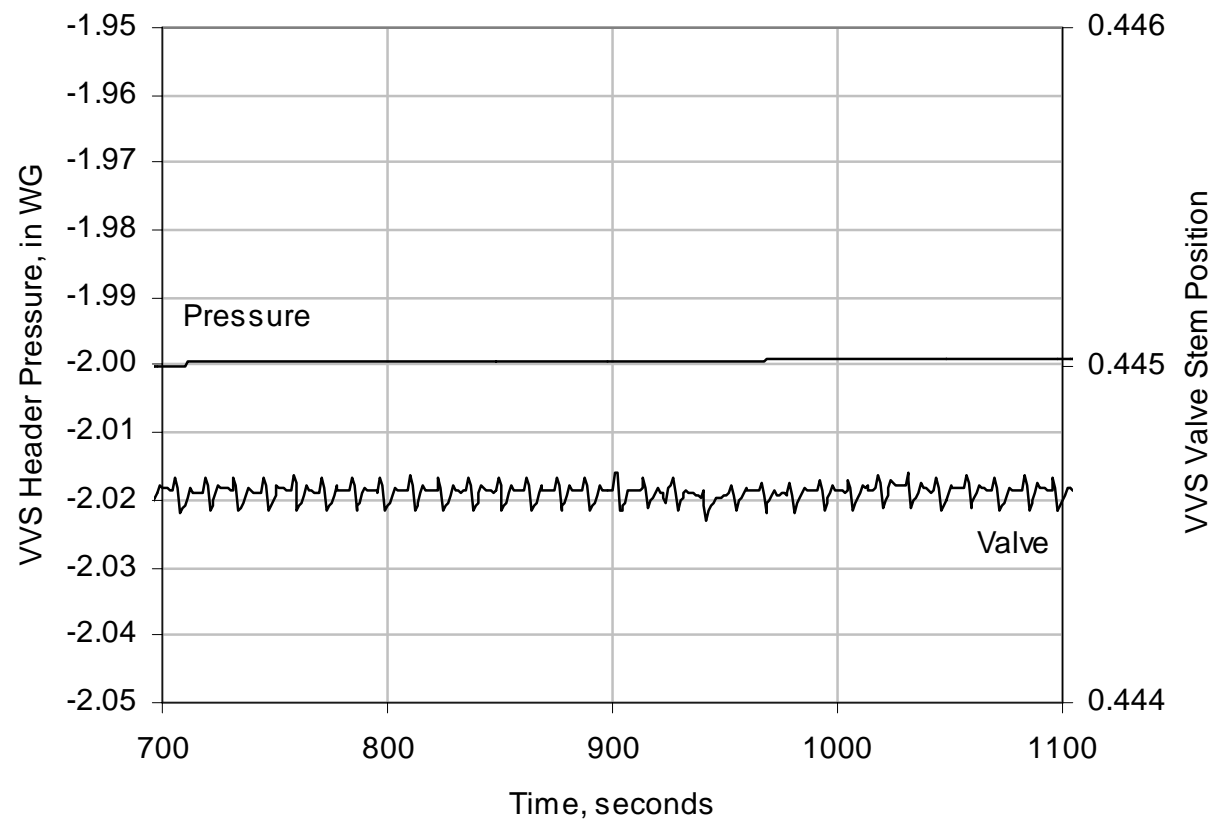

Figure 2.2-3 LAW VVS pressure control response during normal operation and 4X steam surge.

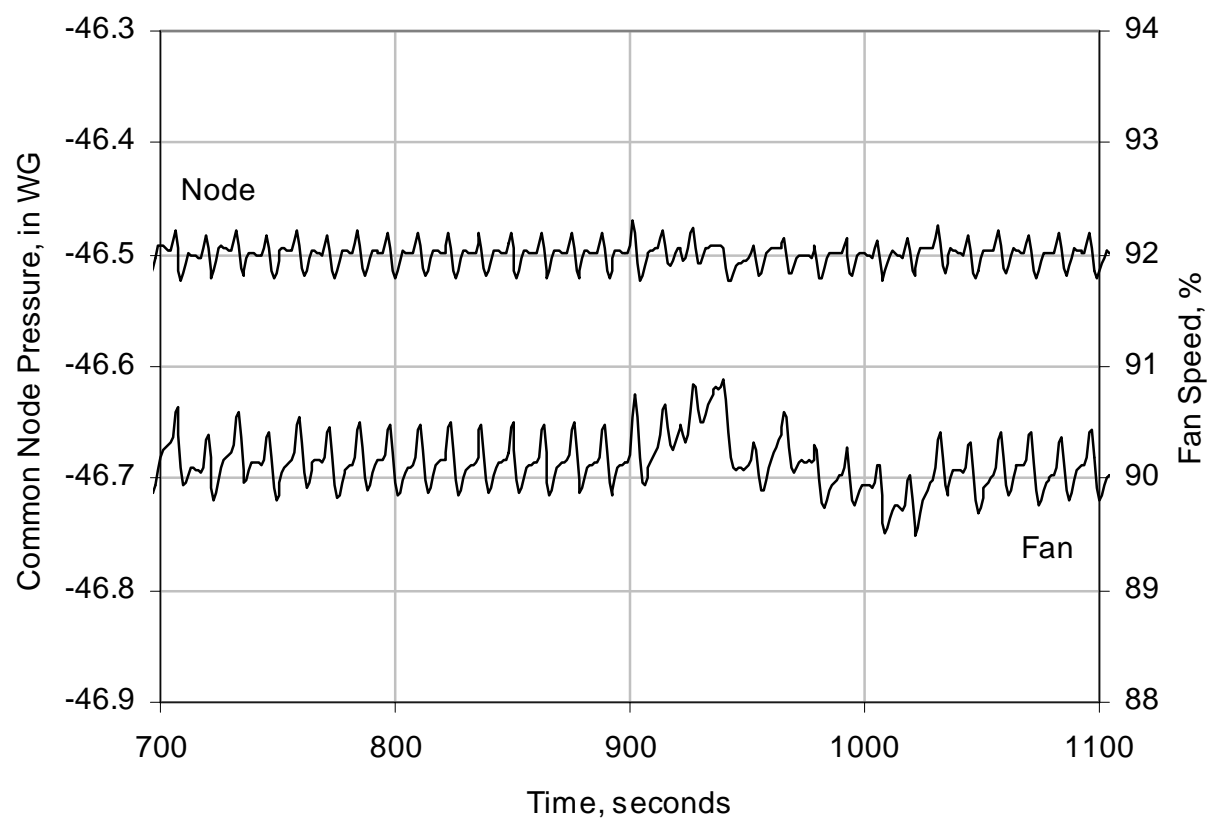

Figure 2.2-4 LAW fan speed control response during normal operation and $4 \mathrm{X}$ steam surge. 


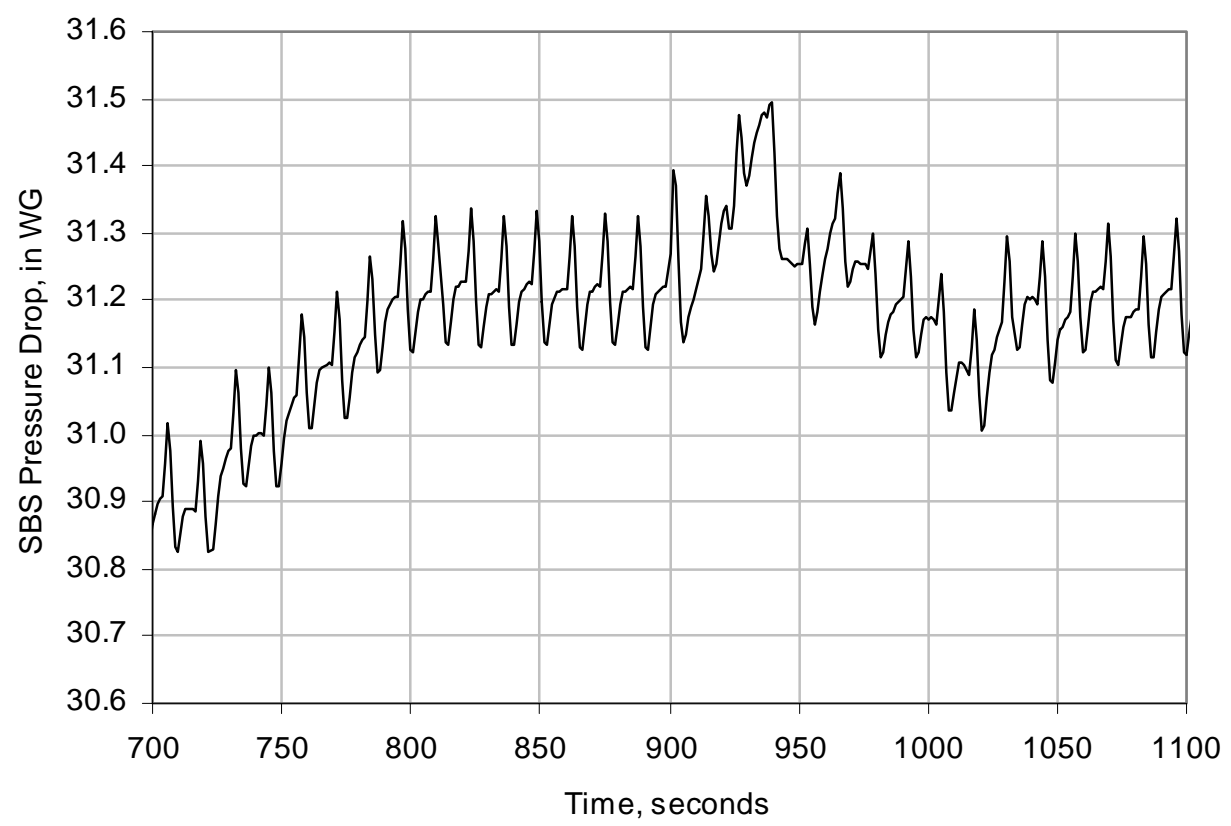

Figure 2.2-5 LAW SBS pressure drop during normal operation and 4X steam surge.

\subsubsection{LAW Melter Pressure Control Loop}

Table 2.2-2 shows the ultimate gain and frequency for the LAW melter pressure control loop and the corresponding controller parameters. Figures 2.2-6 through 2.2-10 show the system response during normal operation and a nominal $4 \mathrm{X}$ steam surge using each of the control settings in Table 2.2-2. Results are similar to those obtained for the HLW melter pressure control system. PID control gave the best response to the pressure surge keeping the plenum pressure within one inch of the set point. However, PID control gives a comparatively noisy signal while PI control with a longer reset time gives almost as good pressure control with significantly smoother valve operation. The Robbins tuning procedure yields a very low gain, which results in poor response to the steam surge and to ADS cycling during routine operation.

Table 2.2-2 LAW Melter Pressure Control Parameters.

[Ultimate gain $\mathrm{K}_{\mathrm{u}}=3.0$, Ultimate time constant $\tau_{\mathrm{u}}=5.6(\mathrm{~s})$ ]

\begin{tabular}{|c||c|c|c|}
\hline Control Method & Gain, $\mathbf{K}_{\mathbf{c}}$ & Reset, $\boldsymbol{\tau}_{\mathbf{i}}(\mathbf{s})$ & Rate, $\boldsymbol{\tau}_{\mathbf{d}}(\mathbf{s})$ \\
\hline \hline P & 1.50 & - & - \\
\hline PI & 1.36 & 4.7 & - \\
\hline PID & 1.76 & 2.8 & 0.7 \\
\hline Robbins (PI) & 0.50 & 7.5 & - \\
\hline PI/Increased Reset & 1.36 & 28.0 & - \\
\hline
\end{tabular}




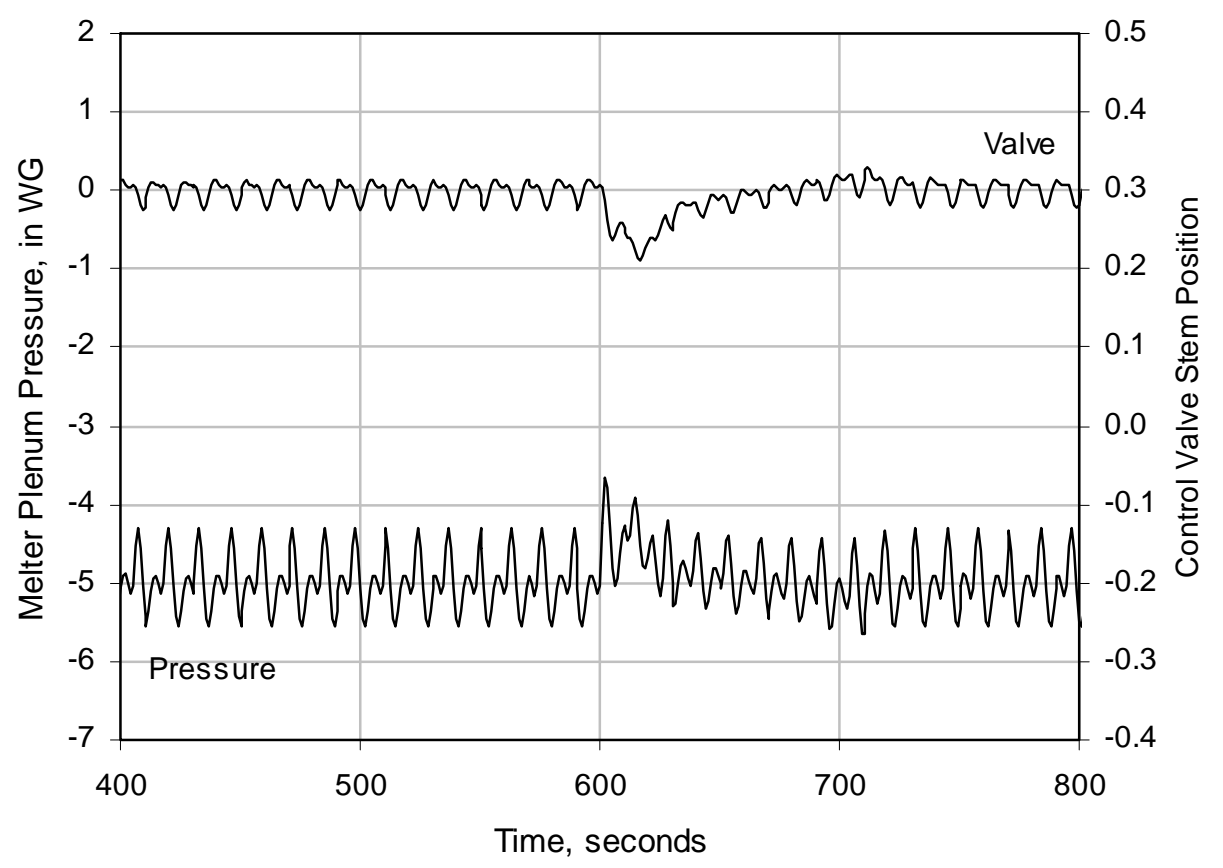

Figure 2.2-6 LAW melter pressure control loop response under proportional control.

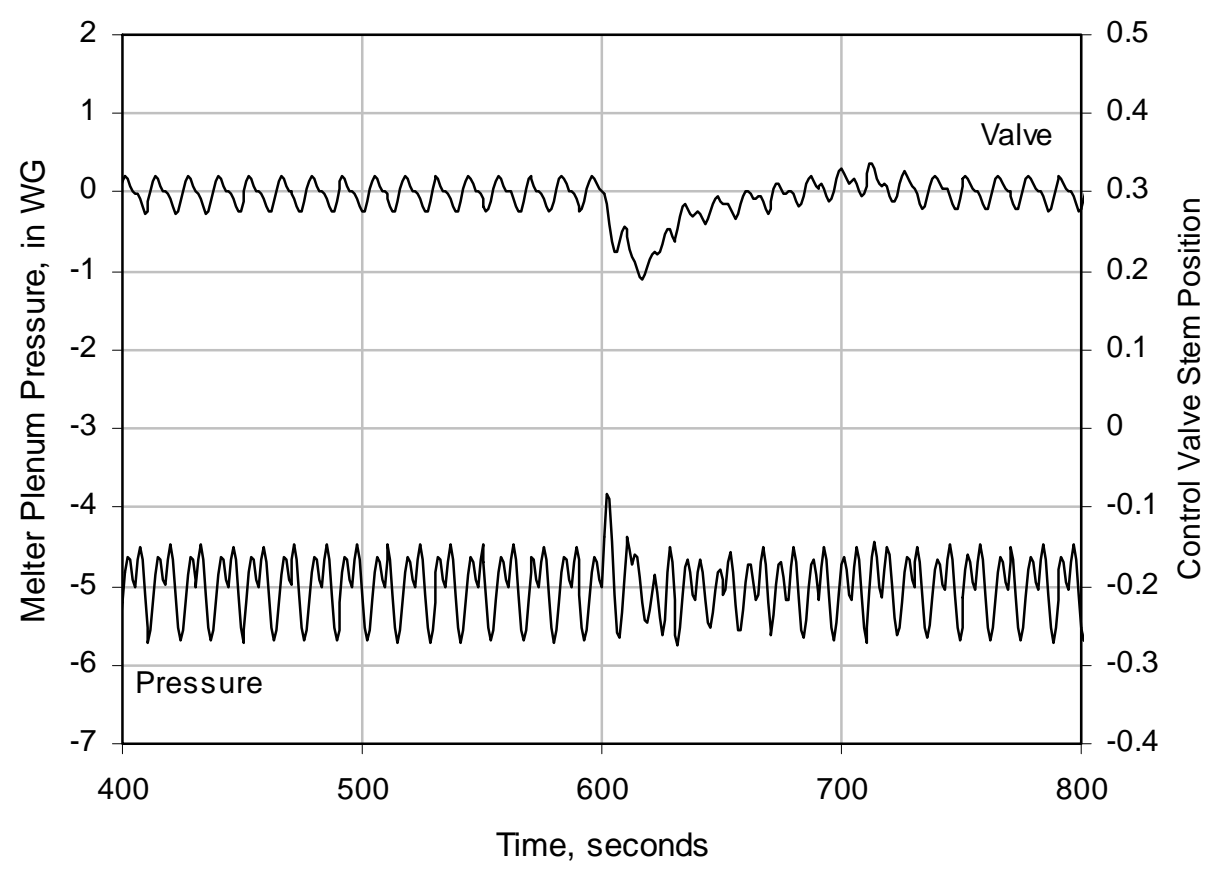

Figure 2.2-7 LAW melter pressure control loop response under PI control. 


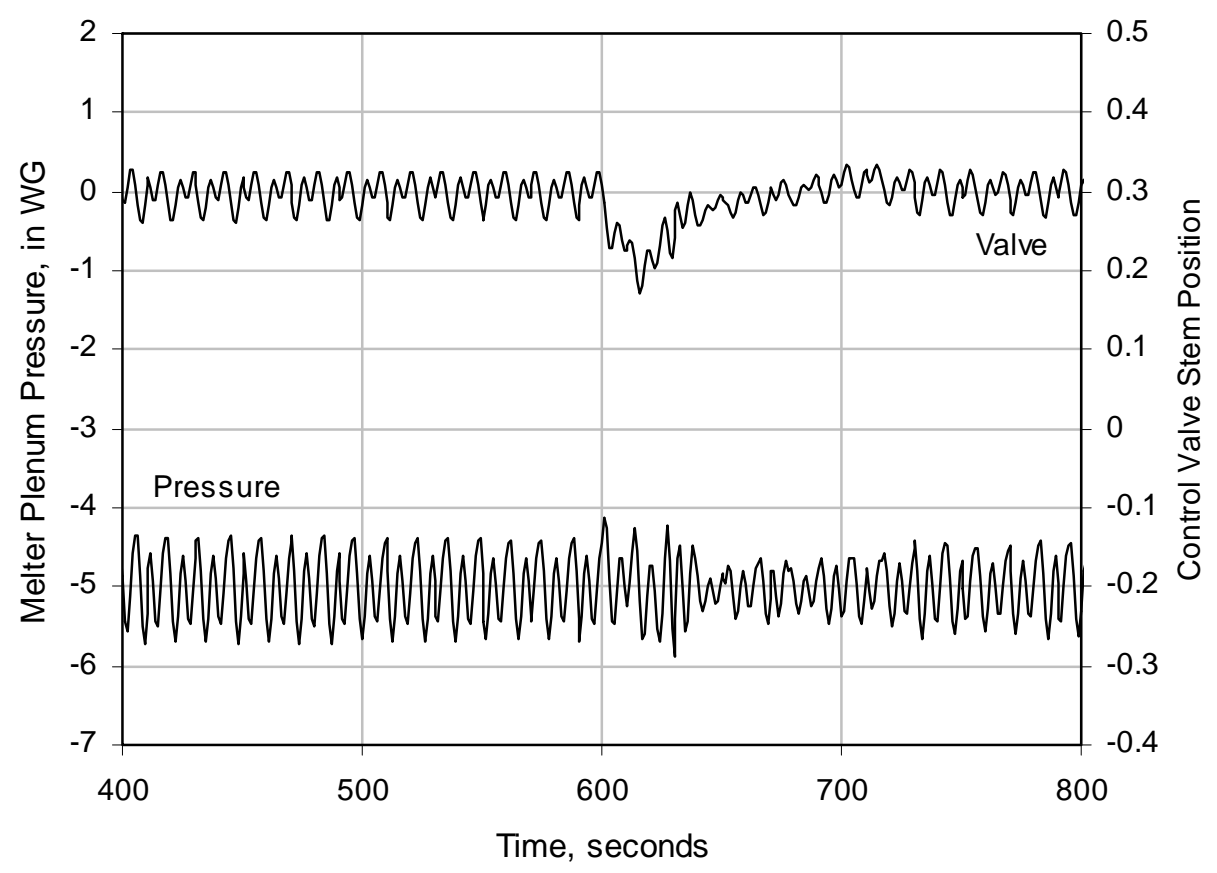

Figure 2.2-8 LAW melter pressure control loop response under PID control.

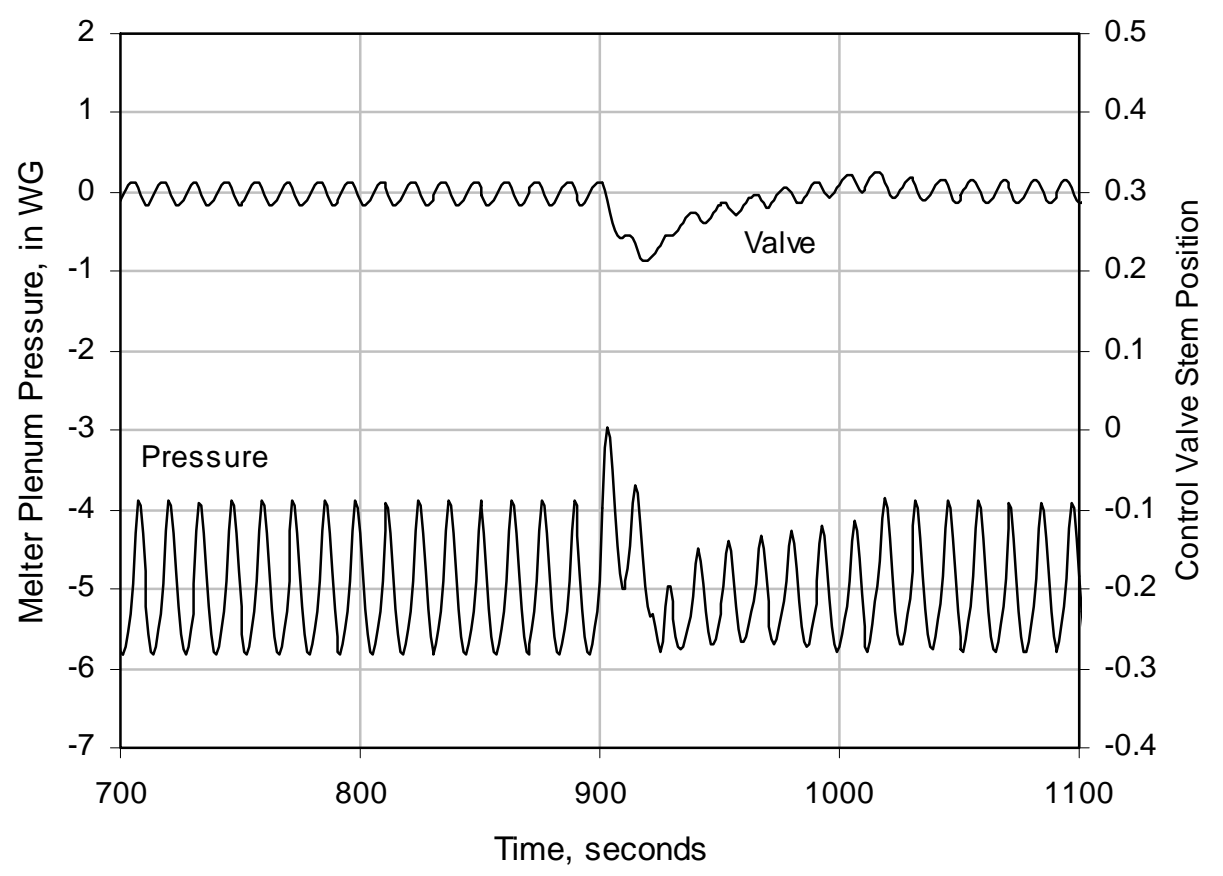

Figure 2.2-9 LAW melter pressure control loop response using Robbins PI control parameters. 


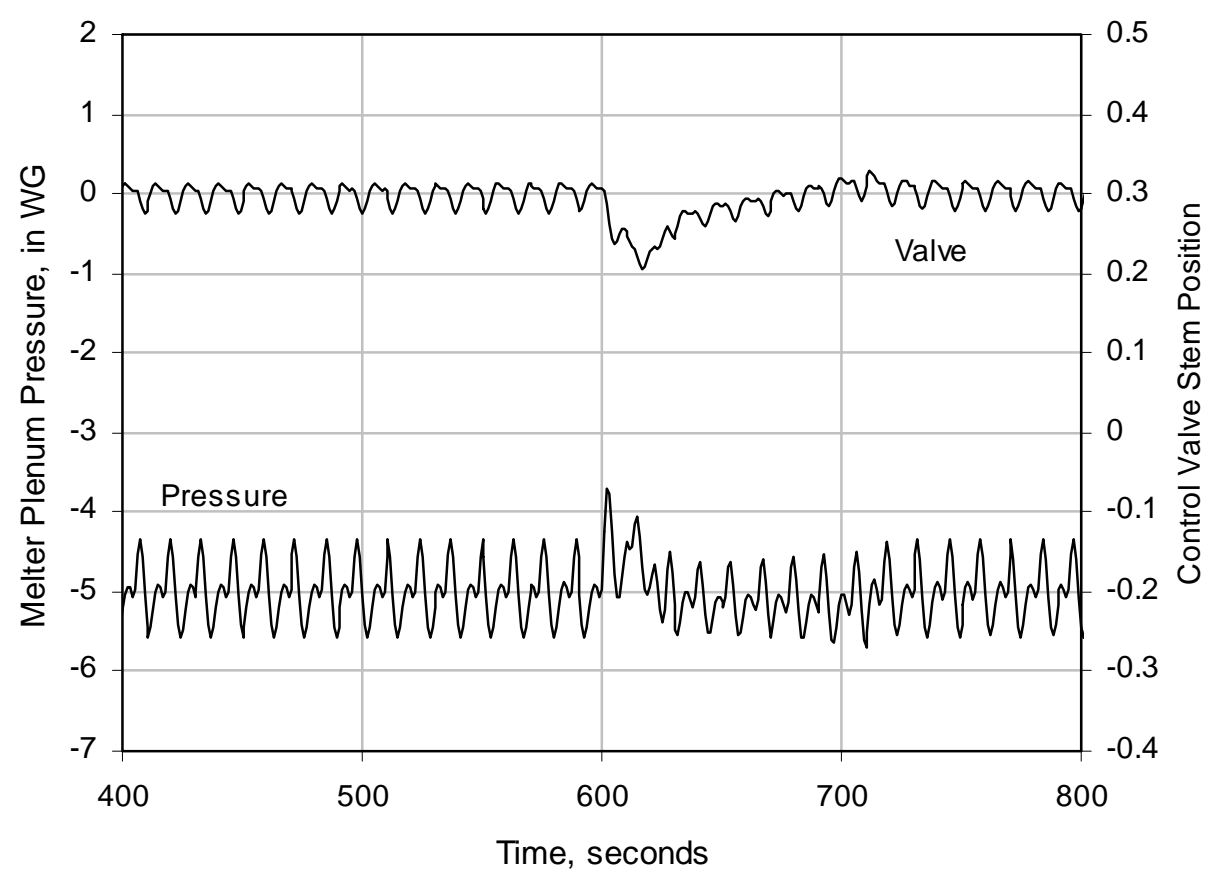

Figure 2.2-10 LAW melter pressure control loop response under PI control with increased reset time.

\subsubsection{LAW Vessel Ventilation Control Loop}

Table 2.2-3 shows the ultimate gain and frequency for the LAW VVS pressure control loop and the corresponding controller parameters. To expedite the calculations, the vessel ventilation system model was simplified for control loop tuning purposes. The individual vessels were replaced with a single gas volume of $20 \mathrm{~m}^{3}$ that is equal to the total gas volume in the VVS vessel head spaces. Nominal gas flow and gas surges were modeled as fixed air flows into this volume. The control valve time constant was fixed at 5 seconds although a fast acting valve may have performed better.

Table 2.2-3 LAW VVS Control Parameters.

[Ultimate gain $\mathrm{K}_{\mathrm{u}}=4.0$, Ultimate time constant $\tau_{\mathrm{u}}=17.0(\mathrm{~s})$ ]

\begin{tabular}{|c||c|c|c|}
\hline Control Method & Gain, $\mathbf{K}_{\mathbf{c}}$ & Reset, $\boldsymbol{\tau}_{\mathbf{i}} \mathbf{( s )}$ & Rate, $\boldsymbol{\tau}_{\mathbf{d}}(\mathbf{s})$ \\
\hline \hline P & 2.0 & - & - \\
\hline PI & 1.8 & 14.0 & - \\
\hline PID & 2.4 & 8.5 & 2.0 \\
\hline Robbins (PI) & 0.1 & 40.0 & - \\
\hline PI/Increased Reset & 1.8 & 84.0 & - \\
\hline
\end{tabular}

Figures 2.2-11 through 2.2-15 show the VVS header pressure and VVS control valve position during $2 \mathrm{X}$ and $4 \mathrm{X}$ flow surges using the five control schemes listed in Table 2.23. The $2 X$ and $4 X$ surges were instantaneously turned on at 600 and 900 seconds, 
respectively, and the higher gas flow kept on for 30 seconds at which point the flow was instantaneously returned to normal.

With proportional control alone, Fig. 2.2-11 shows that there is an offset in the pressure control point after the $2 \mathrm{X}$ surge. With PI or PID control, Figs. 2.2-12 and 2.2-13 show that the header pressure is returned to the set point ( -2 inches WG) following the $2 \mathrm{X}$ surge. PID control provided the best response during the $2 \mathrm{X}$ surge with the least pressure fluctuations. In all cases with the $4 \mathrm{X}$ surge, the control valve fully opens and remains opened until the surge flow is turned off. The control valve is undersized to handle this increase in gas flow and the control settings make little difference in this case although PID control did give a smoother response. During the $4 \mathrm{X}$ surge, VVS header pressures increased to just over +40 inches WG. This is a conservative worst case calculation because the "surge" flow is kept on for 30 seconds and is not a true gas surge. The +40 inches is the equilibrium pressure that the VVS header gas volume reaches with a $4 \mathrm{X}$ gas inflow and outflow through a fully opened control valve.

The Robbins tuning method produced a very small controller gain, which led to completely unsatisfactory pressure control response as shown in Fig. 2.2-14. During the $4 \mathrm{X}$ surge using the Robbins tuning parameters, the header pressure became extremely large (+125 inches WG) as the valve opened very slowly and restricted the gas flow. Robbins has also suggested increasing the integral reset time by a factor of 6 based on the observed pattern that the controlled variable (header pressure) typically crossed the set point when the control variable (valve stem position) reached a maximum or minimum. Comparing Fig. 2.2-12 with Fig. 2.2-15 shows that increasing the controller reset time gave a slightly smoother control response.

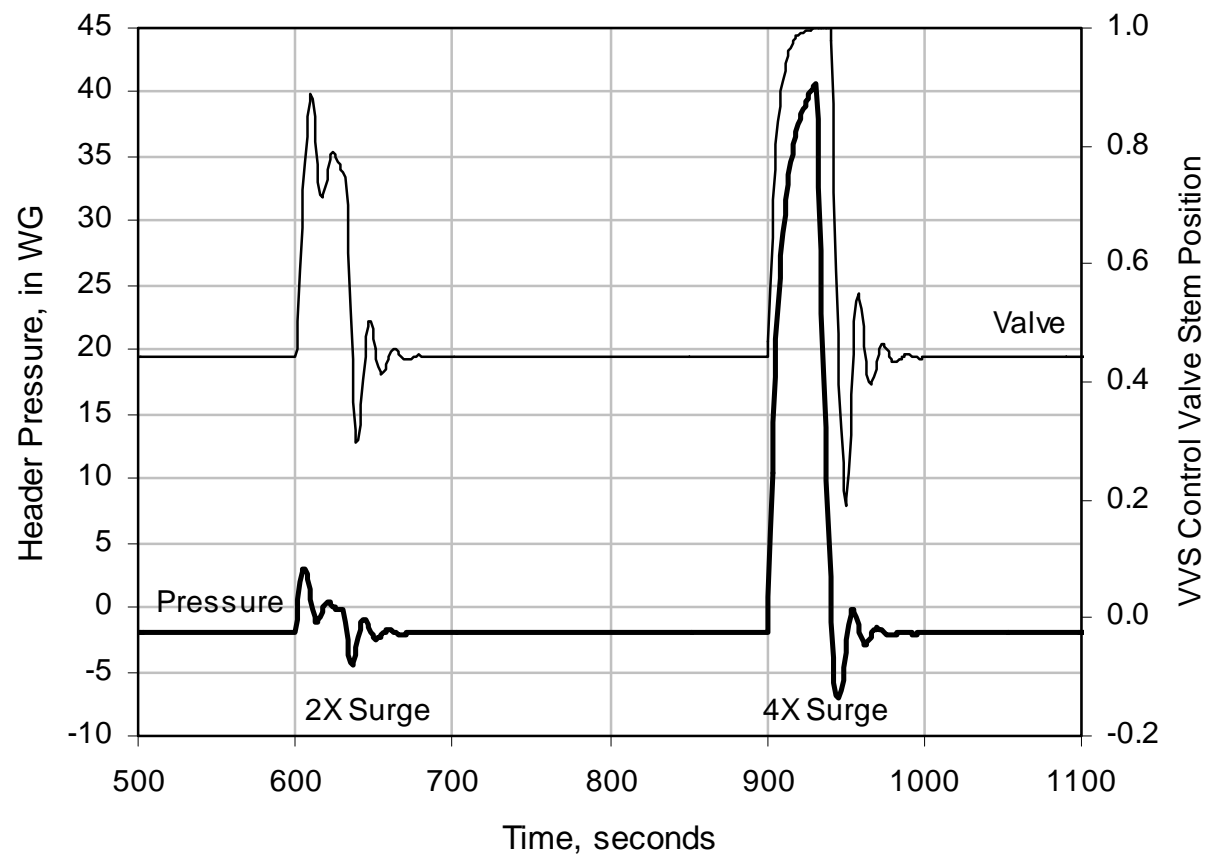

Figure 2.2-11 LAW VVS pressure control loop response using proportional control. 


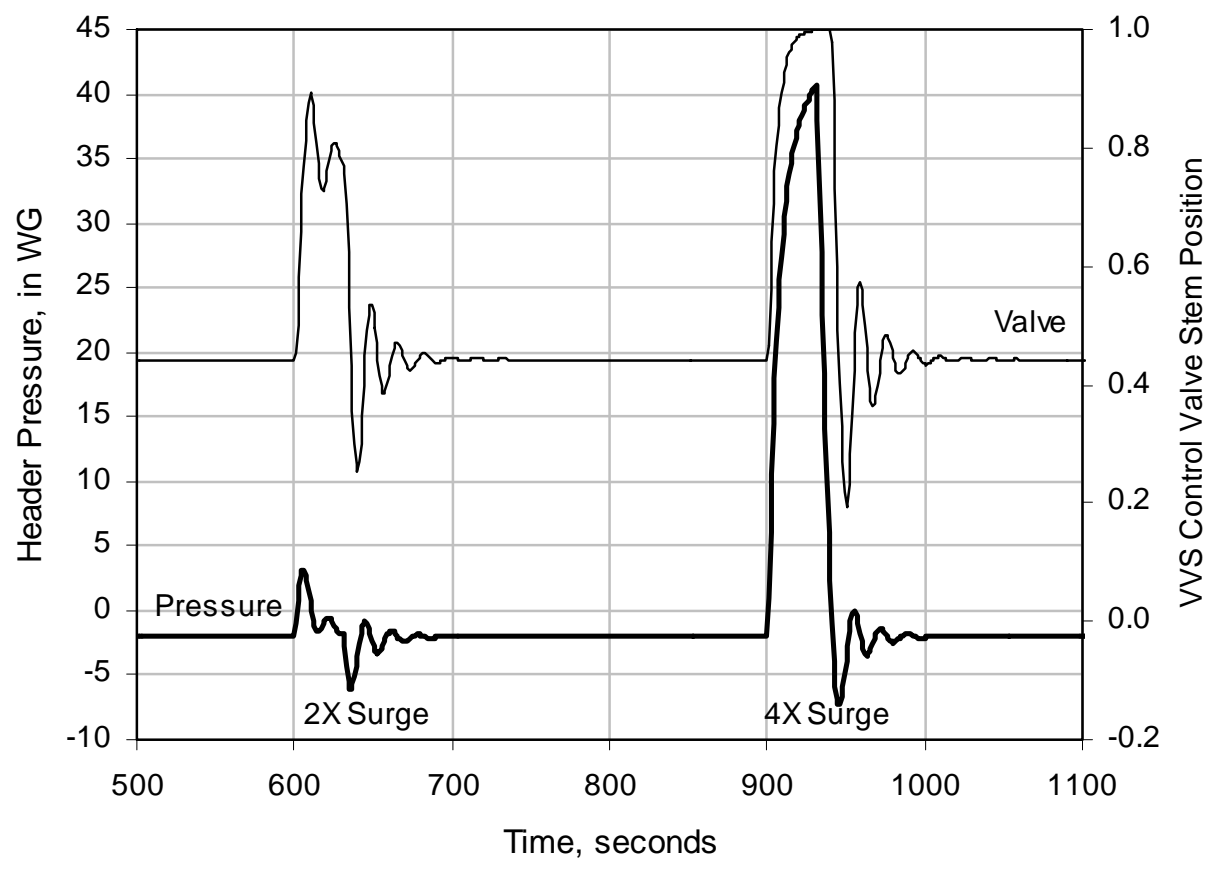

Figure 2.2-12 LAW VVS pressure control loop response using PI control.

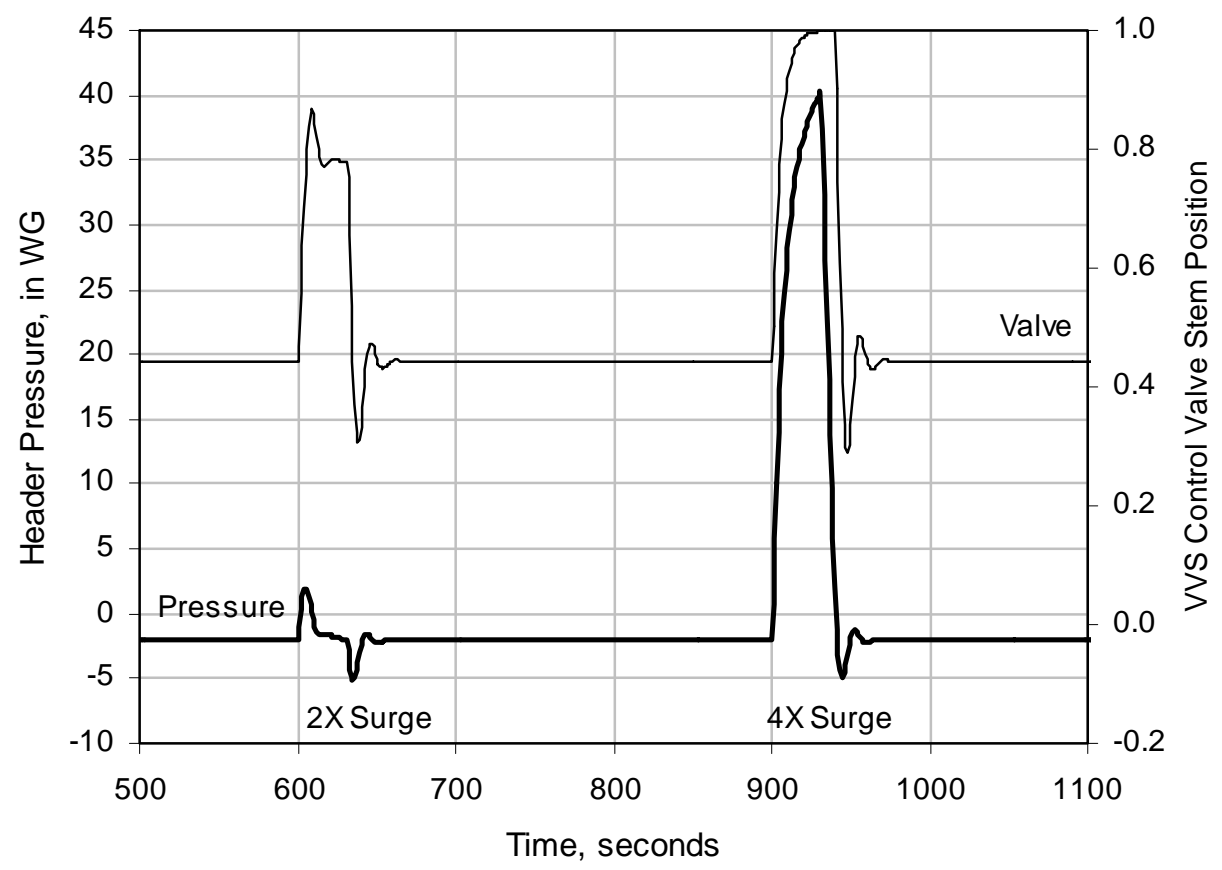

Figure 2.2-13 LAW VVS pressure control loop response using PID control. 


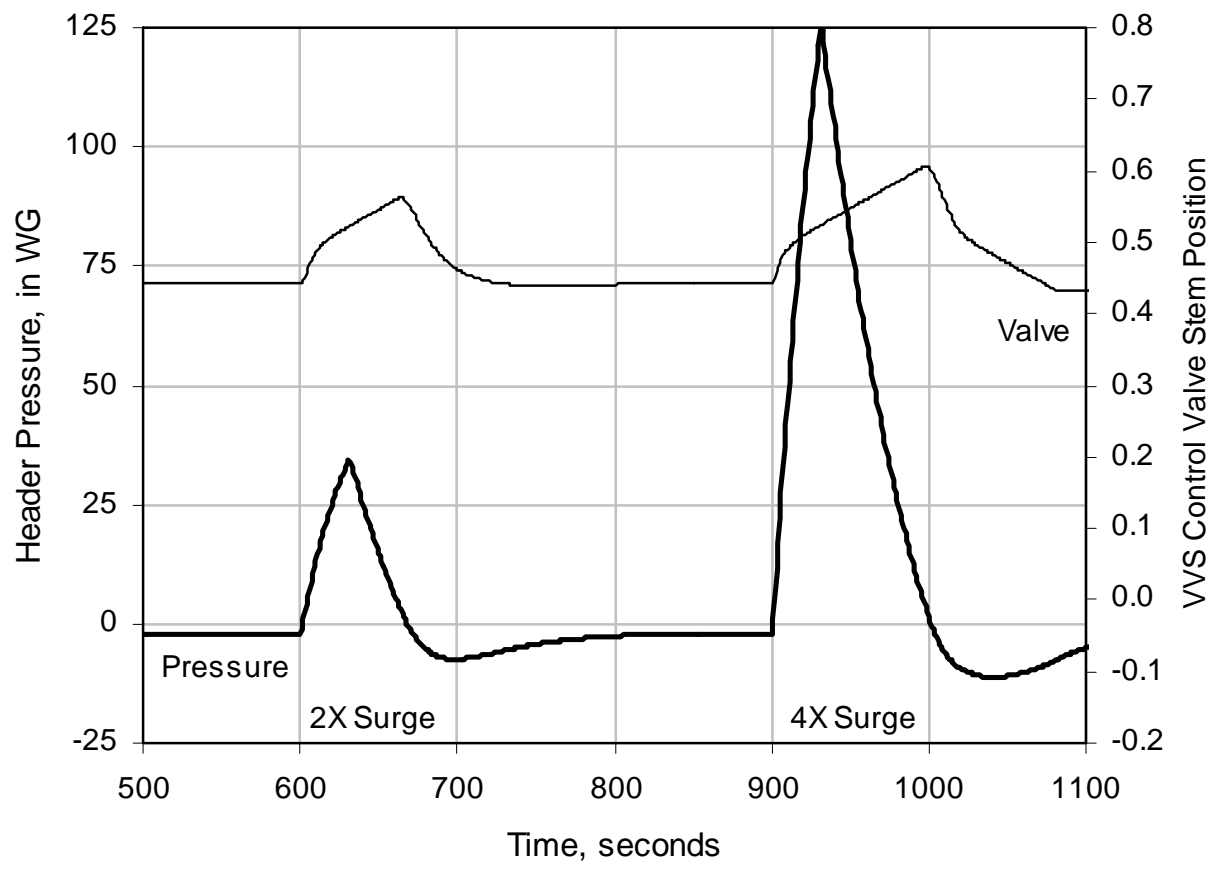

Figure 2.2-14 LAW VVS pressure control loop response using Robbins PI control parameters.

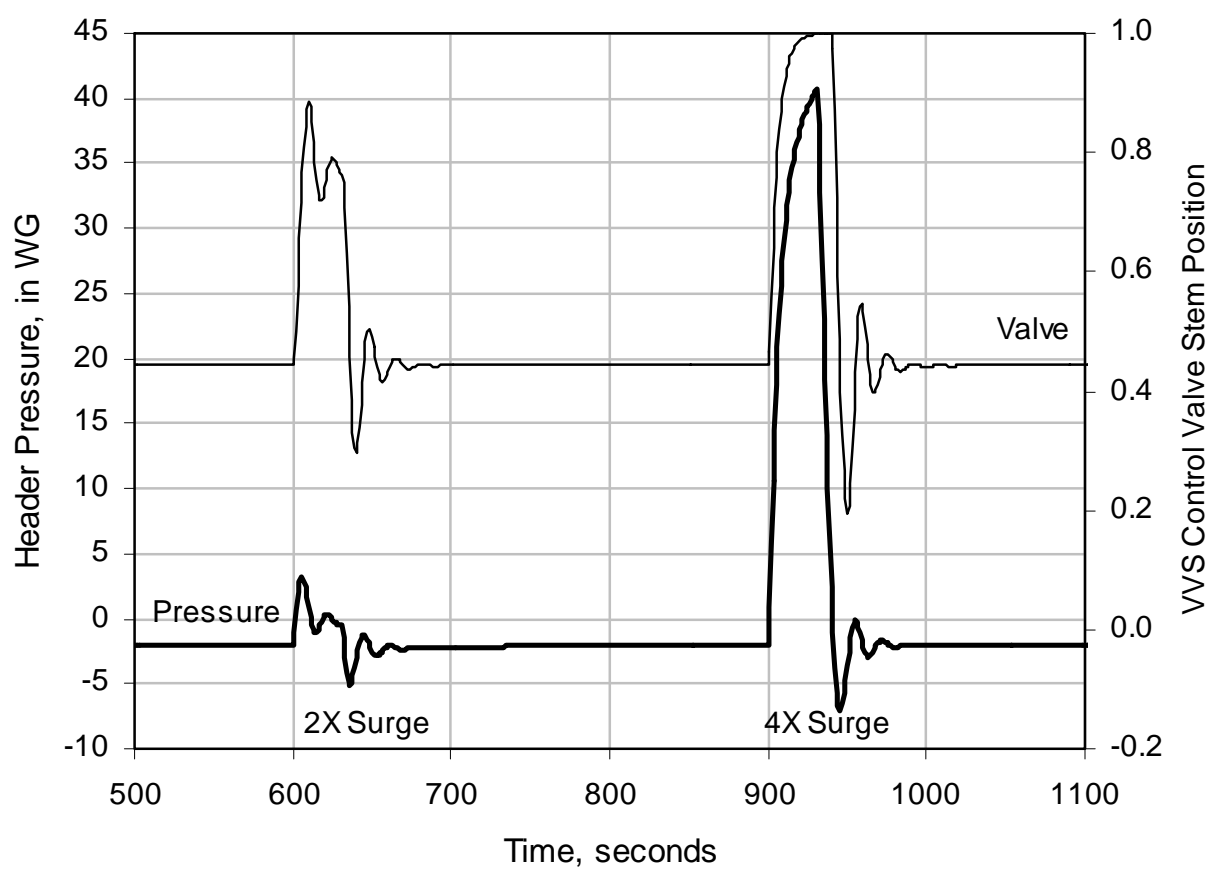

Figure 2.2-15 LAW VVS pressure control loop response using PI control with increased reset time. 


\subsubsection{LAW Damper Valve Control Loop without Signal Averaging}

As in the HLW fan speed control system, the damper valve position does not directly control the flow of air through the pressure control valve but responds to changes in the flow to help the system maintain a constant flow as much as possible. Control airflow is determined from the control valve position set by controller PC_1 and the damper valve is simply responding to changes in airflow. Therefore, as was done in the HLW system, this control loop was tuned with the melter pressure control on. With active pressure control, the set point for the damper valve controller could be changed $\pm 10 \%$ as requested in the tuning instructions and the system behavior observed. Table 2.2-4 shows the ultimate gain and frequency determined for the LAW damper valve control loop without signal averaging and the corresponding controller parameters.

Table 2.2-4 LAW Damper Valve Control Parameters without Averaging. [Ultimate gain $\mathrm{K}_{\mathrm{u}}=0.7$, Ultimate time constant $\tau_{\mathrm{u}}=8.0$ (s)]

\begin{tabular}{|c||c|c|c|}
\hline Control Method & Gain, $\mathbf{K}_{\mathbf{c}}$ & Reset, $\boldsymbol{\tau}_{\mathbf{i}} \mathbf{( s )}$ & Rate, $\boldsymbol{\tau}_{\mathbf{d}} \mathbf{( s )}$ \\
\hline \hline P & 0.25 & - & - \\
\hline PI & 0.23 & 6.7 & - \\
\hline PID & 0.29 & 4.0 & 1.0 \\
\hline Robbins (PI) & 0.10 & 7.0 & - \\
\hline
\end{tabular}

Figures 2.2-16 through 2.2-23 show response of the damper valve and melter pressure using the four control methods listed in Table 2.2-4. These simulations were run with active melter pressure control, VVS pressure control and damper valve control. In each simulation, melter feeding was started at 600 seconds and a $4 \mathrm{X}$ steam surge was modeled at 900 seconds. From 700 to 800 seconds, the SBS pressure drop was increased by $10 \%$. Two figures are presented for each control setting. The first figure shows the melter pressure and pressure drop across the SBS during the transient. The second figure shows the flow of pressure control air and the damper valve response.

PID control performed the worst in this series of tests. In fact, the PID settings appear to be marginally stable as evidenced by the large oscillations in melter pressure and control airflow at the end of the surge. The low gain Robbins tuning parameters performed as well as quarter-decay proportional and PI tuning and kept the SBS pressure drop nearly constant during the steam surge. With Robbins tuning, the damper valve is relatively unresponsive to the pressure fluctuations caused by the cyclic ADS feed but still responds to the steam surge. The Robbins tuning causes a slightly greater decrease in control airflow than is observed with PI tuning. 


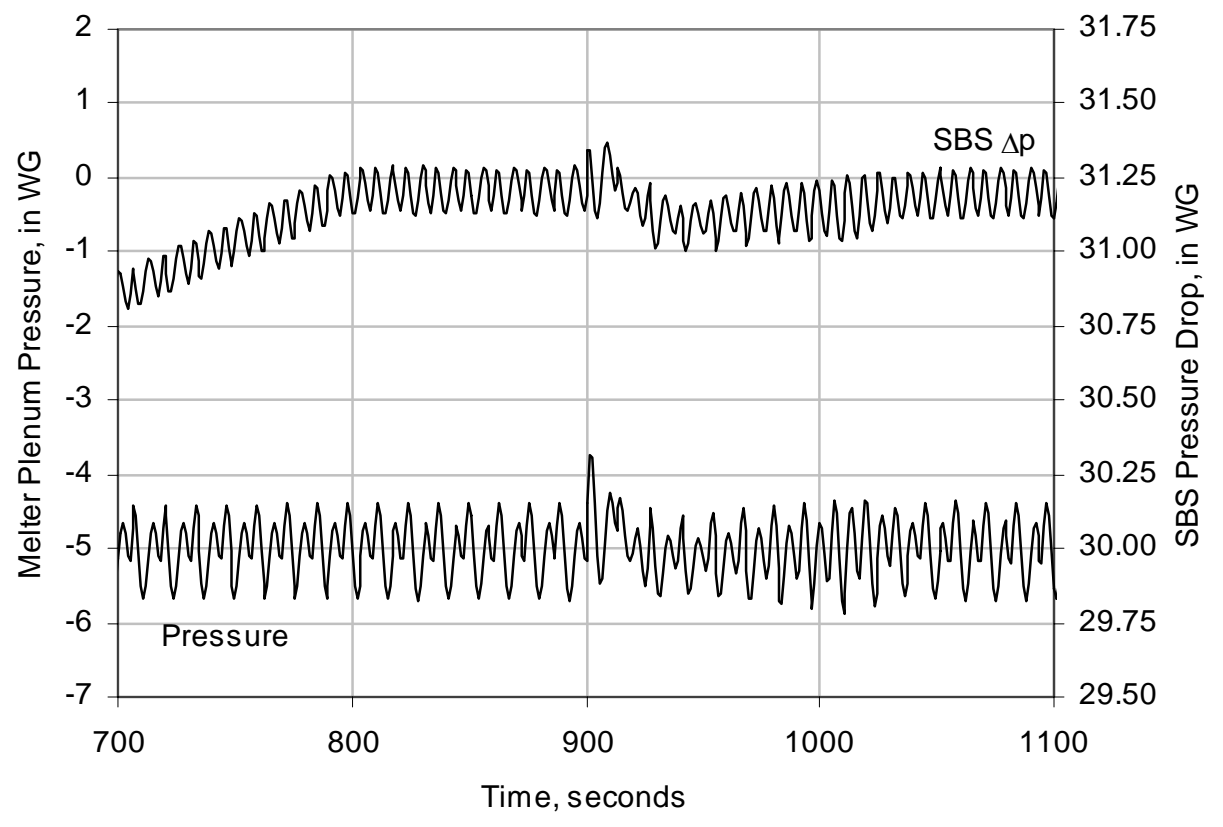

Figure 2.2-16 LAW melter pressure and SBS pressure drop response using proportional damper valve control.

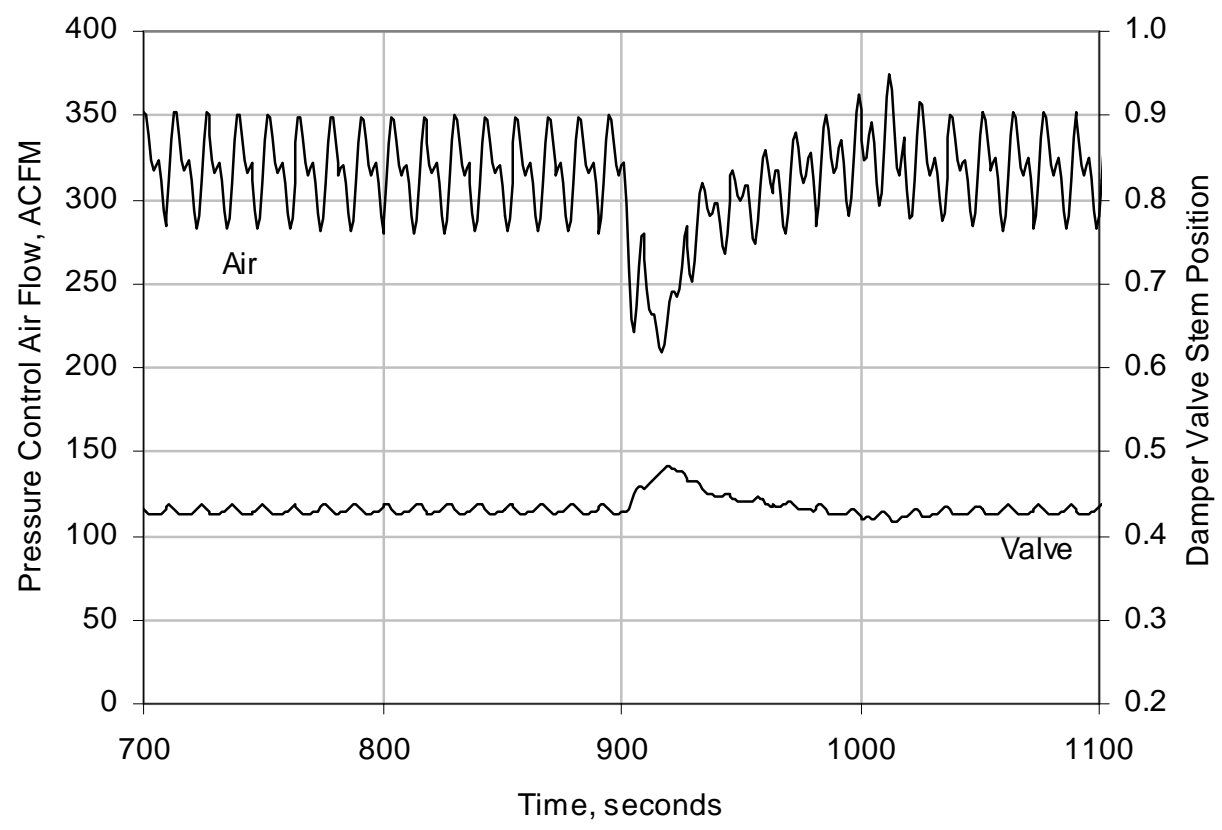

Figure 2.2-17 LAW control airflow and damper valve response using proportional damper valve control. 


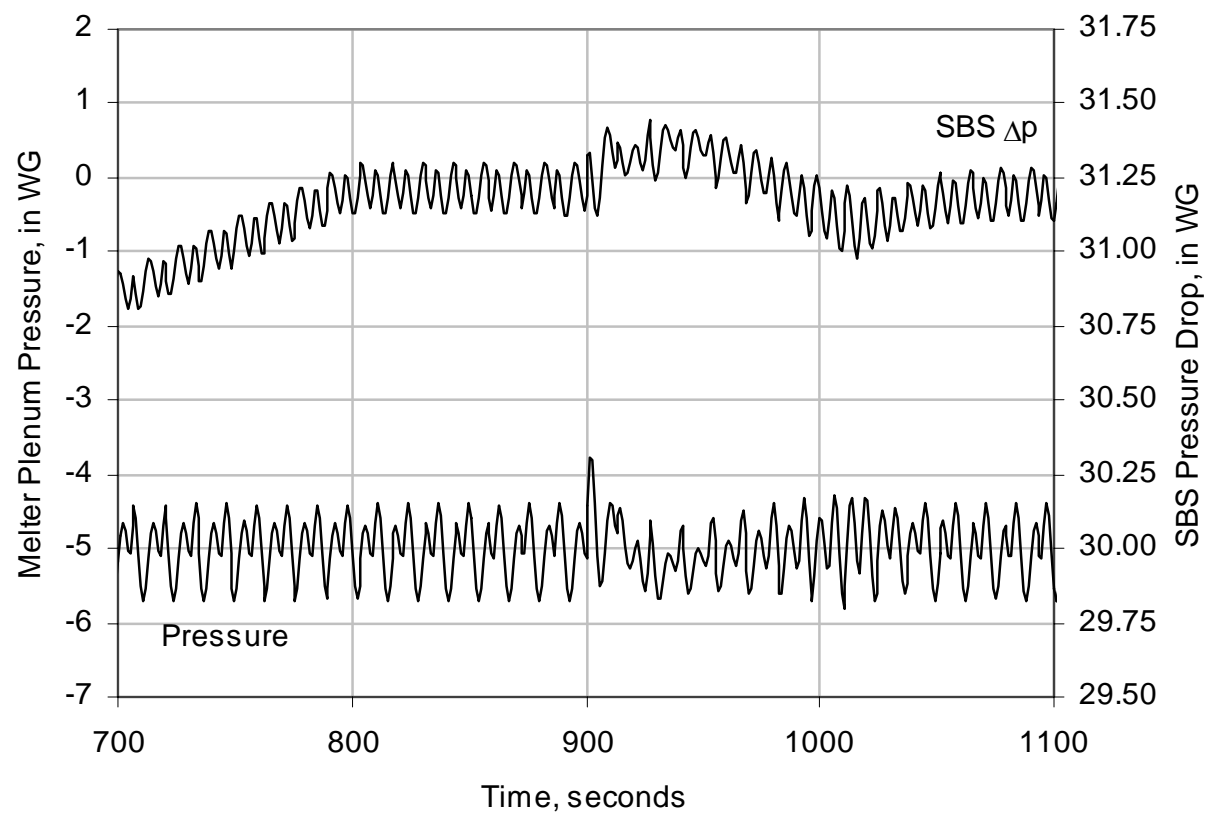

Figure 2.2-18 LAW melter pressure and SBS pressure drop response using PI damper valve control.

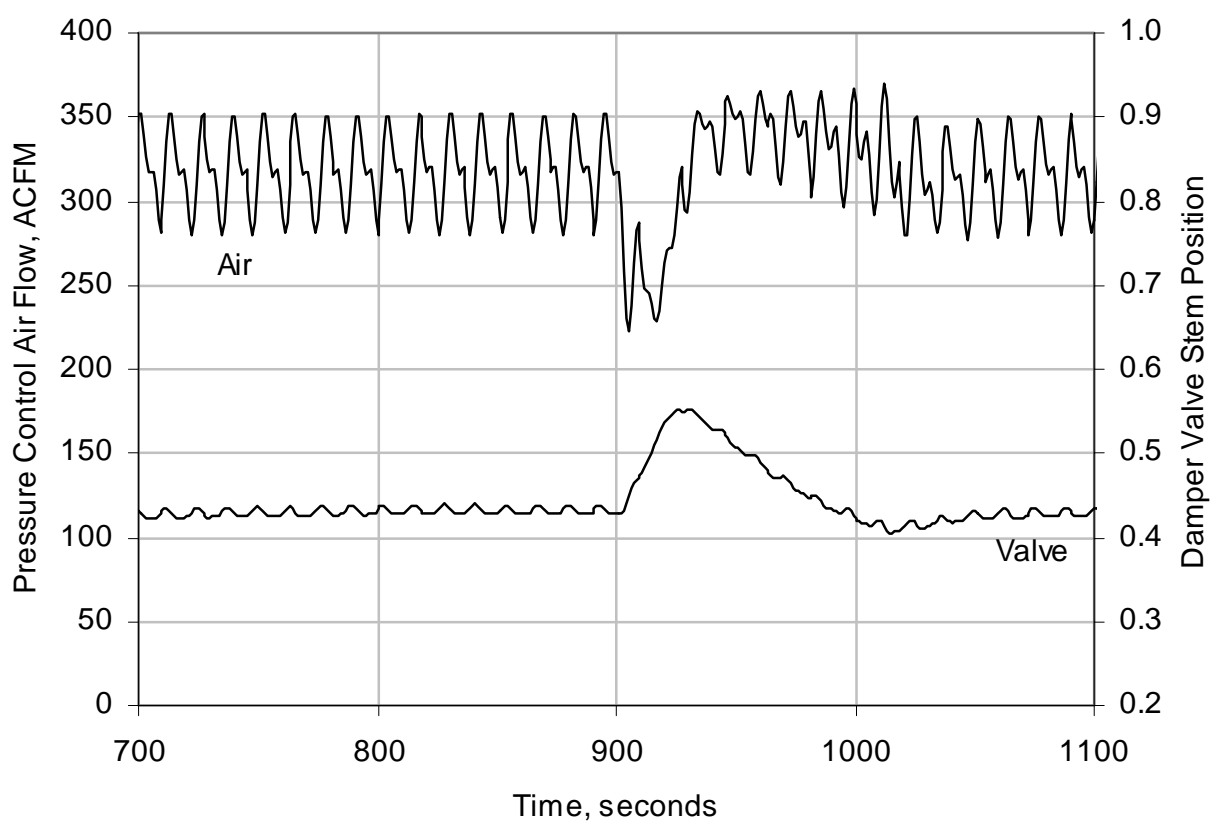

Figure 2.2-19 LAW control airflow and damper valve response using PI damper valve control. 


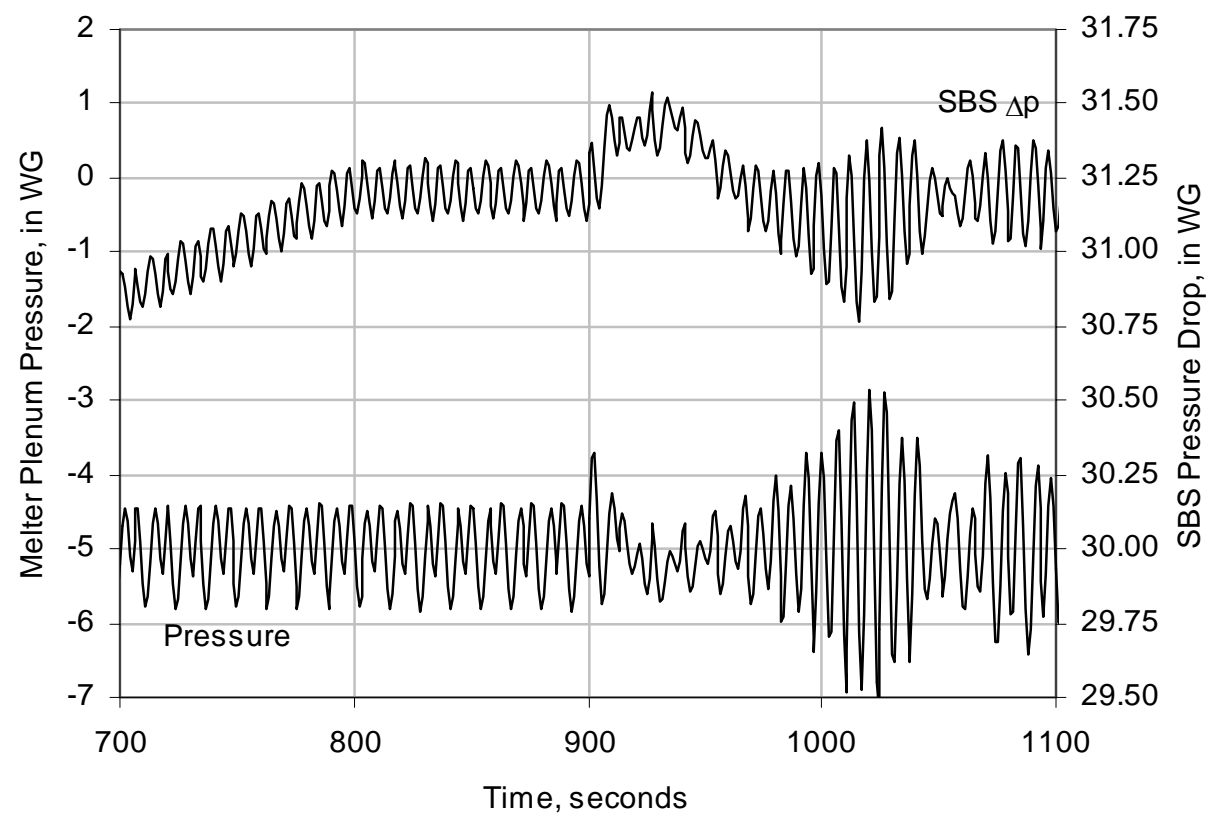

Figure 2.2-20 LAW melter pressure and SBS pressure drop response using PID damper valve control.

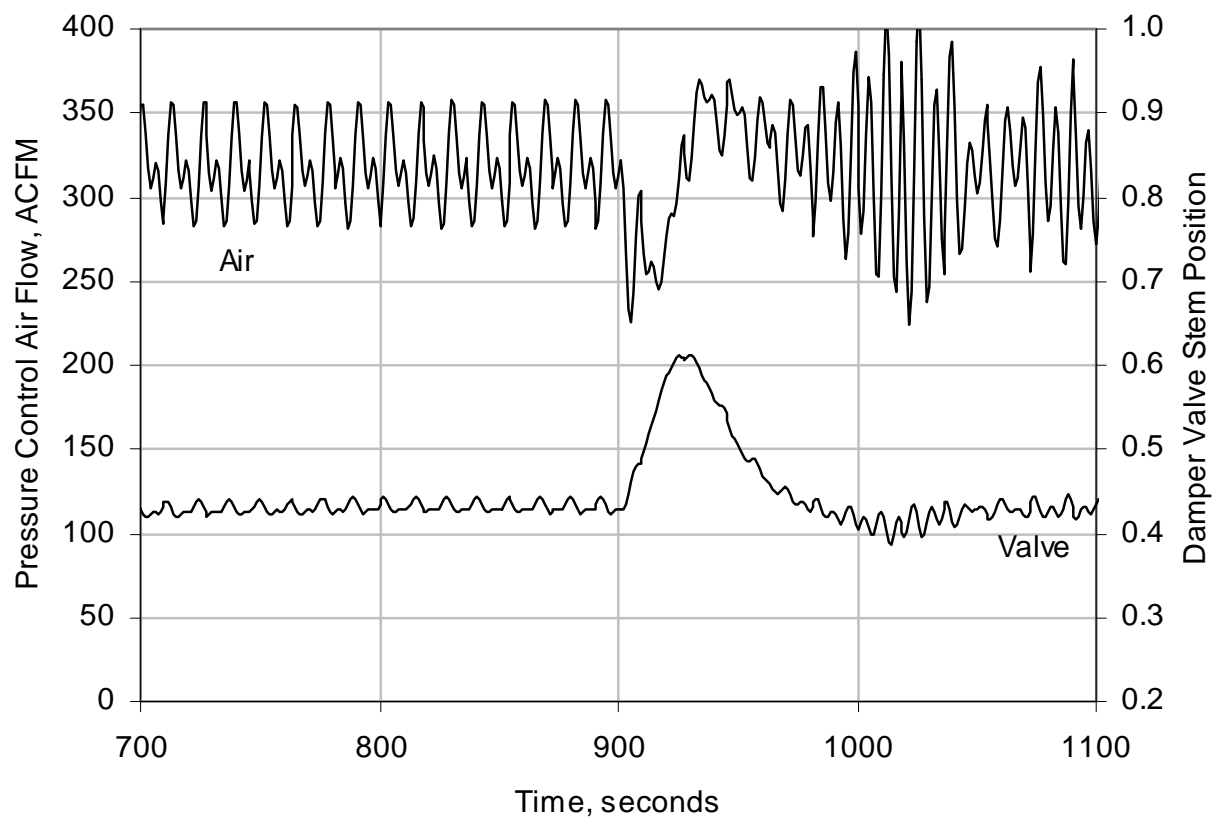

Figure 2.2-21 LAW control airflow and damper valve response using PID damper valve control. 


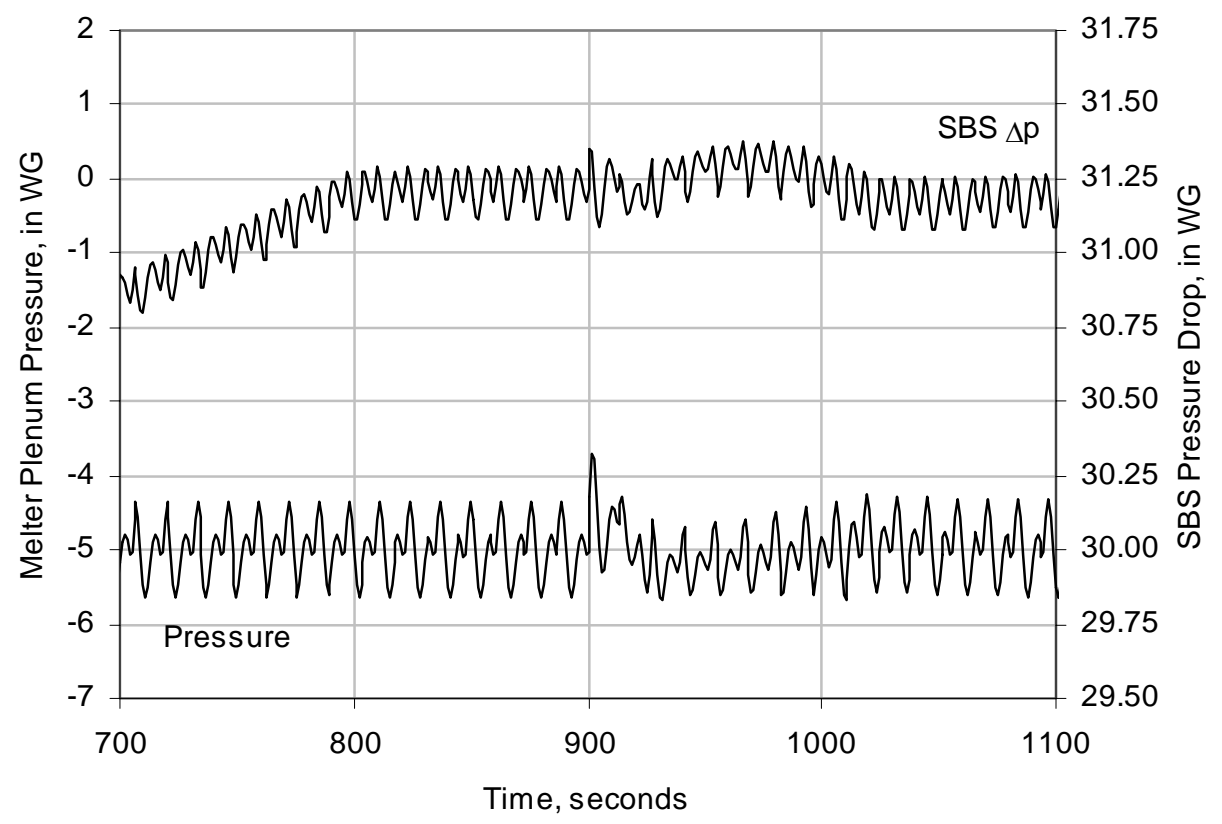

Figure 2.2-22 LAW melter pressure and SBS pressure drop response using Robbins PI damper valve control.

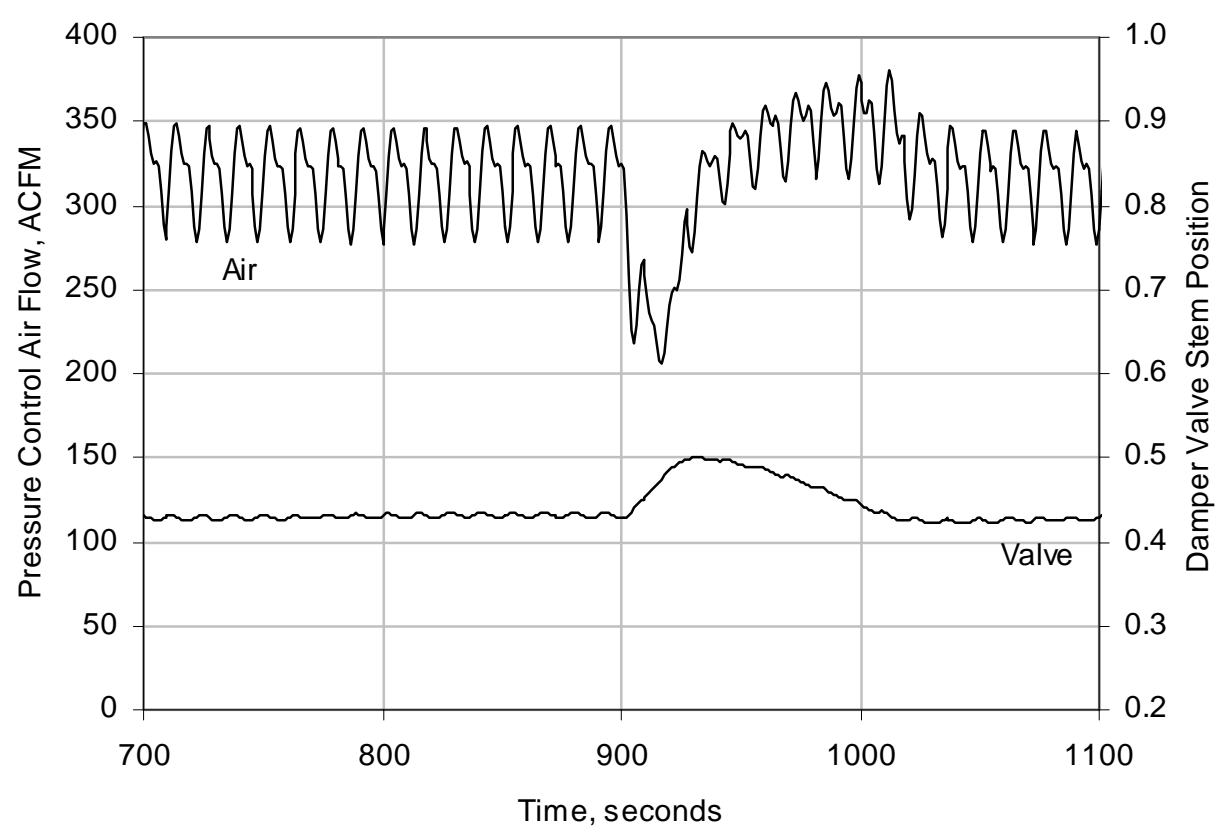

Figure 2.2-23 LAW control airflow and damper valve response using Robbins PI damper valve control. 


\subsubsection{LAW Damper Valve Control Loop with 15 second Signal Averaging}

Table 2.2-5 shows the ultimate gain and frequency for the LAW damper valve control loop with 15 second signal averaging and the corresponding controller parameters. Signal averaging allows higher controller gains to be used and increases the integral reset time and derivative rate constant.

Table 2.2-5 LAW Damper Control Parameters with 15 sec Averaging. [Ultimate gain $\mathrm{K}_{\mathrm{u}}=1.30$, Ultimate time constant $\tau_{\mathrm{u}}=22(\mathrm{~s})$ ]

\begin{tabular}{|c||c|c|c|}
\hline Control Method & Gain, $\mathbf{K}_{\mathbf{c}}$ & Reset, $\boldsymbol{\tau}_{\mathbf{i}}(\mathbf{s})$ & Rate, $\boldsymbol{\tau}_{\mathbf{d}}(\mathbf{s})$ \\
\hline \hline P & 0.65 & - & - \\
\hline PI & 0.59 & 18 & - \\
\hline PID & 0.76 & 11 & 3 \\
\hline Robbins (PI) & 0.20 & 12 & - \\
\hline
\end{tabular}

Figures 2.2-24 through 2.2-31 show responses of the damper valve and melter pressure using the four control methods listed in Table 2.2-5. These simulations were run with active melter pressure control, VVS pressure control and damper valve control. In each simulation, melter feeding was started at 600 seconds and a $4 \mathrm{X}$ steam surge was modeled at 900 seconds. From 700 to 800 seconds, the SBS pressure drop was increased by $10 \%$. Two figures are presented for each control setting. The first figure shows the melter pressure and pressure drop across the SBS during the transient. The second figure shows the flow of pressure control air and the damper valve response.

Signal averaging reduces the response to the cyclic ADS steam flow and leads to a smoother damper valve response. Coupling signal averaging with the lower gain Robbins tuning, the system is no longer responding well to the steam surge (Fig. 2.2-31). With 15 second signal averaging, PI control appears to keep the control airflow most nearly constant. Comparing Figs. 2.2-27 and 2.2-19, 15 second signal averaging does not significantly improve the damper valve response. Nevertheless, PI control with 15 second signal averaging was judged to provide the best control response. 


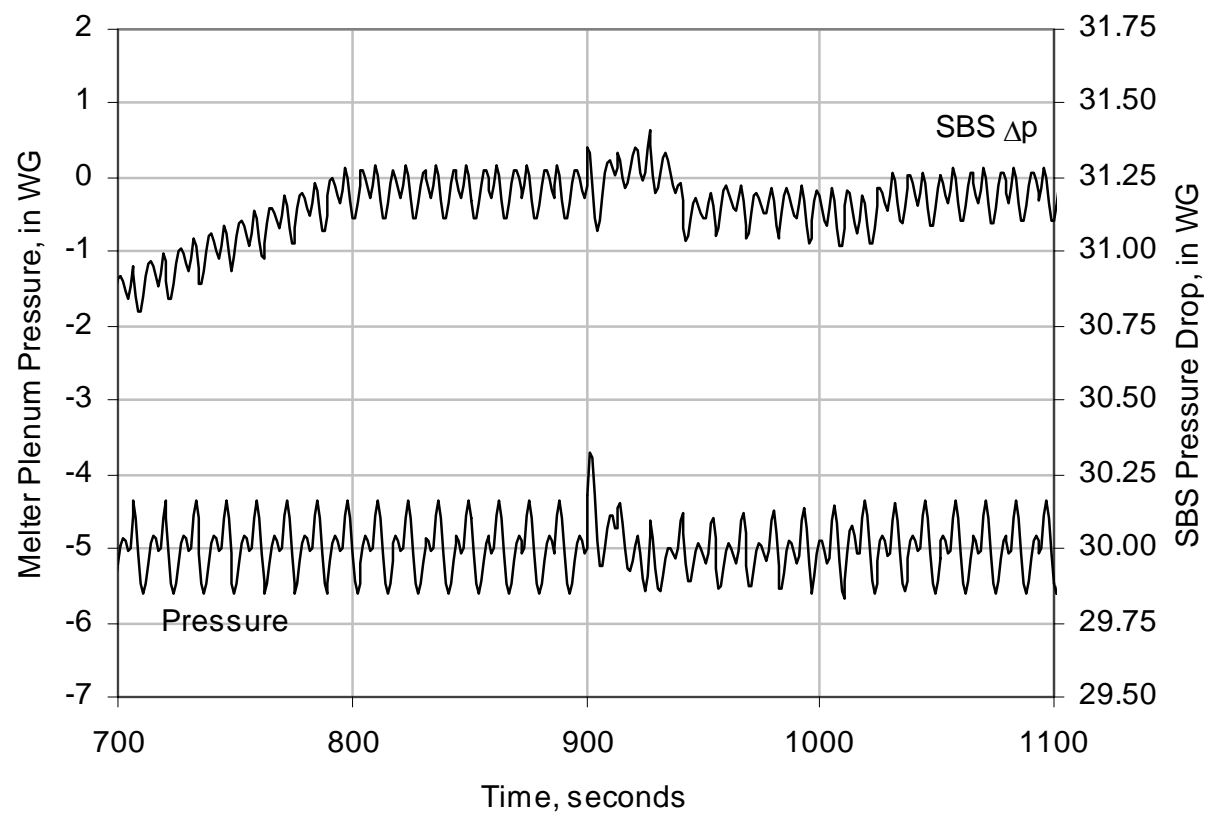

Figure 2.2-24 LAW melter pressure and SBS pressure drop response using proportional damper valve control with 15 second signal averaging.

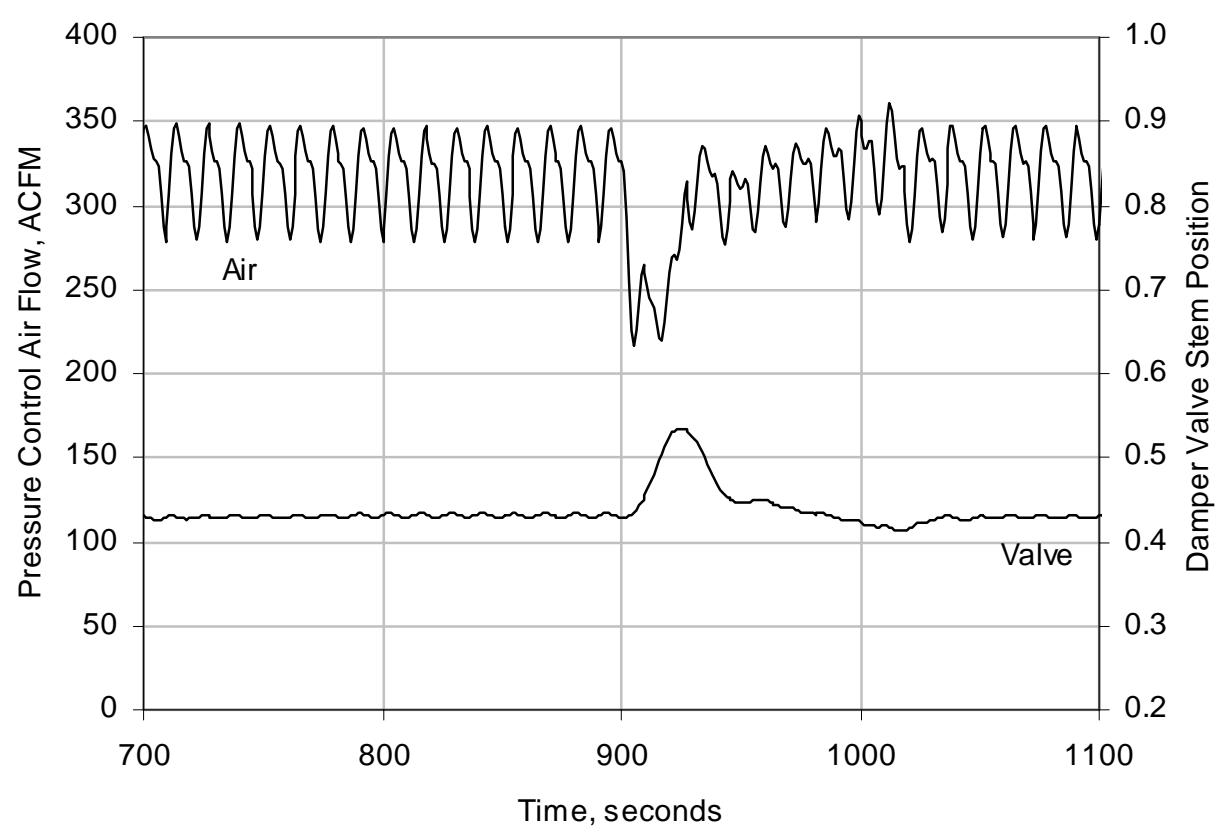

Figure 2.2-25 LAW control airflow and damper valve response using proportional damper valve control with 15 second signal averaging. 


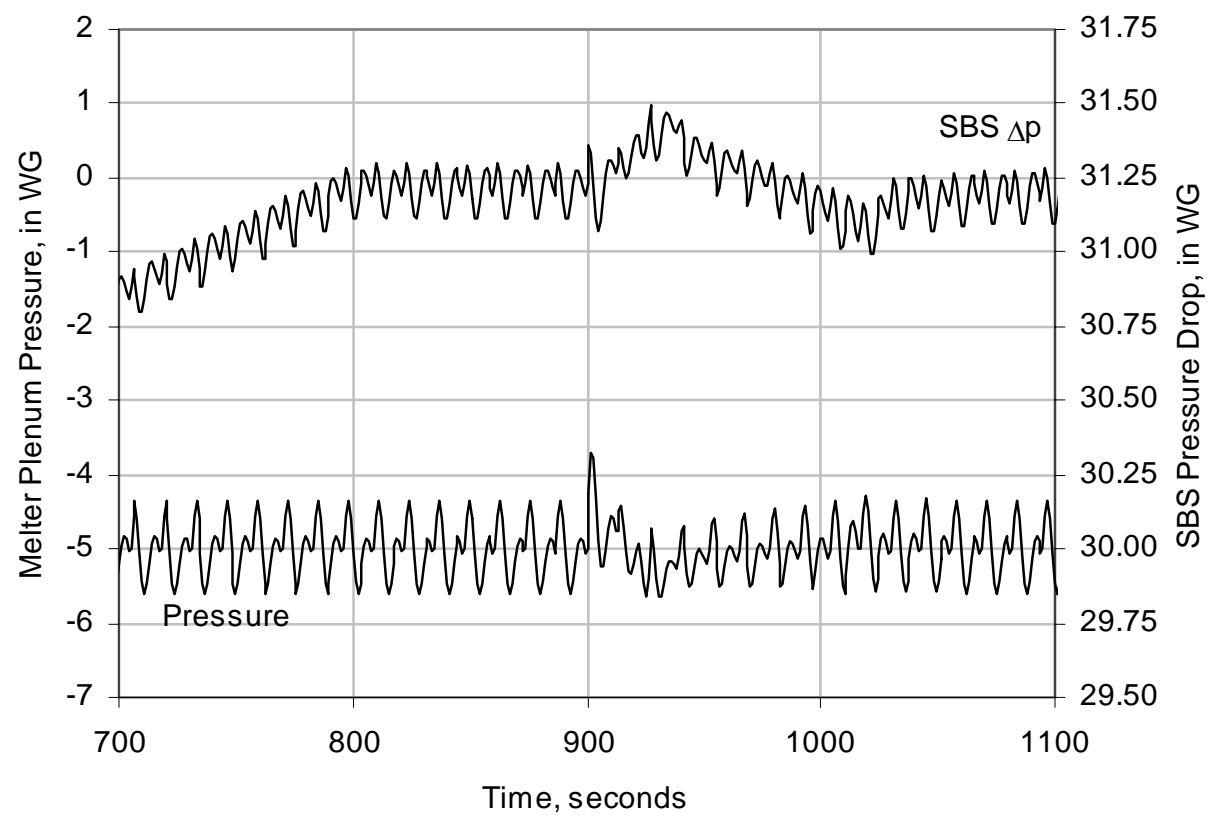

Figure 2.2-26 LAW melter pressure and SBS pressure drop response using PI damper valve control with 15 second signal averaging.

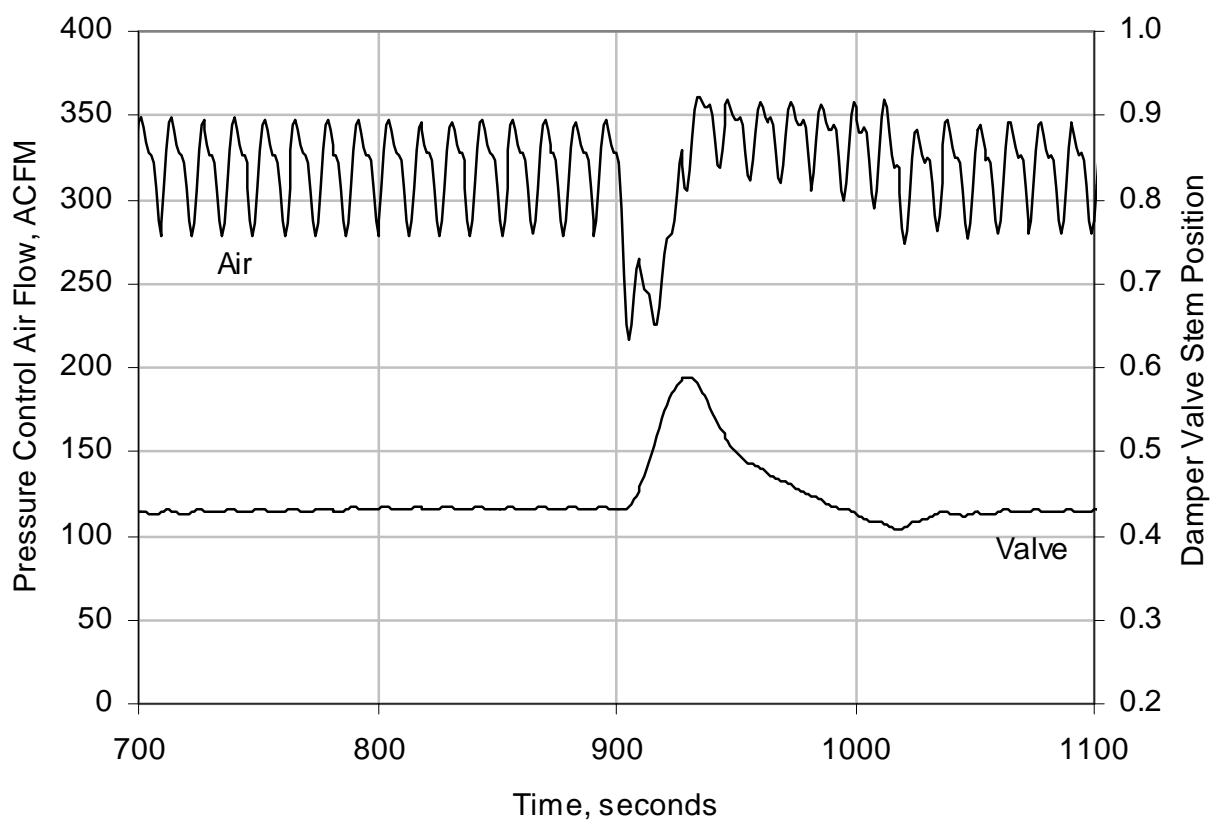

Figure 2.2-27 LAW control airflow and damper valve response using PI damper valve control with 15 second signal averaging. 


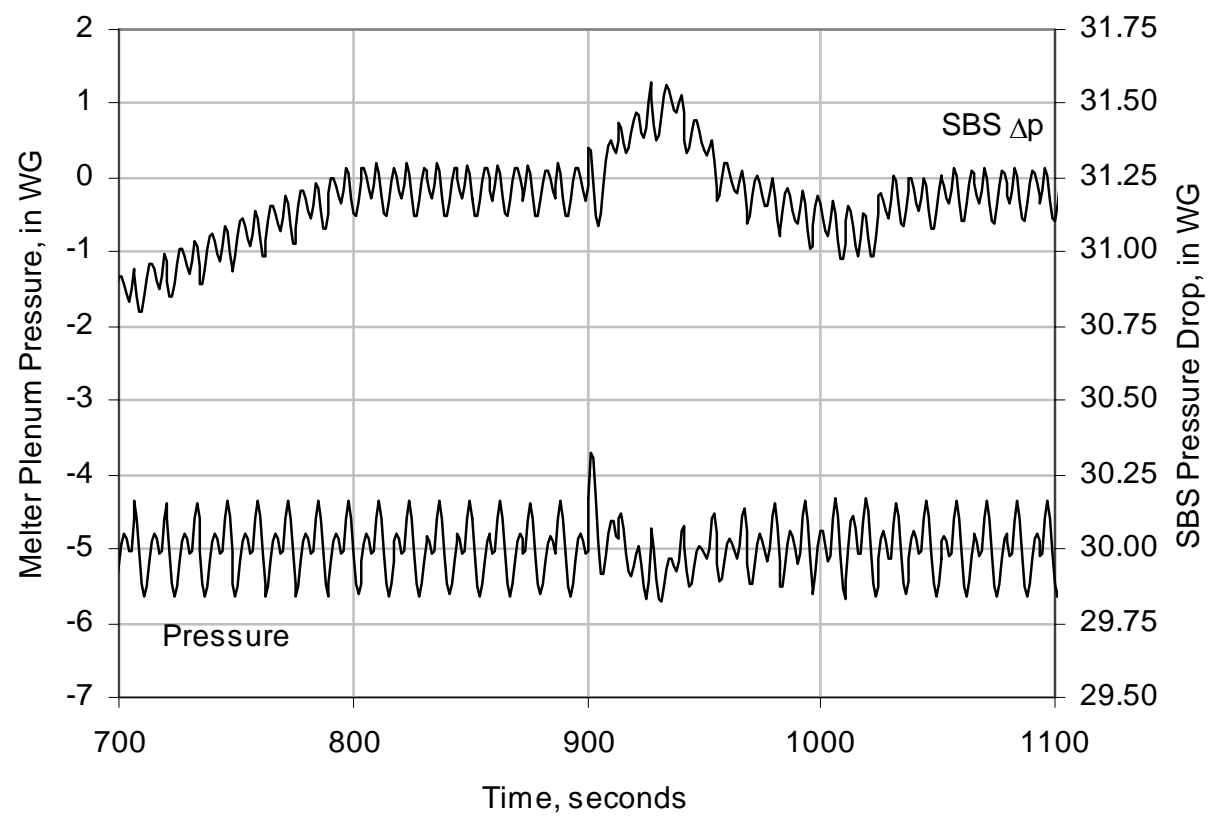

Figure 2.2-28 LAW melter pressure and SBS pressure drop response using PID damper valve control with 15 second signal averaging.

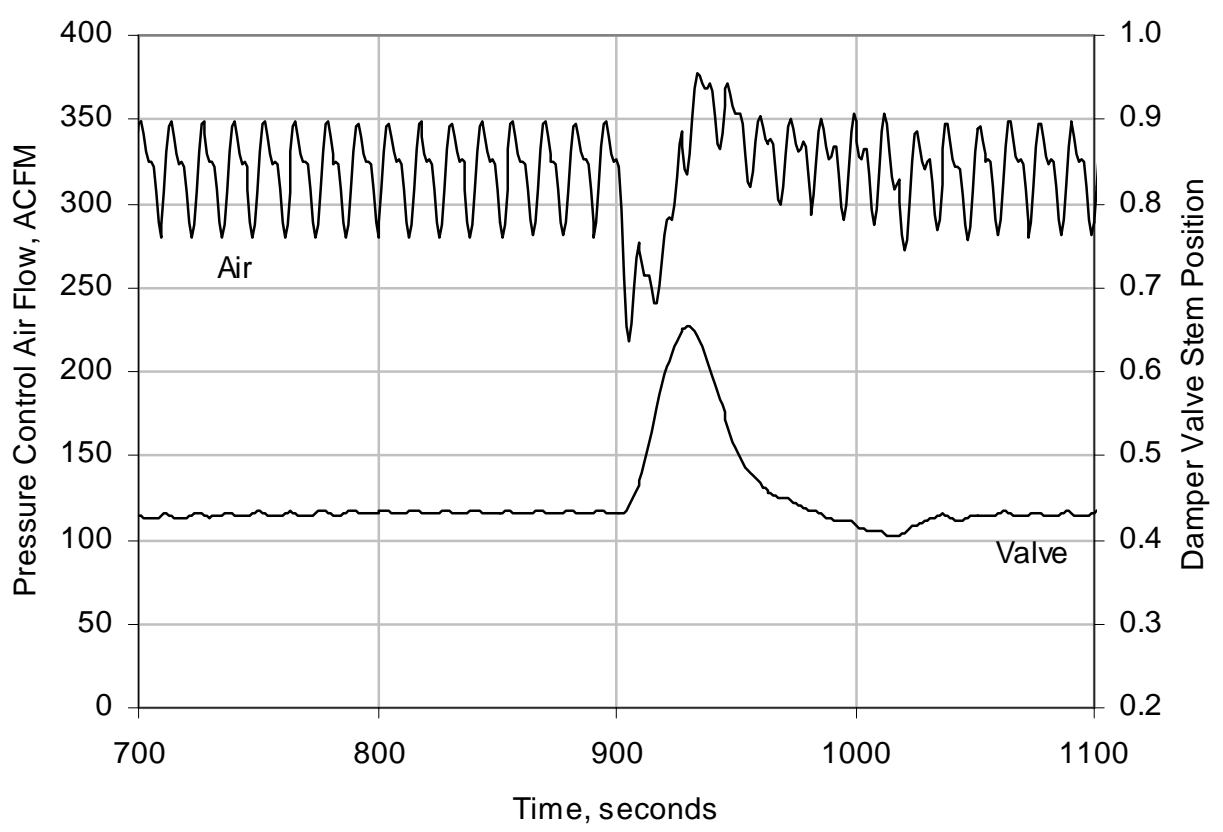

Figure 2.2-29 LAW control airflow and damper valve response using PID damper valve control with 15 second signal averaging. 


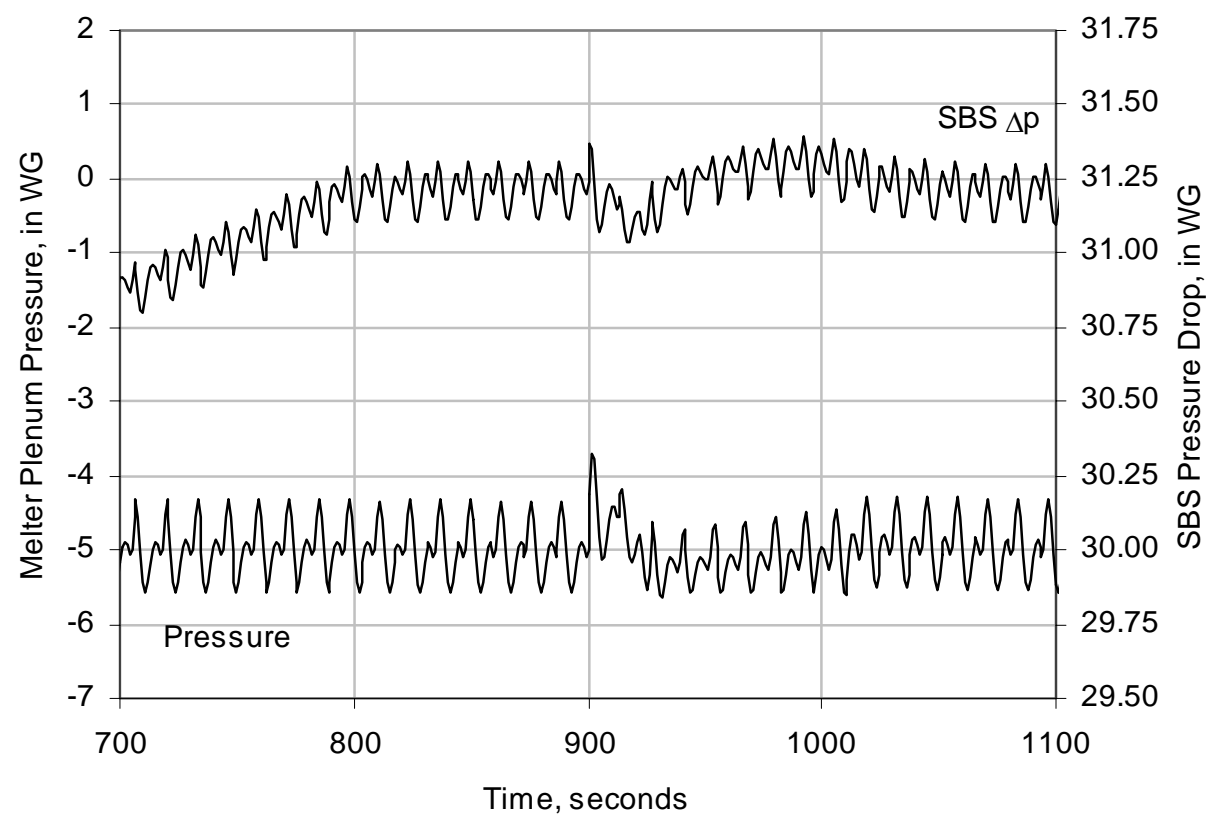

Figure 2.2-30 LAW melter pressure and SBS pressure drop response using Robbins PI damper valve control settings with 15 second signal averaging.

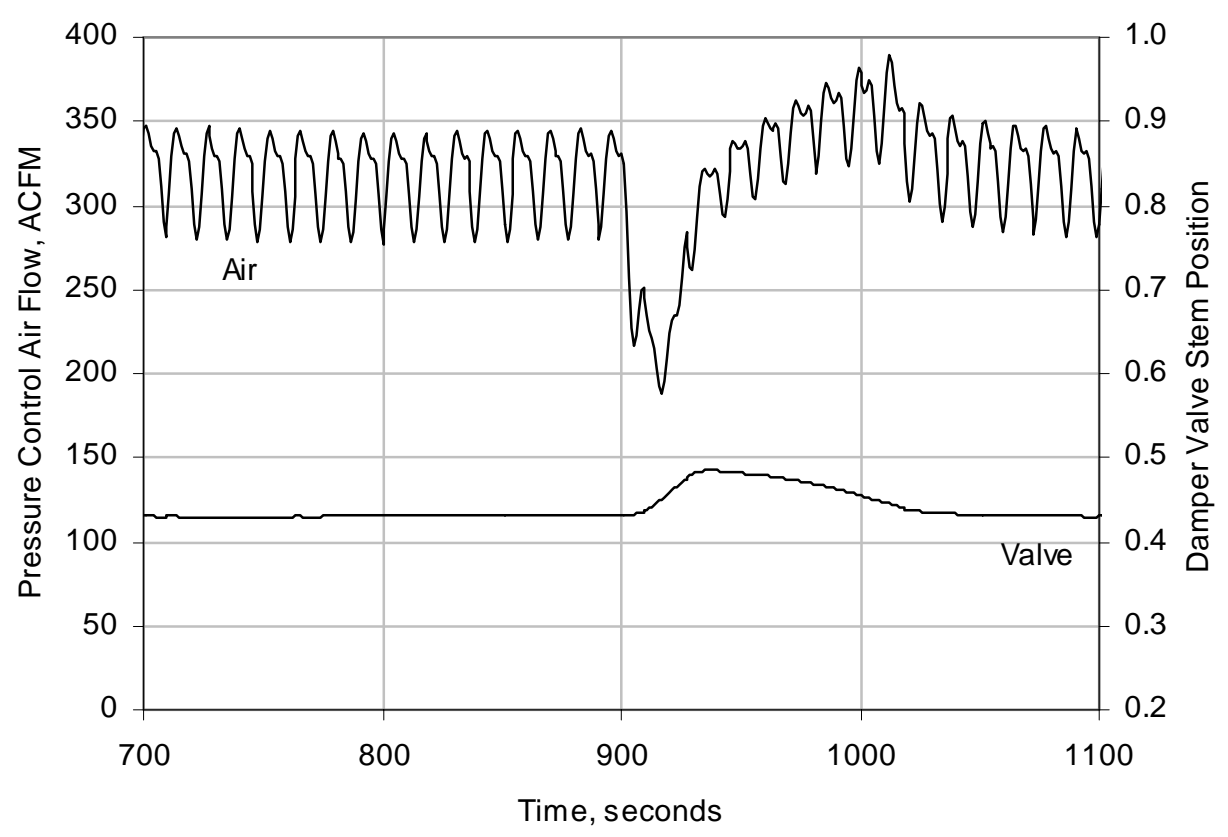

Figure 2.2-31 LAW control airflow and damper valve response using Robbins PI damper valve control settings with 15 second signal averaging. 


\subsubsection{LAW Damper Valve Control Loop with 30 second Signal Averaging}

Table 2.2-6 shows the ultimate gain and frequency for the LAW damper valve control loop with 30 second signal averaging and the corresponding controller parameters.

Table 2.2-6 LAW Damper Control Parameters with 30 sec Averaging.

[Ultimate gain $\mathrm{K}_{\mathrm{u}}=1.65$, Ultimate time constant $\tau_{\mathrm{u}}=40$ (s)]

\begin{tabular}{|c||c|c|c|}
\hline Control Method & Gain, $\mathbf{K}_{\mathbf{c}}$ & Reset, $\boldsymbol{\tau}_{\mathbf{i}} \mathbf{( s )}$ & Rate, $\boldsymbol{\tau}_{\mathbf{d}} \mathbf{( s )}$ \\
\hline \hline P & 0.82 & - & - \\
\hline PI & 0.75 & 33 & - \\
\hline PID & 0.97 & 20 & 5 \\
\hline Robbins (PI) & 0.20 & 15 & - \\
\hline
\end{tabular}

Figures 2.2-32 through 2.2-39 show response of the damper valve and melter pressure using the four control methods listed in Table 2.2-6. These simulations were run with active melter pressure control, VVS pressure control, and damper valve control. In each simulation, melter feeding was started at 600 seconds and a $4 \mathrm{X}$ steam surge was modeled at 900 seconds. From 700 to 800 seconds, the SBS pressure drop was increased by $10 \%$. Two figures are presented for each control setting. The first figure shows the melter pressure and pressure drop across the SBS during the transient. The second figure shows the flow of pressure control air and the damper valve response.

Using 30 second signal averaging produced essentially the same results as with 15 second averaging. The 15 second average response was judged to be slightly smoother and hence the preferred averaging time.

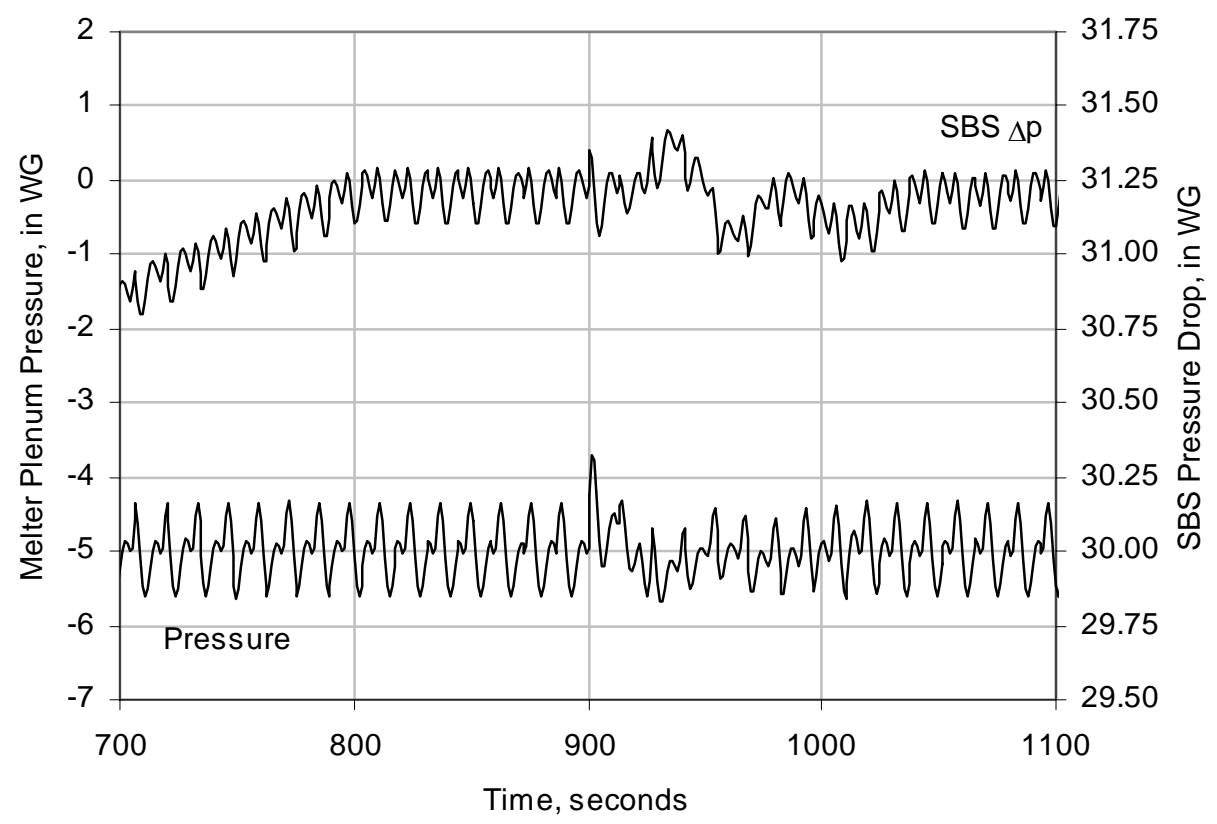

Figure 2.2-32 LAW melter pressure and SBS pressure drop response using proportional damper valve control with 30 second signal averaging. 


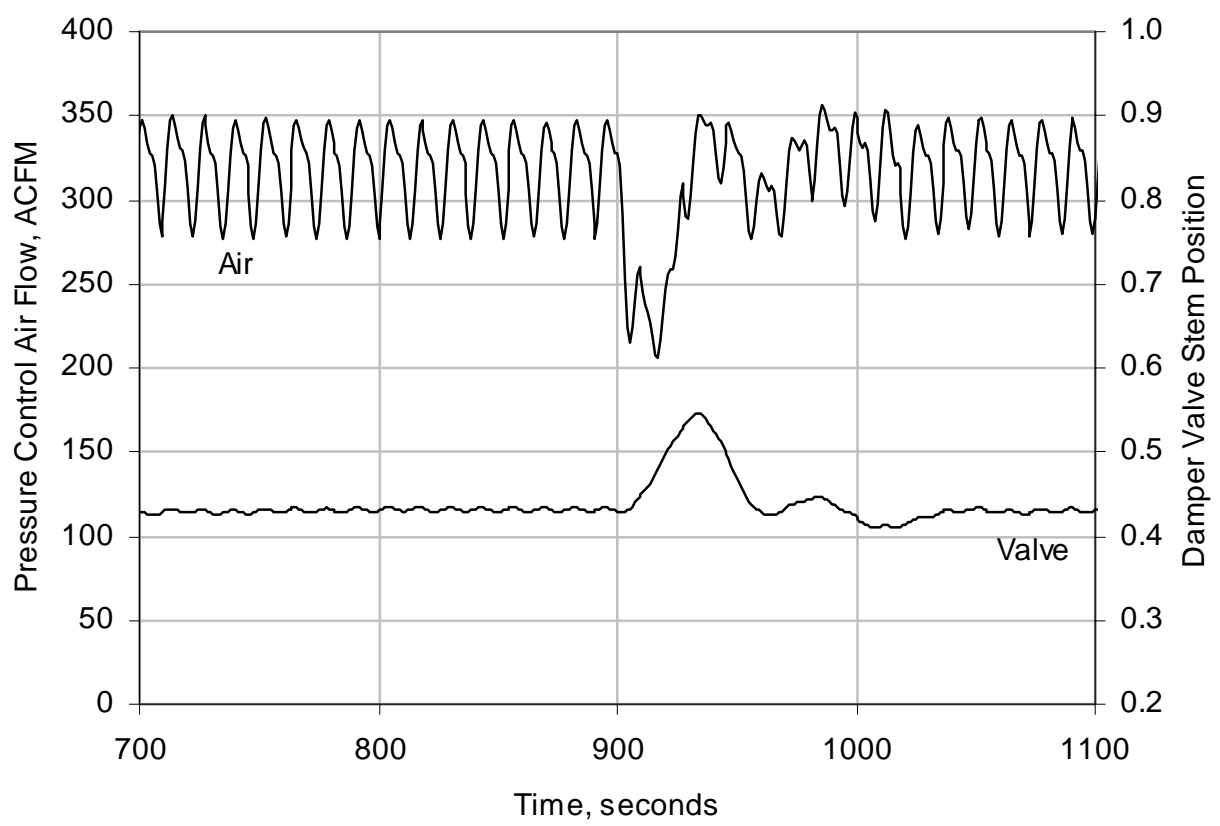

Figure 2.2-33 LAW control airflow and damper valve response using proportional damper valve control with 30 second signal averaging.

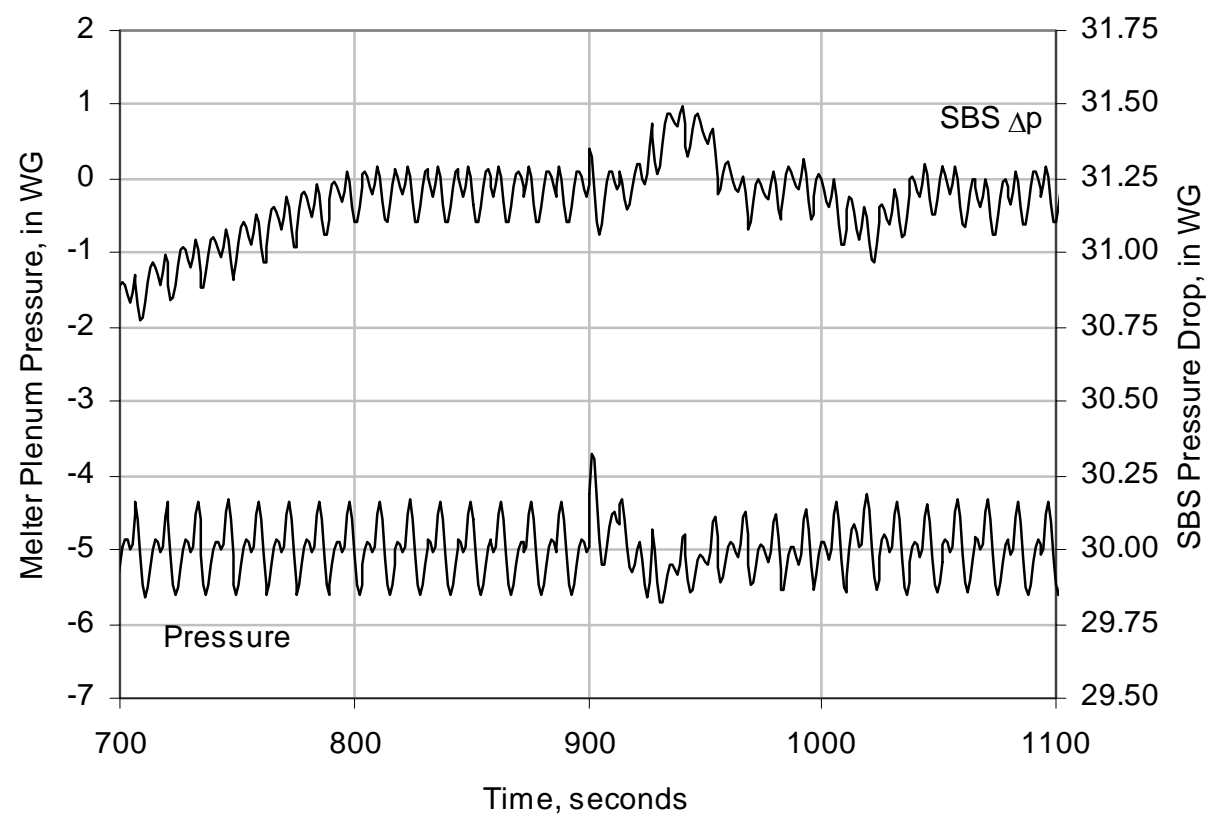

Figure 2.2-34 LAW melter pressure and SBS pressure drop response using PI damper valve control with 30 second signal averaging. 


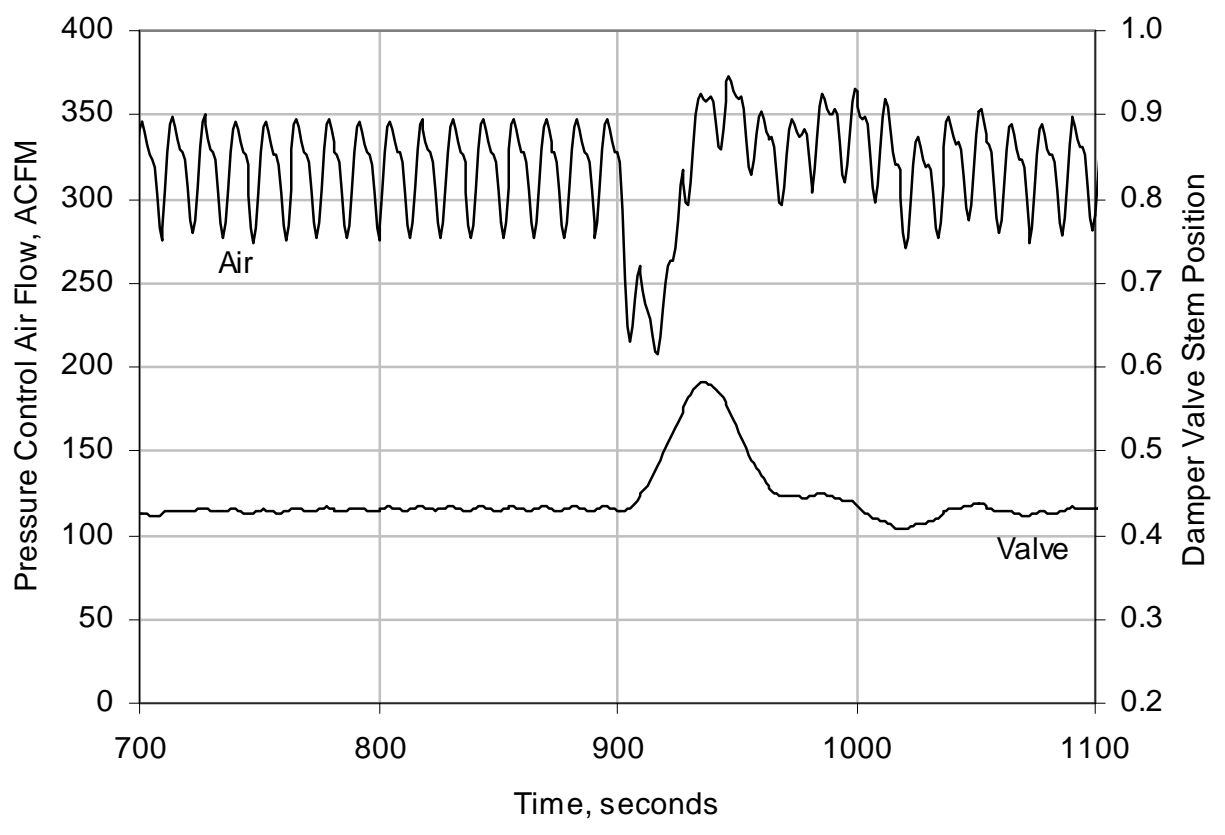

Figure 2.2-35 LAW control airflow and damper valve response using PI damper valve control with 30 second signal averaging.

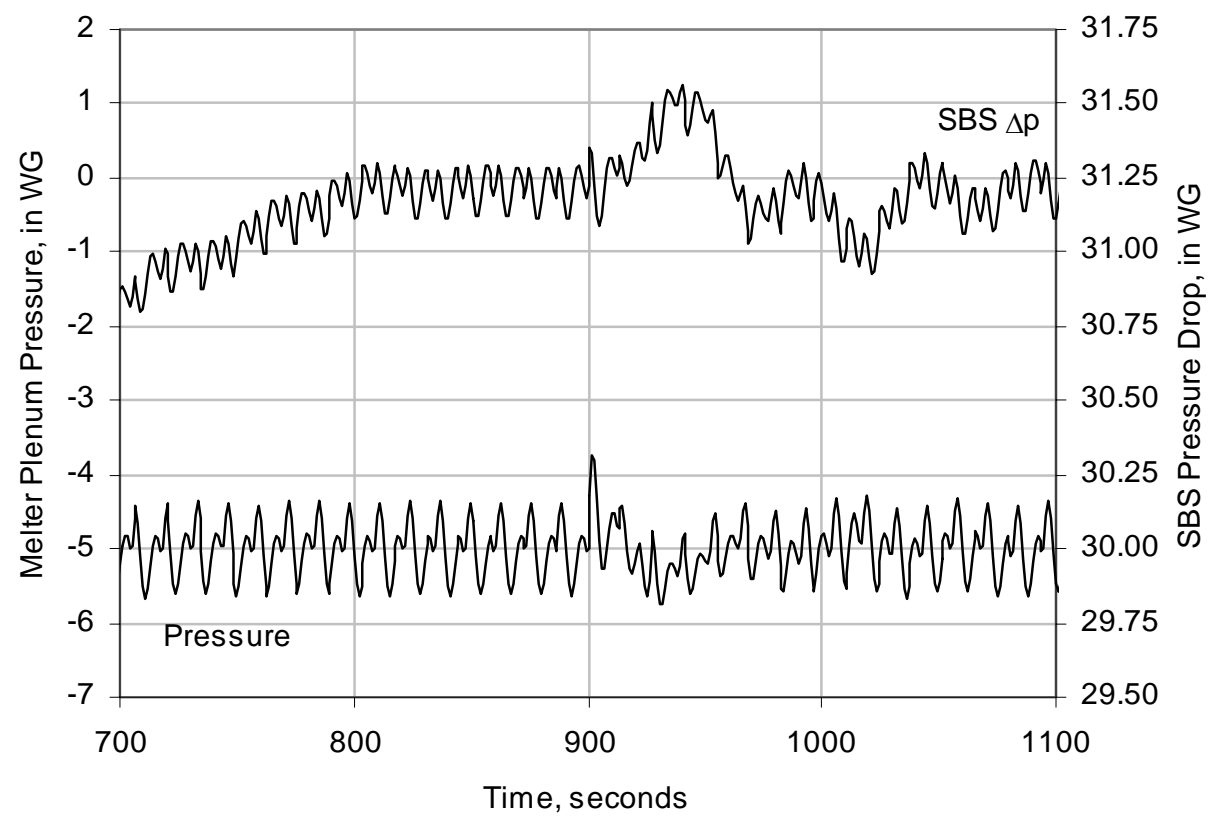

Figure 2.2-36 LAW melter pressure and SBS pressure drop response using PID damper valve control with 30 second signal averaging. 


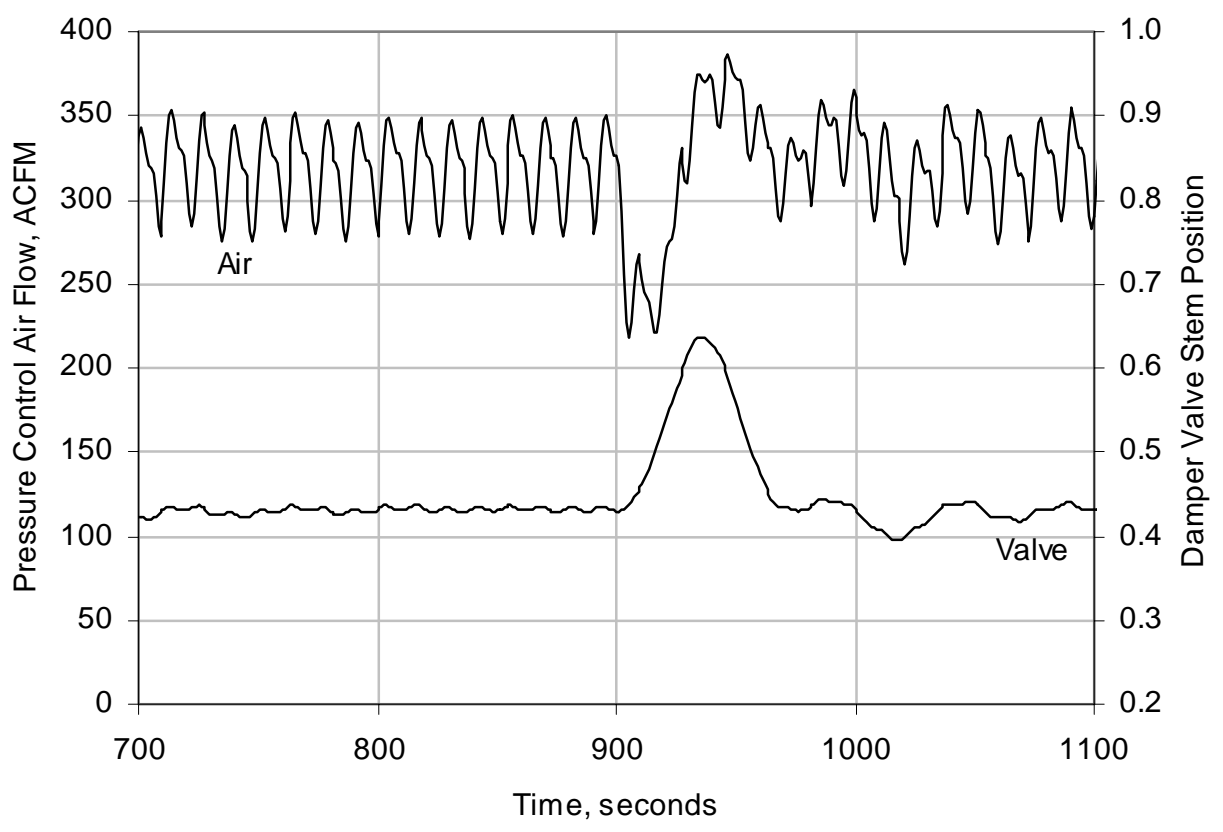

Figure 2.2-37 LAW control airflow and damper valve response using PID damper valve control with 30 second signal averaging.

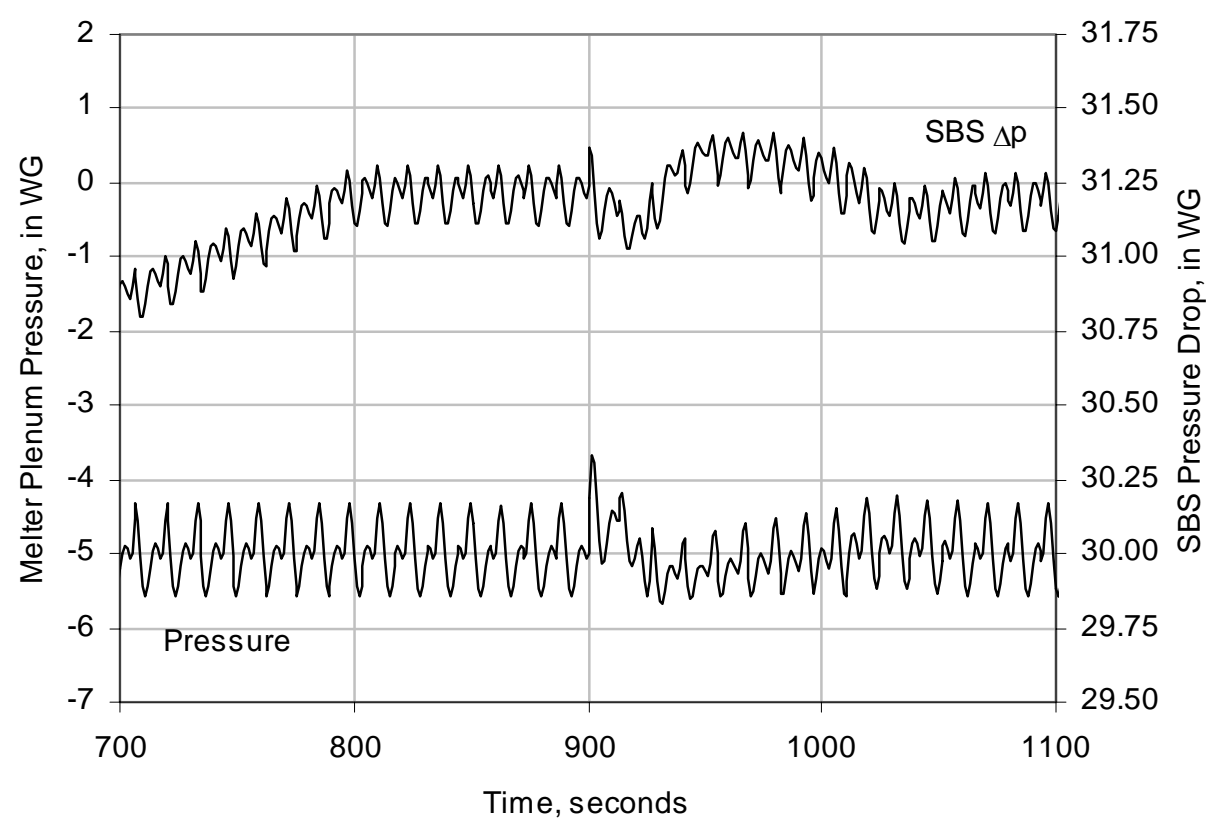

Figure 2.2-38 LAW melter pressure and SBS pressure drop response using Robbins PI damper valve control settings with 30 second signal averaging. 


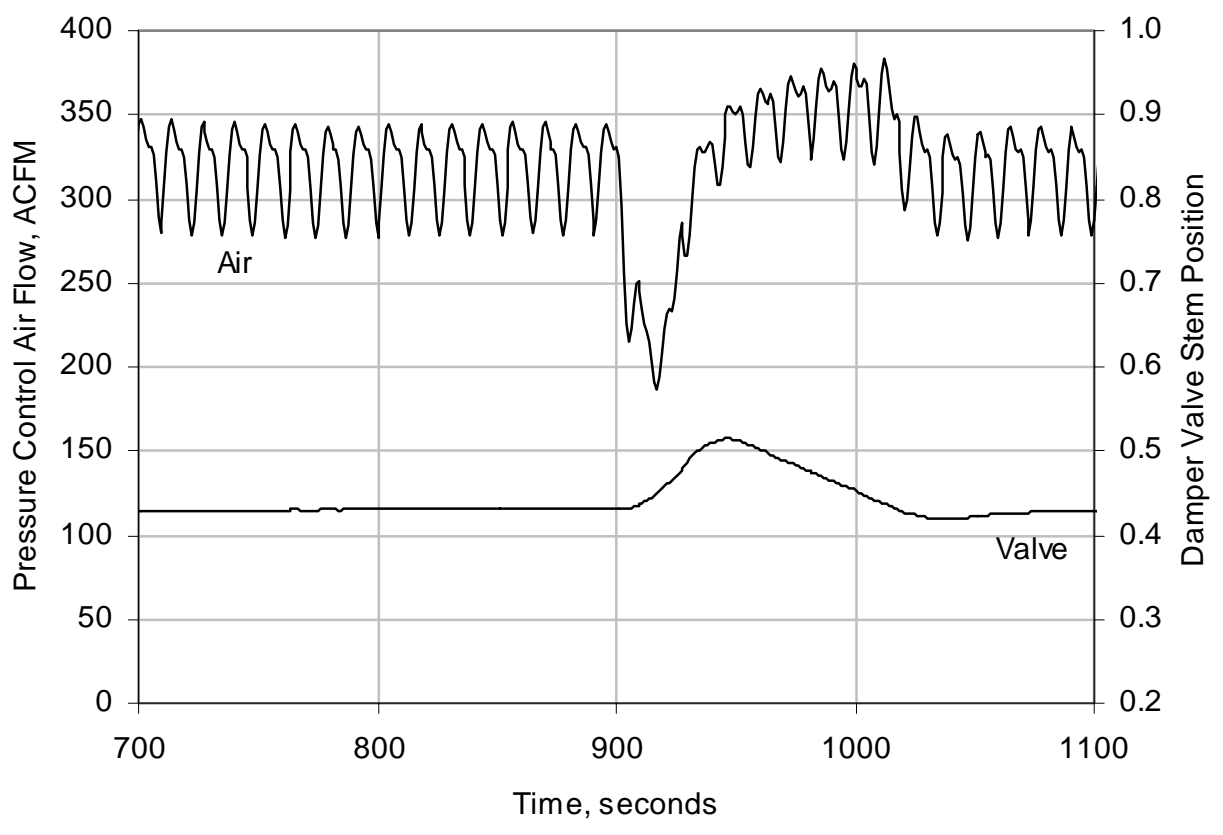

Figure 2.2-39 LAW control airflow and damper valve response using Robbins PI damper valve control settings with 30 second signal averaging.

\subsubsection{LAW Fan Speed Control Loop}

Table 2.2-7 shows the ultimate gain and frequency for the LAW fan speed control loop and the corresponding controller parameters. These tuning parameters were determined with the other control systems in manual mode. When the system runs requested in step E.9 of Appendix B were made, it was obvious that the system was unstable. Attempts were then made to tune the fan speed controller with the other control loops active. The damper valve controller gain was initially set to 0.6 based on the results in Section 2.2.4. With this gain, it was very difficult to tune the fan speed controller. The system exhibited unstable behavior at fan speed gains less than one. Lowering the gain on the damper controller from 0.6 to 0.4 made a significant difference in overall system stability. At the lower damper gain, fan speed was relatively insensitive to gain as was observed during the initial controller tuning. Since the tuning was insensitive to the controller gain and since the cycling was already at a relatively high frequency that lead to large reset and rate times, it appeared that little benefit would be derived from testing the Robbins control tuning method for this system.

Table 2.2-7 LAW Fan Speed Control Parameters.

[Ultimate gain $\mathrm{K}_{\mathrm{u}}=10.0$, Ultimate time constant $\tau_{\mathrm{u}}=28.0$ (s)]

\begin{tabular}{|c||c|c|c|}
\hline Control Method & Gain, $\mathbf{K}_{\mathbf{c}}$ & Reset, $\boldsymbol{\tau}_{\mathbf{i}} \mathbf{( s )}$ & Rate, $\boldsymbol{\tau}_{\mathbf{d}}(\mathbf{s})$ \\
\hline \hline P & 5.0 & - & - \\
\hline PI & 4.5 & 23.0 & - \\
\hline PID & 6.0 & 14.0 & 3.5 \\
\hline
\end{tabular}


Figures 2.2-40 through 2.2-42 show the fan speed and common node pressure for the three sets of control parameters in Table 2.2-7. These runs were made with all of the control systems active, melter feeding starting at 600 seconds, a $10 \%$ increase in SBS pressure drop between 700 and 800 seconds and a nominal 4X steam surge at 900 seconds. All of the settings gave very tight control on the common node pressure. PID control performed best and was chosen as the preferred control strategy. The common node pressure is maintained within \pm 0.02 in WG during the transient under PID control. A more complete display of the system behavior using this control strategy in conjunction with the other controllers tuned to optimize performance is shown in Figs. 2.2-1 through 2.2-5 at the beginning of this section.

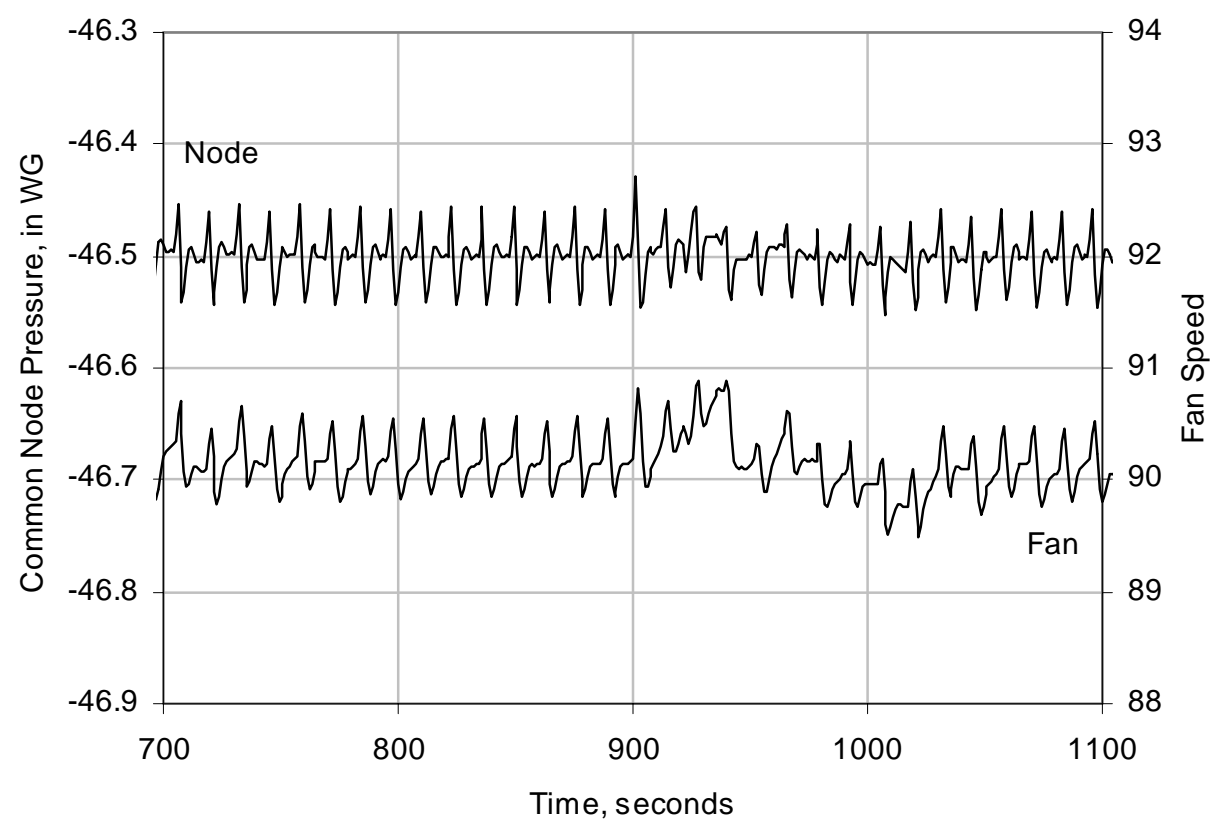

Figure 2.2-40 LAW fan speed control response using proportional control. 


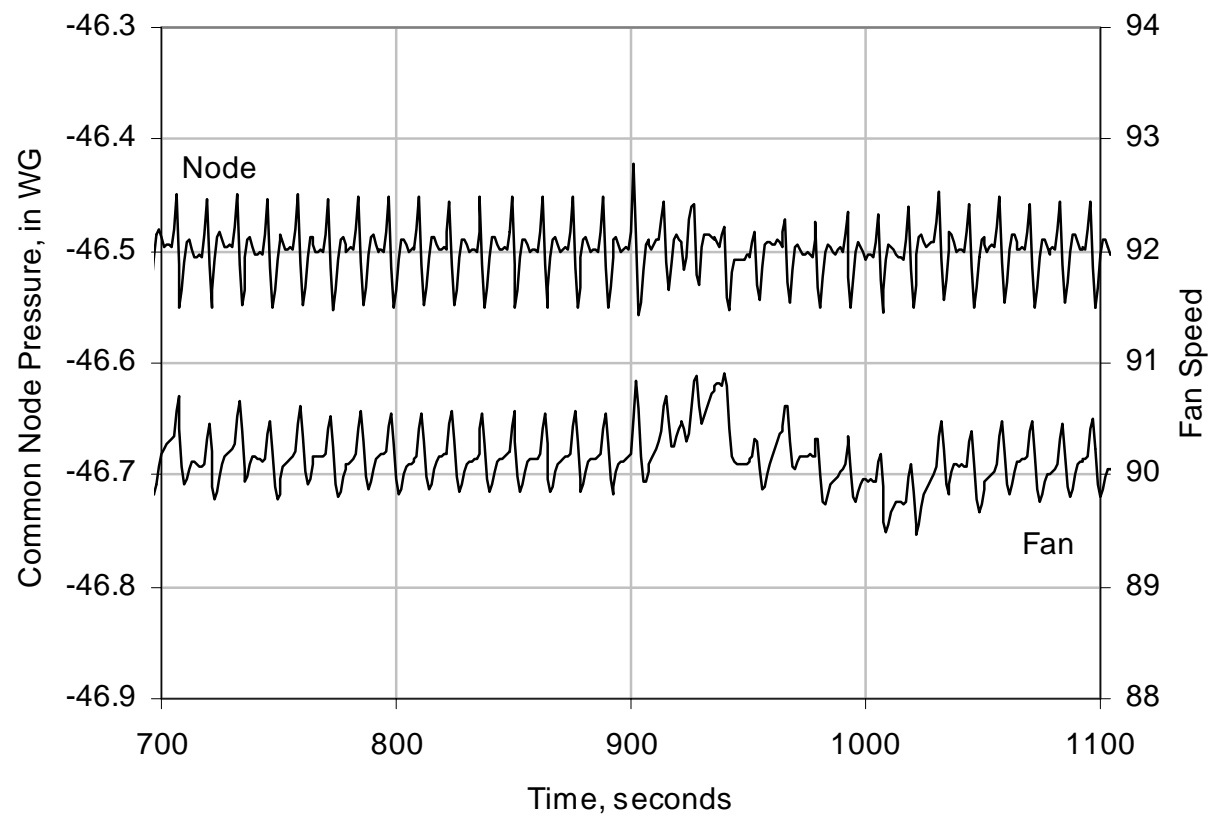

Figure 2.2-41 LAW fan speed control response using PI control.

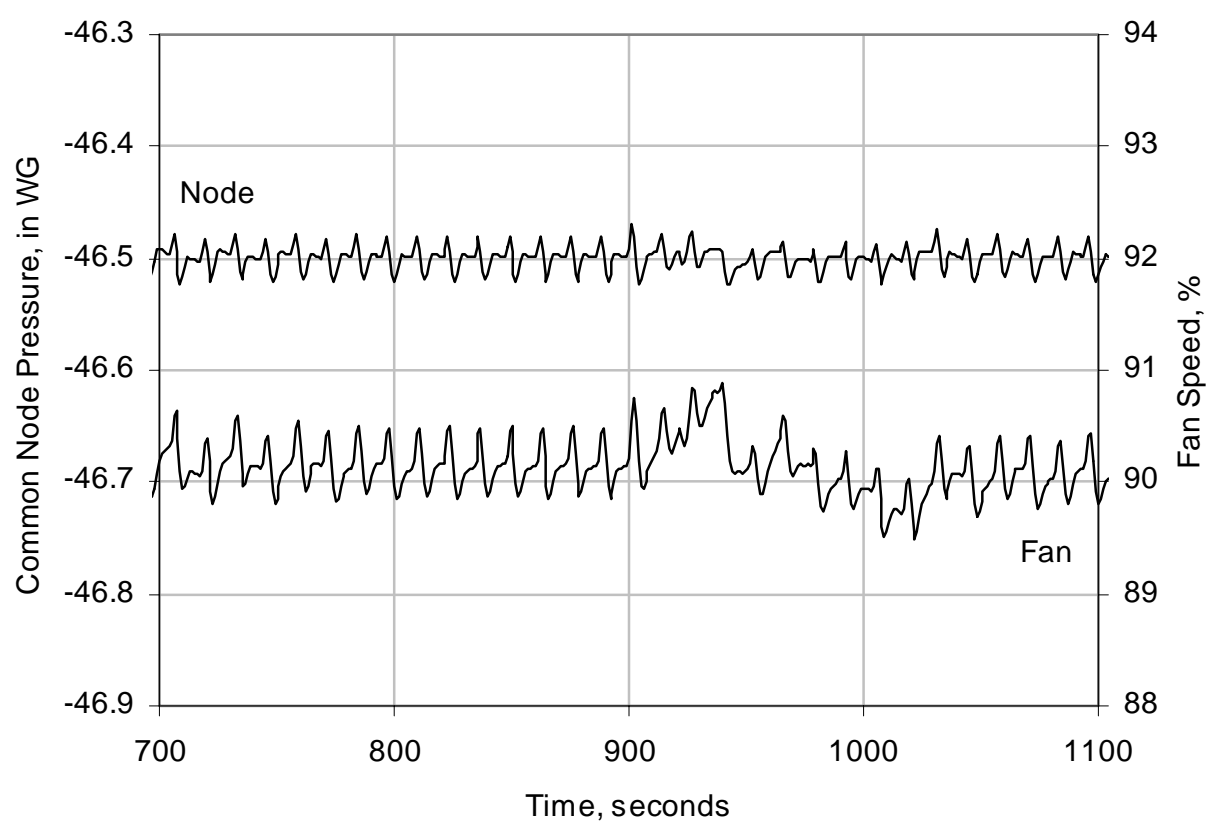

Figure 2.2-42 LAW fan speed control response using PID control. 


\subsection{HLW Pulse Jet Ventilation System}

For tuning purposes, a simplified model of the HLW Pulse Jet Ventilation system, shown in Fig. D-3, which replaces the vessels with a single constant-flow air source was used to determine control parameter values. Airflow was set to $1.51 \mathrm{~m}^{3} / \mathrm{s}$ or 3200 ACFM and the pressure at the HEPA preheater inlet was set to an absolute value of $95000 \mathrm{~Pa}$ or -20 inches WG. As requested, each of the control methods was tested with three different pulse-jet flow patterns simulating minimum, average and maximum operation using the full model (Smith, 2002a). Figure 2.3.1 shows the exhaust airflow profile from a single pulse jet mixer over a typical 30 second time period (Fassett, 2002). This flow profile was built into the model as the nine linear segments indicated on the figure between 0 and 20 seconds. Outside of the 20 second operating cycle, the flow from each functioning PJM is the baseline flow of 75 SCFM. PJM flows during an operating cycle are linearly interpolated on the nine line segments as needed for the calculations. The flow pattern shown in Fig. 2.3-1 was repeated at a specified frequency to model operation of the PJM. The time spent at the baseline flow, shown as ten seconds in Fig. 2.3-1, will vary for each PJM depending on the assumed operating sequence.

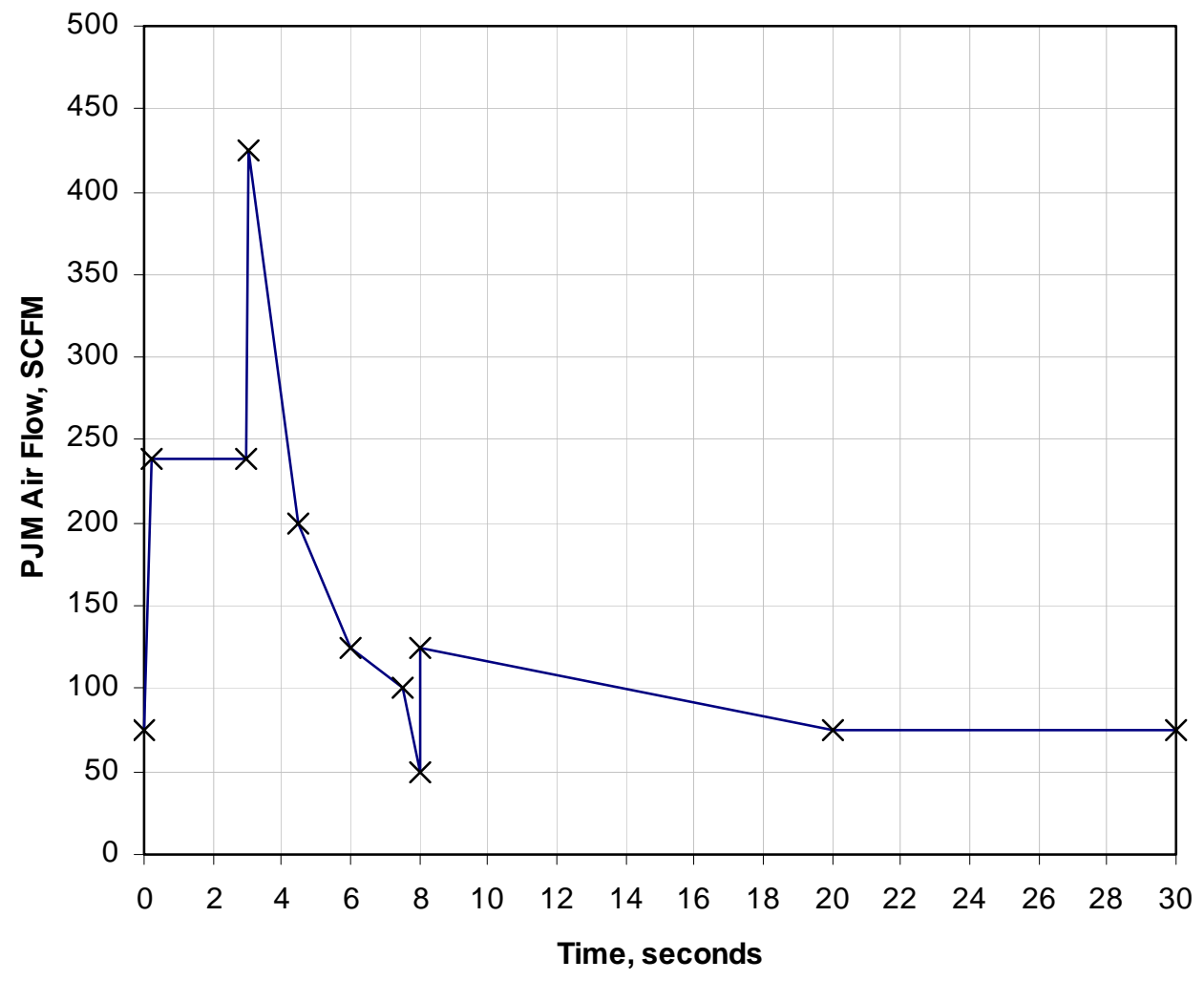

Figure 2.3-1 Pulse jet mixer airflow profile. 
Table 2.3-1 PJV Vessel PJM Flow Sequencing Parameters.

(Timings in table in seconds)

\begin{tabular}{|c|c|c|c|c|c|c|c|}
\hline \multirow[b]{2}{*}{ Vessel } & \multirow{2}{*}{$\begin{array}{c}\text { PJM } \\
\text { No. }\end{array}$} & \multicolumn{2}{|c|}{ Minimum Flow } & \multicolumn{2}{|c|}{ Average Flow } & \multicolumn{2}{|c|}{ Maximum Flow } \\
\hline & & $\mathrm{t}_{\text {sequence }}$ & $\mathrm{t}_{\text {start }}$ & $\mathrm{t}_{\text {sequence }}$ & $\mathrm{t}_{\text {start }}$ & $\mathrm{t}_{\text {sequence }}$ & $\mathrm{t}_{\text {start }}$ \\
\hline HCP-VSL-00001 & 6 & 10 & 0 & 10 & 0 & 0 & 0 \\
\hline HCP-VSL-00002 & 6 & 10 & 10 & 10 & 10 & 5 & 0 \\
\hline RLD-VSL-00007 & 4 & 20 & 0 & 20 & 0 & 10 & 0 \\
\hline RLD-VSL-00008 & 4 & off & off & 20 & 10 & 10 & 5 \\
\hline HOP-VSL-00903 & 4 & off & off & 20 & 30 & 10 & 15 \\
\hline HOP-VSL-00904 & 4 & 20 & 15 & 20 & 30 & 10 & 15 \\
\hline
\end{tabular}

To model the variability in PJV offgas flow, three different PJM operating sequences, termed the minimum, average and maximum flows, were tested. Table 2.3-1 lists the parameters used for each flow sequence. The start times $\left(\mathrm{t}_{\text {start }}\right)$ are the times at which the PJMs in a particular vessel begin to sequence following system startup. For example, if minimum flow is started at 600 seconds:

PJMs for vessel HCP-VSL-00001 with $\mathrm{t}_{\text {start }}=0$ will begin sequencing at 600 seconds PJMs for vessel RLD-VSL-00007 with $\mathrm{t}_{\text {start }}=0$ will begin sequencing at 600 seconds PJMs for vessel HCP-VSL-00002 with $t_{\text {start }}=10$ will begin sequencing at 610 seconds PJMs in vessel HOP-VSL-00904 with $\mathrm{t}_{\text {start }}=15$ will begin sequencing at 615 seconds

The PJMs in vessels RLD-VSL-00008 and HOP-VSL-00903 remain off and generate no gas at minimum flow. The sequence times ( $\left.\mathrm{t}_{\text {sequence }}\right)$ in Table 2.3-1 set the frequency at which the PJMs operate. A sequence time of 10 seconds means that the PJMs in that vessel will operate continuously at 10 second intervals. That is, the second PJM will start 10 seconds after the first, the third PJM 10 seconds after the third and so forth. The first PJM will restart 10 seconds after the last PJM to continue the operating sequence. The sequence time of 0 for vessel HCP-VSL-00001 at maximum flow means that all of the mixers operate together. 


\subsubsection{PJV Pressure Control Loop without Signal Averaging}

Table 2.3-2 lists the control system parameters determined using the quarter-decay and Robbins tuning methods. Figures 2.3-2 through 2.3-5 show the system response to minimum, average and maximum airflow for the four control settings. In each figure, minimum airflow is maintained from 10 to 15 minutes, average airflow from 15 to 20 minutes, and maximum airflow from 20 to 25 minutes. An examination of Figs. 2.3-2 through 2.3-5 shows that there is little difference between the system responses for the different control settings. As shown in Fig. 2.3-1, flow changes are assumed to occur instantaneously. Time lags and response times in the control system introduce some delay in the control response and prevent the system from responding effectively to the rapid changes in gas flow and pressure.

Table 2.3-2 HLW PJV Control Parameters without Signal Averaging.

[Ultimate gain $\mathrm{K}_{\mathrm{u}}=8.0$, Ultimate time constant $\tau_{\mathrm{u}}=1.8(\mathrm{~s})$ ]

\begin{tabular}{|c||c|c|c|}
\hline Control Method & Gain, $\mathbf{K}_{\mathbf{c}}$ & Reset, $\boldsymbol{\tau}_{\mathbf{i}} \mathbf{( s )}$ & Rate, $\boldsymbol{\tau}_{\mathbf{d}} \mathbf{( s )}$ \\
\hline \hline P & 4.0 & - & - \\
\hline PI & 3.6 & 1.5 & - \\
\hline PID & 4.7 & 0.9 & 0.2 \\
\hline Robbins (PI) & 1.0 & 2.5 & - \\
\hline
\end{tabular}

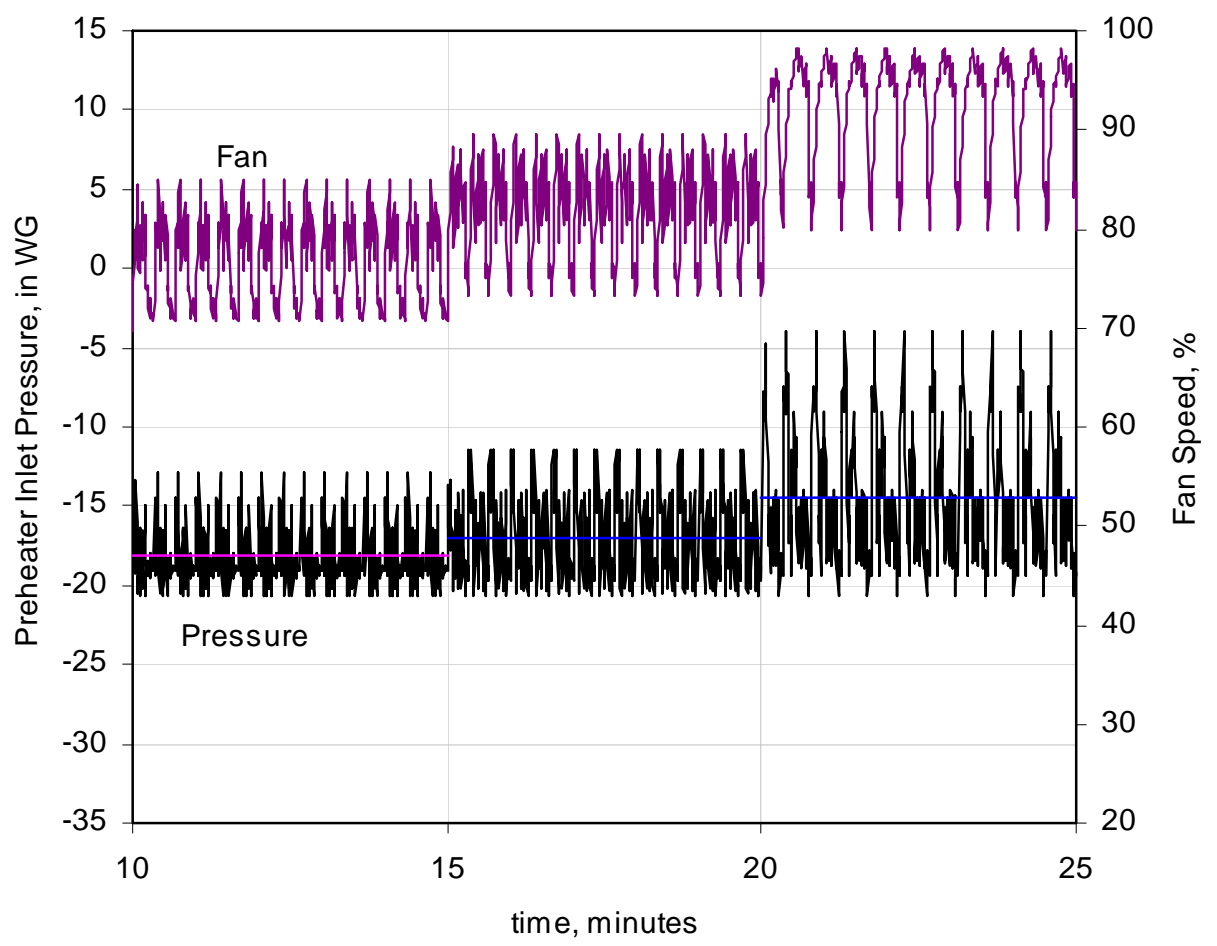

Figure 2.3-2 PJV pressure control loop response using proportional control. 


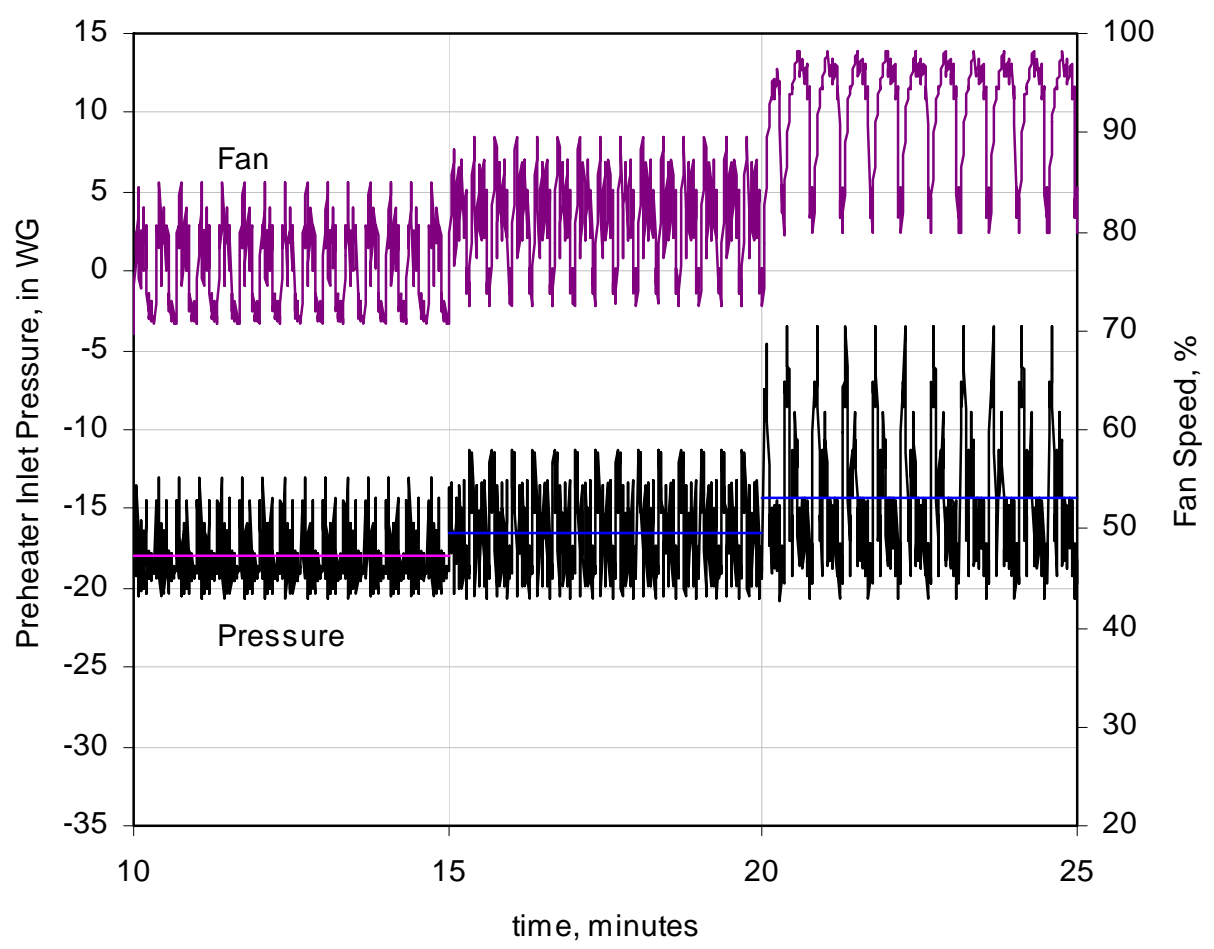

Figure 2.3-3 PJV pressure control loop response using PI control.

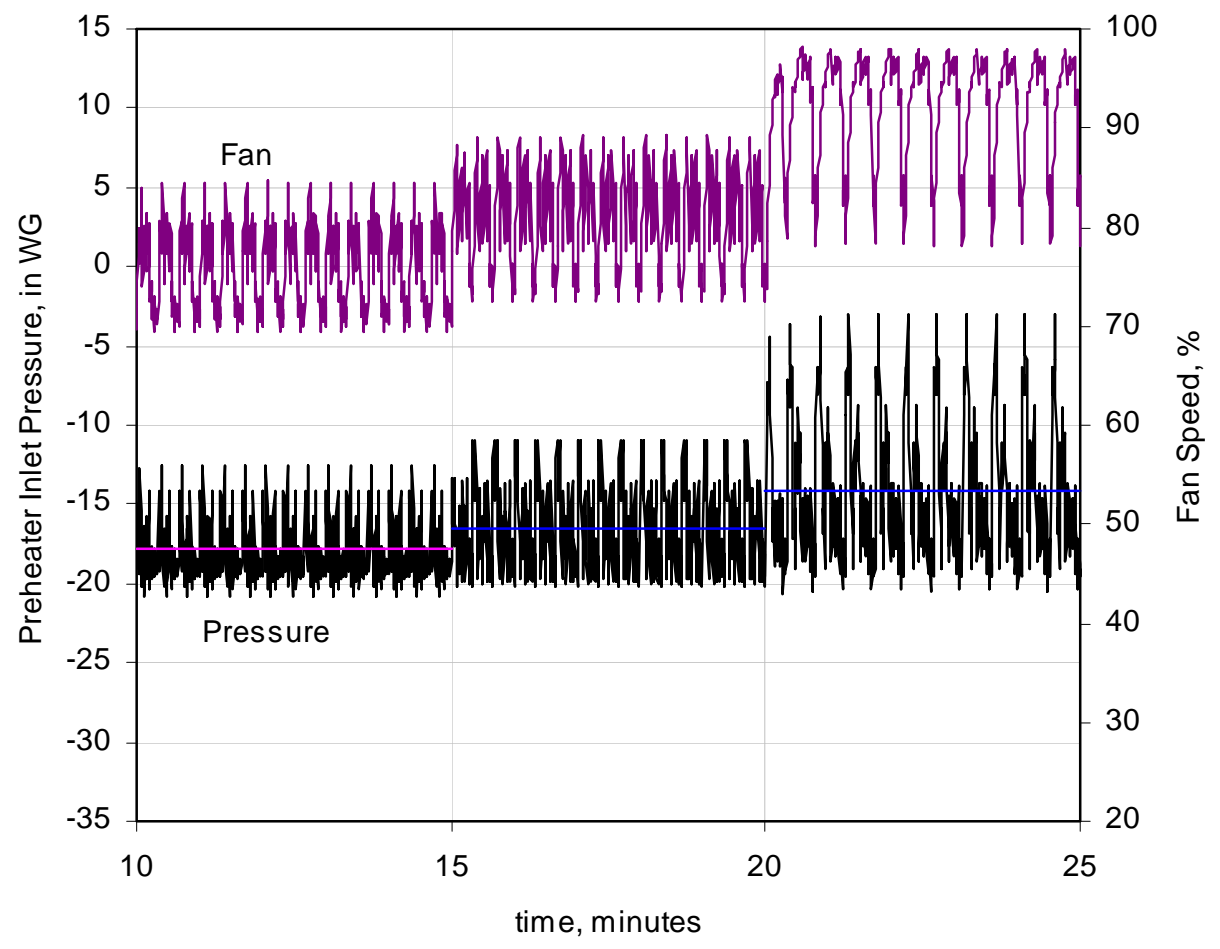

Figure 2.3-4 PJV pressure control loop response using PID control. 


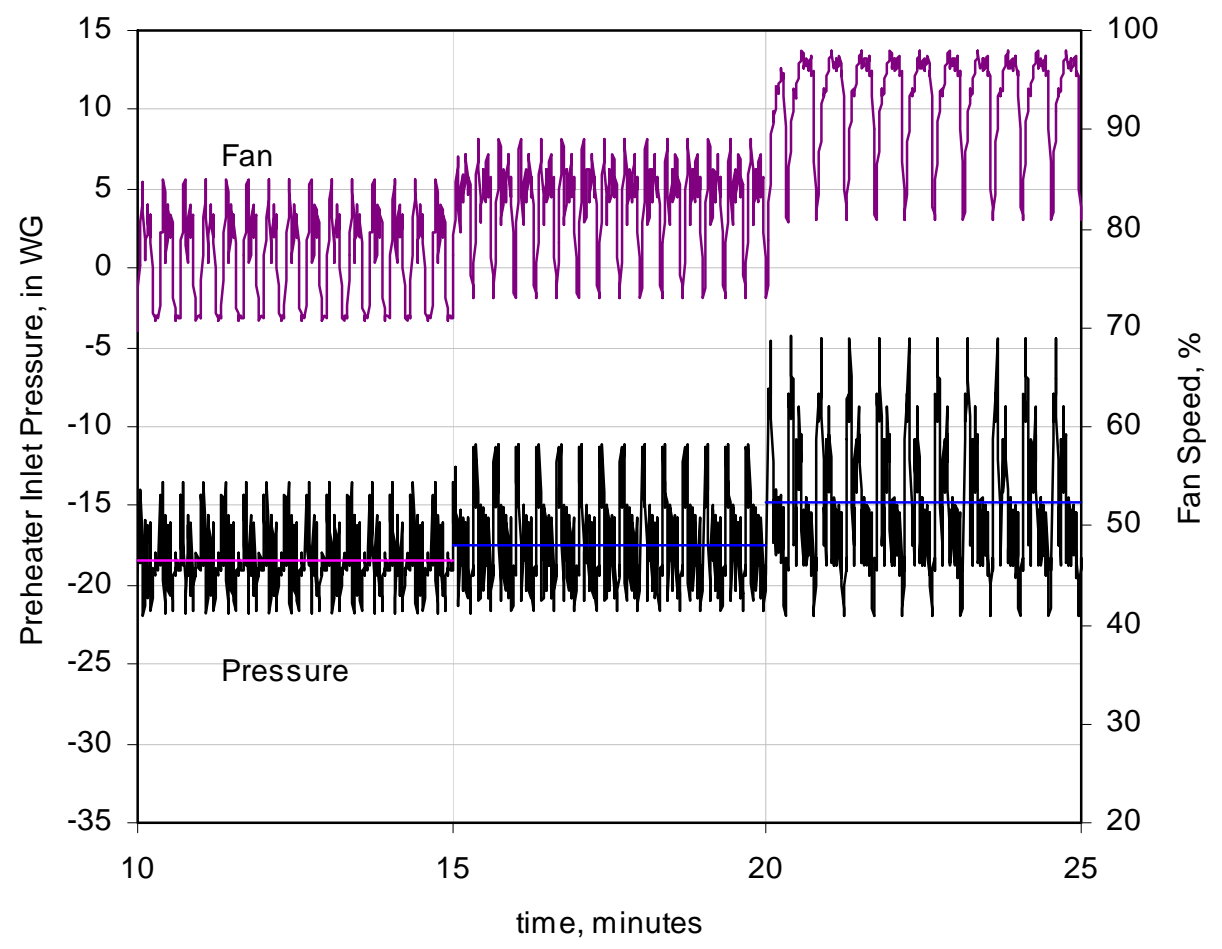

Figure 2.3-5 PJV pressure control loop response using Robbins PI control. 


\subsubsection{PJV Pressure Control Loop with 30 Second Signal Averaging}

Table 2.3-3 lists the control system tuning parameters determined when the pressure signal to the controller was averaged over a 30 second time interval. A comparison with the results in Table 2.3-2 shows that using signal averaging results in lower gain and larger rate constants.

Table 2.3-3 HLW PJV Control Parameters with 30 sec Averaging.

[Ultimate gain $\mathrm{K}_{\mathrm{u}}=1.0$, Ultimate time constant $\tau_{\mathrm{u}}=40(\mathrm{~s})$ ]

\begin{tabular}{|c||c|c|c|}
\hline Control Method & Gain, $\mathbf{K}_{\mathbf{c}}$ & Reset, $\boldsymbol{\tau}_{\mathbf{i}}(\mathbf{s})$ & Rate, $\boldsymbol{\tau}_{\mathbf{d}}(\mathbf{s})$ \\
\hline \hline P & 0.50 & - & - \\
\hline PI & 0.45 & 33 & - \\
\hline PID & 0.60 & 20 & 5 \\
\hline Robbins (PI) & 0.10 & 14 & - \\
\hline
\end{tabular}

System response during the three PJV flow regimes using these control settings is shown in Figs. 2.3-6 through 2.3-9. Comparison with the corresponding cases in Figs. 2.3-2 through 2.3-5 shows that using signal averaging allowed the control system to maintain the average pressure closer to the set point and reduced the maximum pressures at the expense of pronounced spikes to lower pressures. Signal averaging significantly reduced fluctuations in fan speed. Without signal averaging, pressures were maintained within a narrower range. However, the maximum pressure reached at maximum flow was controlled better with signal averaging. With low gain Robbins tuning and signal averaging; the PJV system approached the condition of simply maintaining a constant fan speed that responds to the average airflow which may be a desirable operating mode. Of all of the methods tested, higher gain PI control (not Robbins parameters) with 30 second signal averaging was judged to provide the best control strategy for the PJV system. 


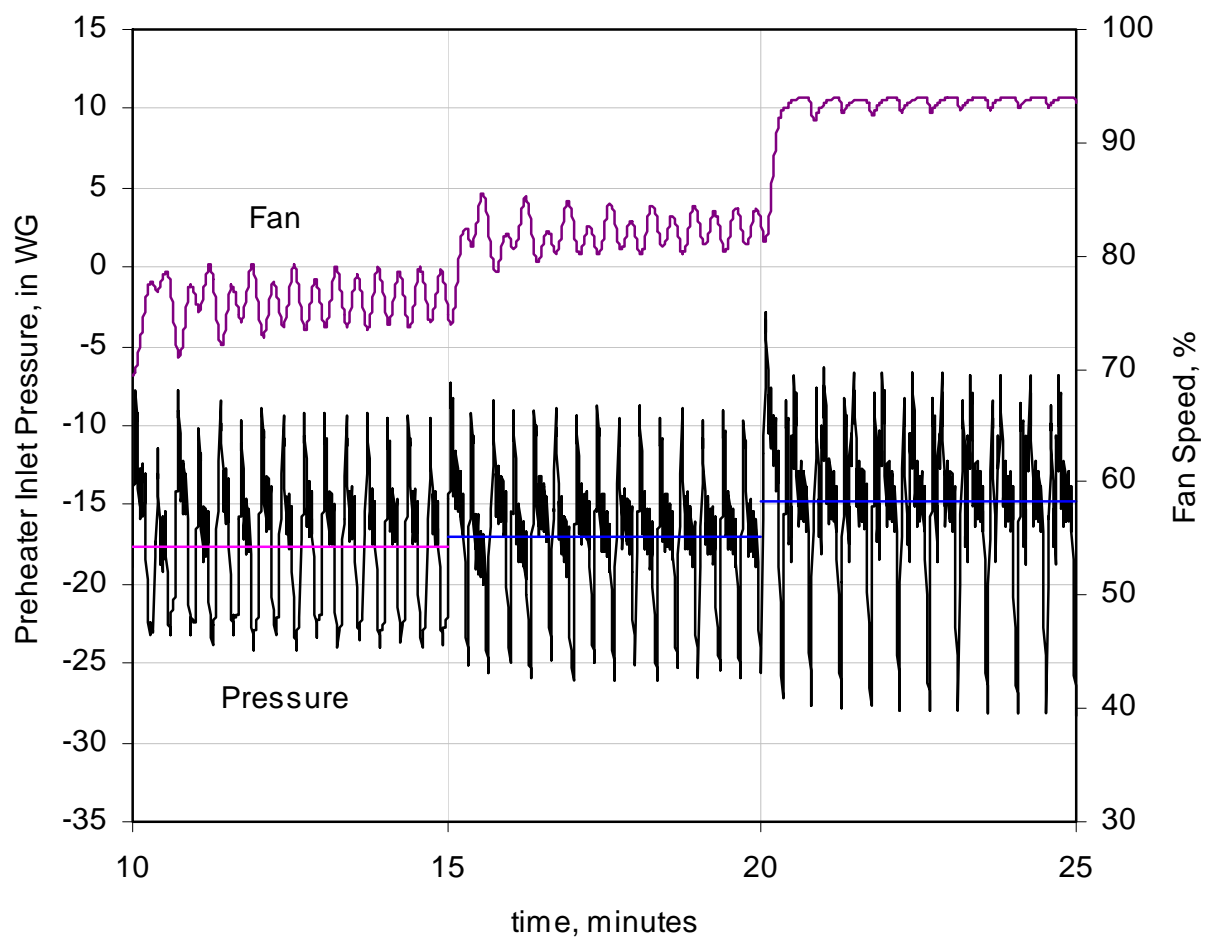

Figure 2.3-6 PJV pressure control loop response using proportional control.

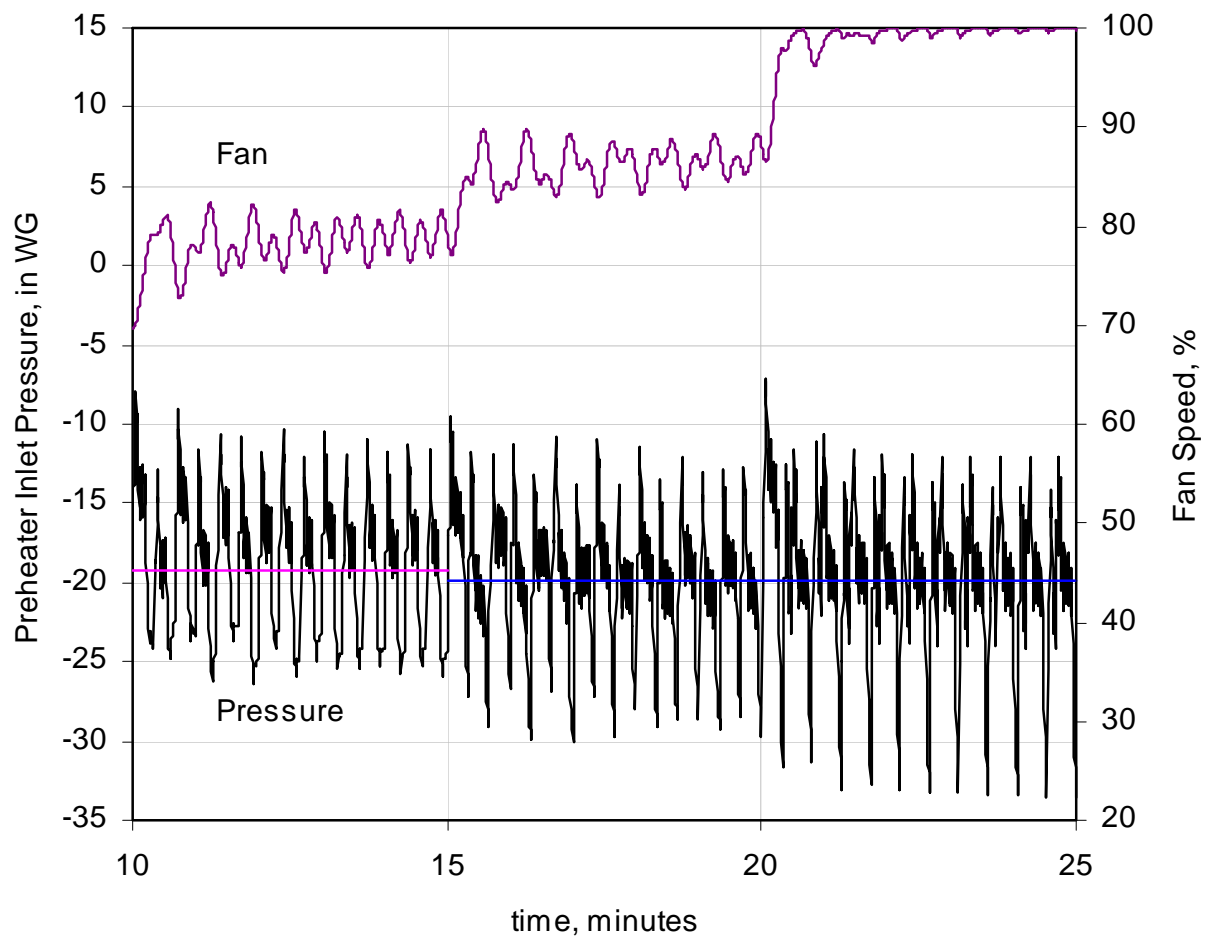

Figure 2.3-7 PJV pressure control loop response using PI control. 


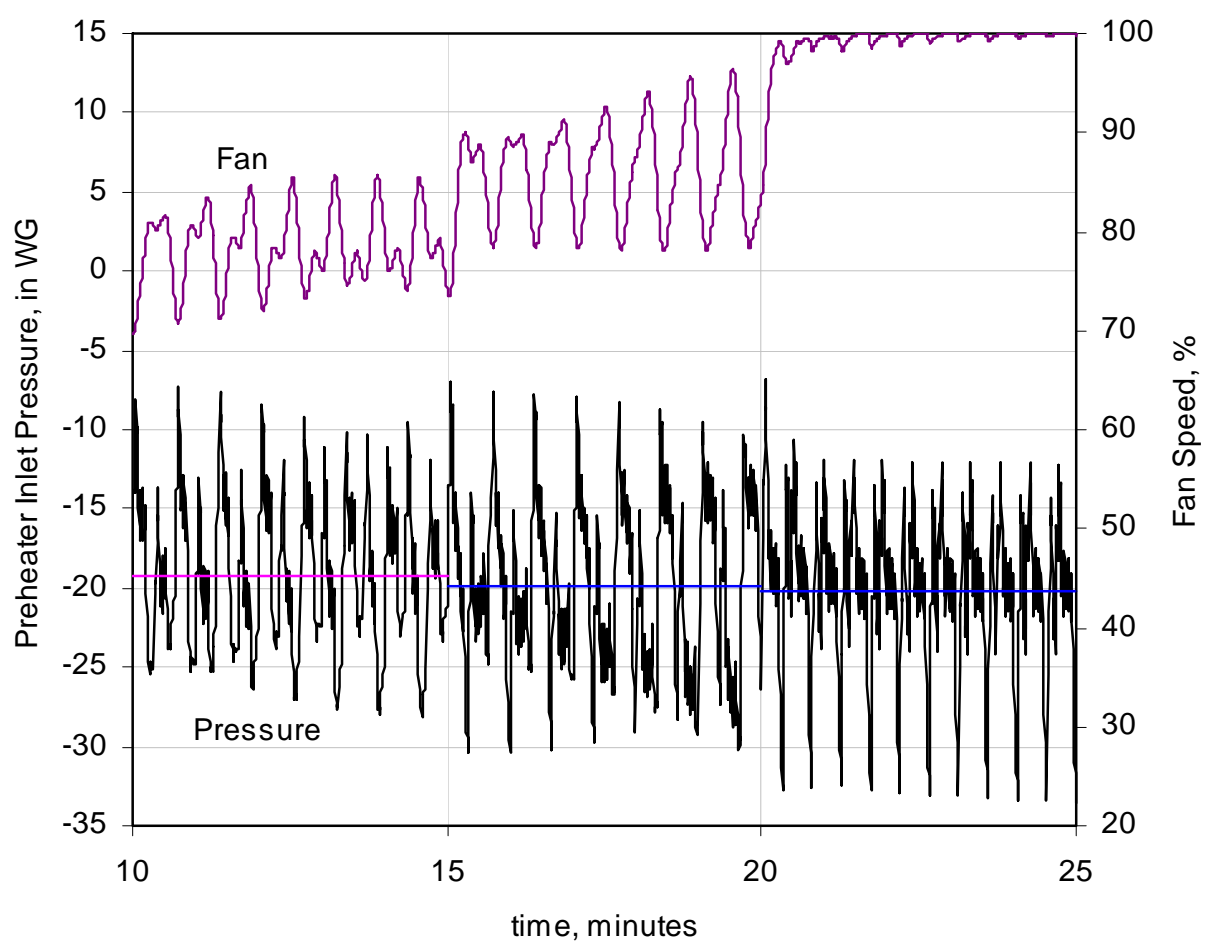

Figure 2.3-8 PJV pressure control loop response using PID control.

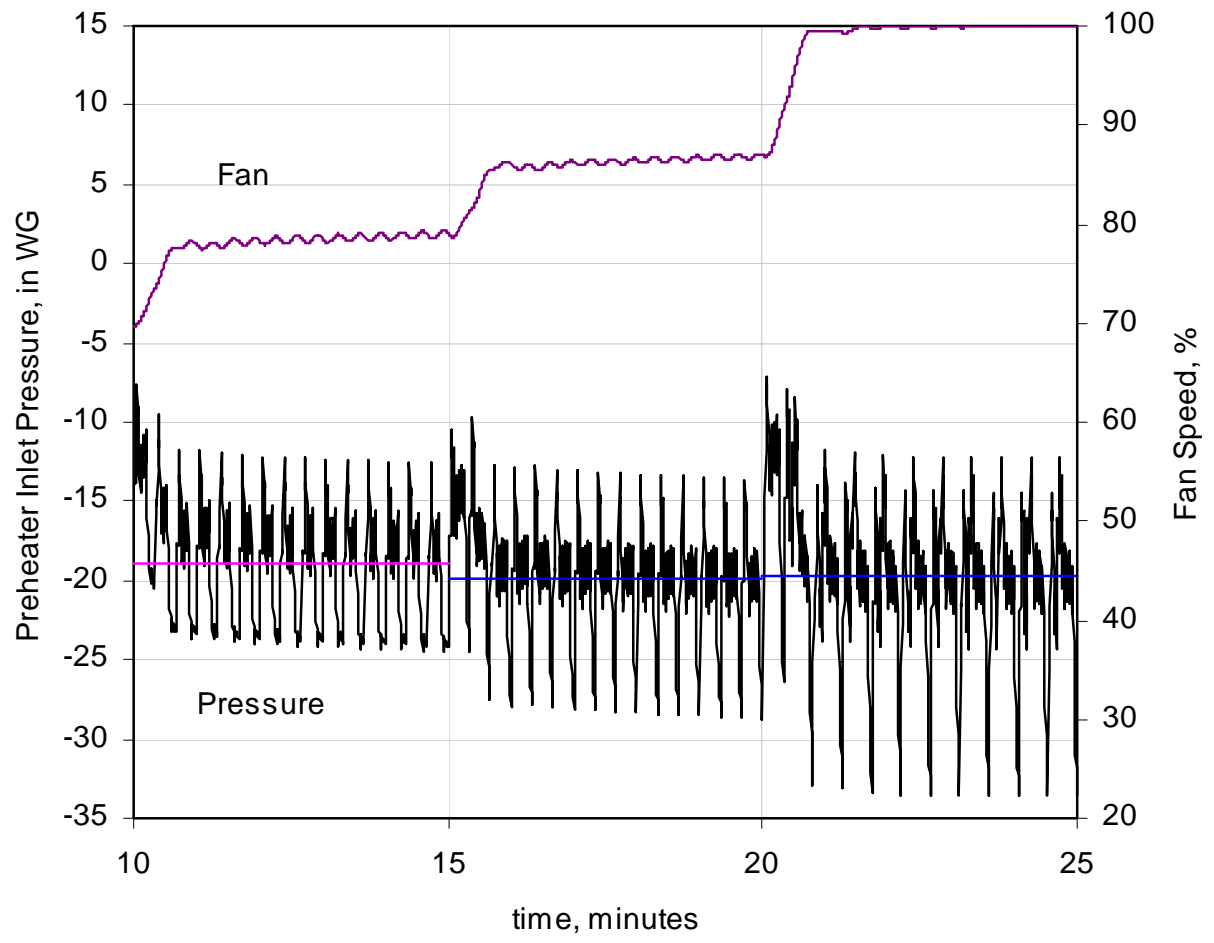

Figure 2.3-9 PJV pressure control loop response using Robbins PI control. 


\section{$\underline{\text { 3.0 Steam Surge Response }}$}

In addition to the control loop tuning described above, a study was conducted to determining the pressure response in the HLW and LAW melter plenum during steam surges. These calculations were run using the optimum control parameters determined in the previous section. On the surge response graphs shown below (Figs. 3-1 and 3-4):

$\mathrm{V}_{\text {normal }}$ is the total average steam flow from the melter during normal operation,

$\mathrm{V}_{\text {minimum }}$ is the smallest steam flow such that an instantaneous step change from

$\mathrm{V}_{\text {normal }}$ to this flow will just cause the melter pressure to become positive, and

$\mathrm{V}_{\text {capacity }}$ is the minimum constant steam flow at which the melter pressure is just positive.

Points on the surge response graphs were determined from model runs where the surge volume was fixed and the surge rate adjusted until the melter pressurized. To the left of the curve connecting the calculated points is the operating region where the melter pressure does not become positive. Model runs were made without simulating the oscillatory ADS component of melter feeding since the fluctuations induced by the ADS pump operation made interpretation of the surge results difficult. ADS cycling caused pressure spikes large enough to push the melter from negative to positive pressure. Since it was difficult to coordinate the surge peaks with the feeding cycle and obtain consistent results, melter slurry feeding was assumed to generate a continuous steam flow during the surge analysis. The surge calculations assume that the pressure relief system that initiates flow through the bypass loop to the SBS and terminates airflow to the film cooler does not operate.

\subsection{HLW Melter Offgas System}

Figure 3-1 shows the pressure response in the HLW melter as a function of the steam surge maximum flow (V) and the rate of increase in steam production (dV/dt). The normal steam flow rate is assumed to be $190 \mathrm{~kg} / \mathrm{hr}$. Therefore, during a $7 \mathrm{X}$ surge, the maximum steam flow is $1330 \mathrm{~kg} / \mathrm{hr}$ and during a 20X surge $3800 \mathrm{~kg} / \mathrm{hr}$. During both the nominal 7X and 20X surges, the increased steam flows of $6 \mathrm{X}$ and 19X, respectively are assumed to peak in 18.5 seconds giving increase rates of $62 \mathrm{~kg} / \mathrm{hr} / \mathrm{s}$ for the $7 \mathrm{X}$ surge and $195 \mathrm{~kg} / \mathrm{hr} / \mathrm{s}$ for the $20 \mathrm{X}$ surge. The fast $7 \mathrm{X}$ surge is assumed to occur in 5 seconds giving a rate of increase of $228 \mathrm{~kg} / \mathrm{hr} / \mathrm{s}$.

The nominal $7 \mathrm{X}$ steam surge falls well within the region where the melter pressure can be maintained negative. However, the fast $7 \mathrm{X}$ surge falls just within this region and the nominal 20X steam surge falls outside of the region. These results are in good agreement with the most recent case studies reported by Smith (2003b) which also showed that the HLW melter could successfully respond to a nominal 7X but not to a nominal 20X steam surge where the SBS standby valve fails to open. In the case studies, the increase in melter plenum pressure was just barely below the +5 inch WG limit during a fast $7 \mathrm{X}$ surge whereas this study indicates that the plenum will just pressurize during this event. 
Both sets of calculations use the same exhausters, control valves and unit operations but somewhat different controller settings. Earlier calculations (Smith, 2001b) showed that the HLW system could withstand a 20X surge. Significant differences exist between the previous model and the current version which likely account for the difference in the $20 \mathrm{X}$ surge response. As noted in Section 2.0, delay times have been added to the control loops and the previous model used a faster acting pressure control valve with a response time of 1 second instead of the conservative 5 second response time used in the current modeling. An attempt was made to retune the current model with a 1 second valve response but stability problems were encountered. Another factor is that both the overall pressure drop across the system and the exhauster capacity have been increased in the revised HLW model in response to the addition of more offgas treatment equipment. Nevertheless, many of these factors apply to the LAW system as well and the LAW surge response was essentially the same as previously found (Smith, 2002b). If the rate of increase in steam production was the same for the 20X surge as for the nominal 7X surge, the $20 \mathrm{X}$ surge would not cause the melter to pressurize. With very slow steam evolution, the melter can withstand steam production as high as $6300 \mathrm{~kg} / \mathrm{hr}\left(\mathrm{V}_{\text {capacity }}\right)$.

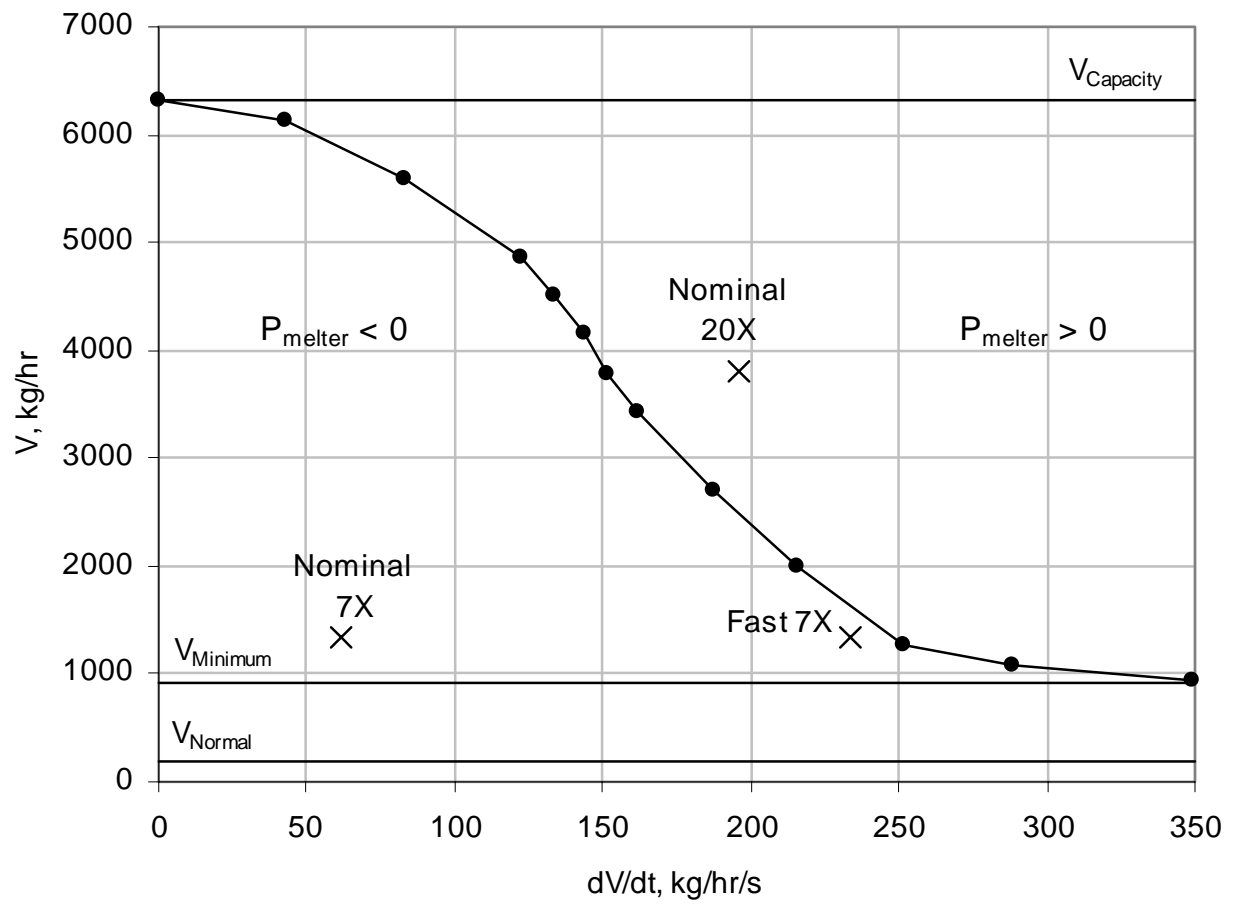

\section{Figure 3-1 HLW melter pressure response to steam surges of different total flow and rate of increase.}

Figure 3-2 shows the melter plenum pressure and the steam surge profile during a surge of $3800 \mathrm{~kg} / \mathrm{s}$ at a surge rate of $151 \mathrm{~kg} / \mathrm{hr} / \mathrm{s}$. At this combination of surge volume and surge rate the plenum pressure just reaches the pressure limit. Figure 3-3 shows the control air flow along with the plenum pressure. The maximum pressure occurs at the peak of the surge where control air flow has been lost. During the initial few seconds of the surge, the pressure increases rapidly and the control air quickly decreases. Within 10 
to 15 seconds, the control air flow is less than 50 CFM and the pressure in the melter plenum begins to increase again since the steam flow is still rising.

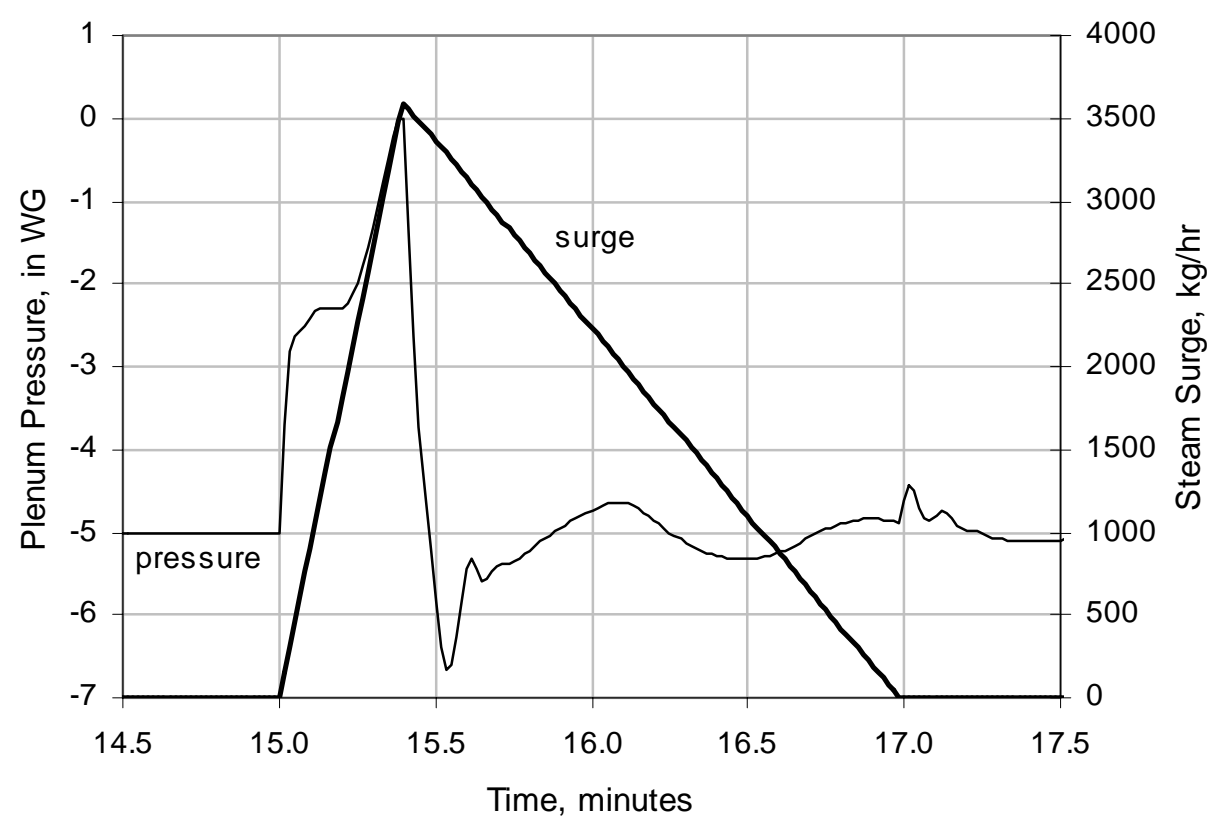

Figure 3-2 HLW melter pressure response to steam surges of different total flow and rate of increase.

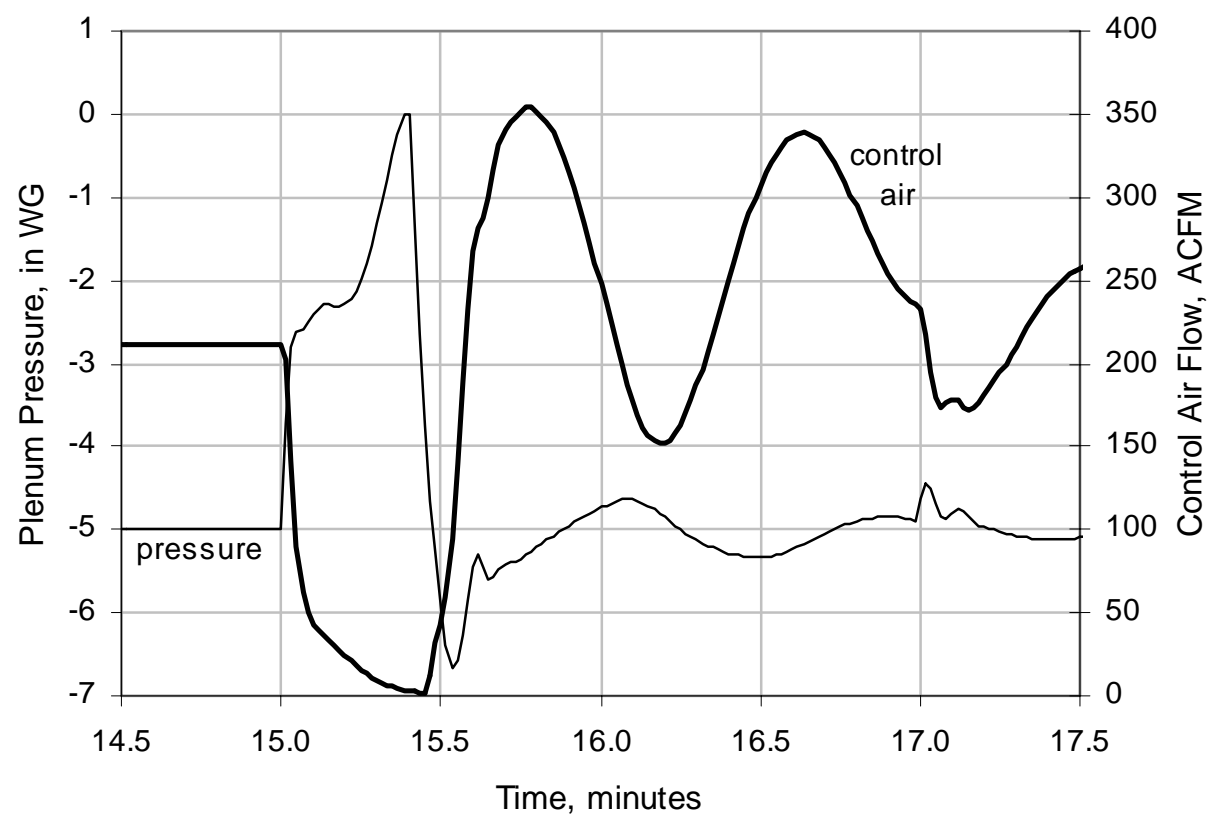

Figure 3-3 HLW melter pressure response to steam surges of different total flow and rate of increase. 


\subsection{LAW Melter Offgas System}

Figure 3-4 shows the pressure response in the LAW melter as a function of steam surge maximum flow $(\mathrm{V})$ and rate of increase $(\mathrm{dV} / \mathrm{dt})$. The normal steam flow rate is assumed to be $400 \mathrm{~kg} / \mathrm{hr}$. Therefore, during a $4 \mathrm{X}$ surge, the maximum steam flow is $1600 \mathrm{~kg} / \mathrm{hr}$ and during a $10 \mathrm{X}$ surge $4000 \mathrm{~kg} / \mathrm{hr}$. During both the nominal $4 \mathrm{X}$ and $10 \mathrm{X}$ surges, the increased steam flows of $3 \mathrm{X}$ and $9 \mathrm{X}$, respectively are assumed to peak in 22 seconds giving increase rates of $55 \mathrm{~kg} / \mathrm{hr} / \mathrm{s}$ for the $4 \mathrm{X}$ surge and $164 \mathrm{~kg} / \mathrm{hr} / \mathrm{s}$ for the $10 \mathrm{X}$ surge. The fast $4 \mathrm{X}$ surge is assumed to occur in 5 seconds giving a rate of increase of 240 $\mathrm{kg} / \mathrm{hr} / \mathrm{s}$.

The nominal and fast $4 \mathrm{X}$ steam surges fall well within the region of negative melter pressure. The $10 \mathrm{X}$ steam surge is very nearly equal to the capacity flow that will cause the melter to pressurize irrespective of the ramp rate. These results are in good agreement with those reported previously (Smith, 2002b and 2003a). The LAW melter plenum has a much larger gas volume $\left(9.2 \mathrm{~m}^{3}\right)$ than the HLW melter $\left(3.6 \mathrm{~m}^{3}\right)$. This larger gas volume may partially account for less sensitivity to the rate of steam surging in the LAW system.

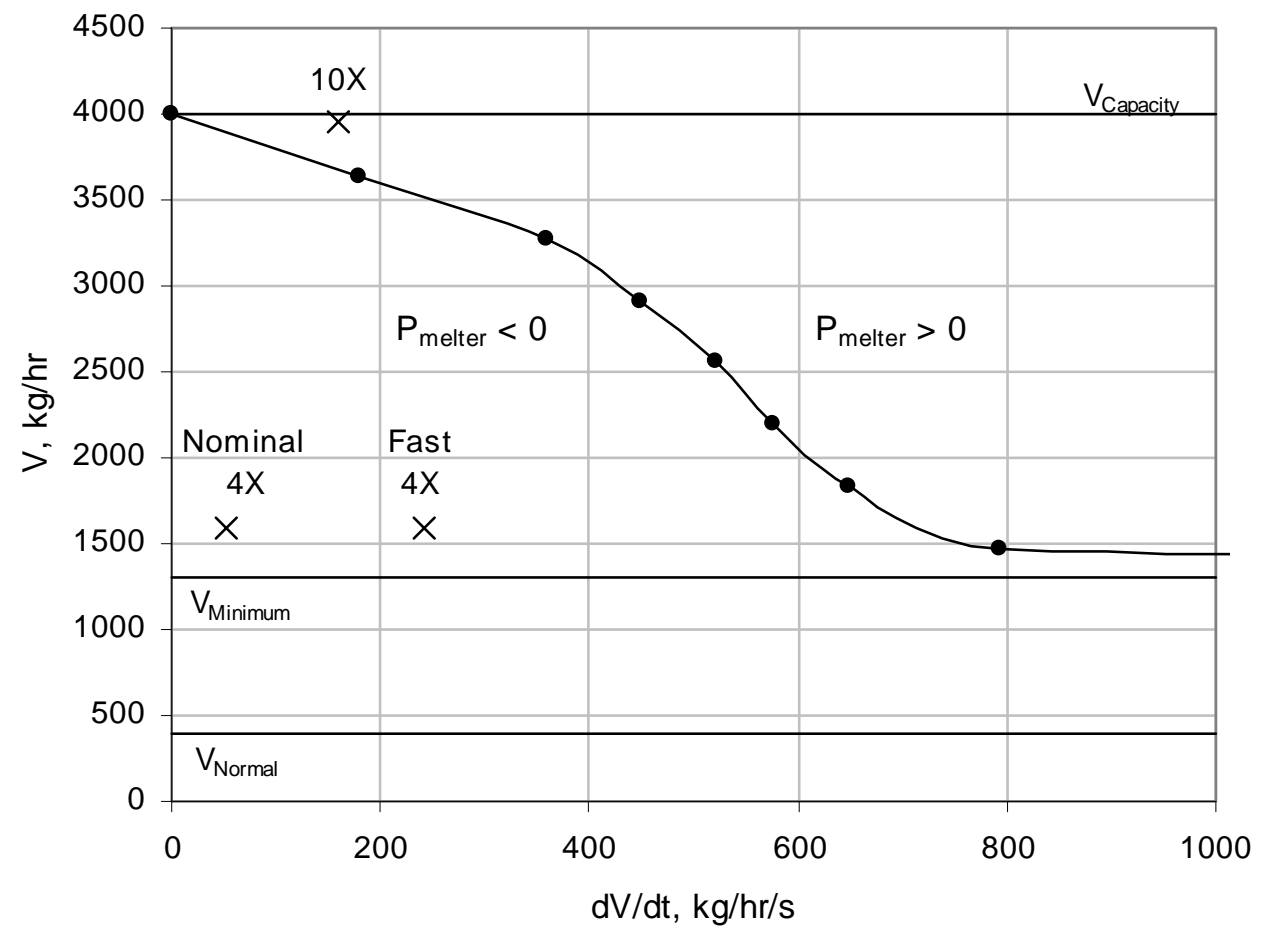

Figure 3-4 LAW melter pressure response to steam surges of different total flow and rate of increase. 


\subsection{References}

Smith, F. G., 2001a, "Preliminary Dynamic Modeling of the Hanford Waste Treatment Plant Melter Offgas Systems,” WSRC-TR-2001-000140, Rev. 0, SRP-RPP-2001-00031, August, 2001, Westinghouse Savannah River Co., Aiken, SC.

Smith, F. G., 2001b, "Case Studies with the RPP HLW Melter Offgas/Vessel Ventilation Dynamic Pressure and Control Model," WSRC-TR-2001-000609, SRP-RPP-200100235, Rev. 0, December, 2001, Westinghouse Savannah River Co., Aiken, SC.

Smith, F. G., 2002a, "Case Studies with the RPP HLW Pulse Jet Ventilation System Dynamic Pressure and Control Model,” WSRC-TR-2002-000166, SRT-RPP-200200083, Rev. 0, April, 2002, Westinghouse Savannah River Co., Aiken, SC.

Smith, F. G., 2002b, “Case Studies with the Hanford WTP LAW Melter Offgas/Vessel Ventilation Dynamic Pressure and Control Model,” WSRC-TR-2002-000371, Rev. 0, SRP-RPP-2002-00196, August, 2002, Westinghouse Savannah River Co., Aiken, SC.

Smith, F. G., 2003a, "Case Studies with Updated Hanford WTP LAW Melter Offgas/Vessel Ventilation Dynamic Pressure and Control Model," WSRC-TR-2003000225, Rev. 0, SRP-RPP-2002-00495, October, 2003, Westinghouse Savannah River Co., Aiken, SC.

Smith, F. G., 2003b, "Case Studies with Updated Hanford WTP HLW Melter Offgas/Vessel Ventilation Dynamic Pressure and Control Model,” WSRC-TR-2003000565, Rev. 0, SRP-RPP-2003-00246, December, 2003, Westinghouse Savannah River Co., Aiken, SC. 


\section{Appendix A: HLW Dynamic Modeling Tuning Procedural Steps}

A.1 Melter Pressure Control Loop using Control Air

1. The HLW melter extraction fans should be manually adjusted to achieve a vacuum of -5 ”WG in the melter plenum and a control air flowrate at 200 SCFM. All other air additions should be turned on as normal. The vessel vent flowrate should be fixed and the vessel vent control valve fixed at a nominal position (i.e., vessel vent pressure control loop placed in manual). Fan speed should be fixed at this speed and the speed/flowrate control loop should not be turned on. Melter feeding should also not be initiated. The goal is to have all system variables "fixed" except for the control loop in question. The result should be a "flat" melter plenum vacuum with no "dynamics" occurring anywhere in the system.

2. Set the reset and rate settings of the melter plenum PID controller to zero.

3. With the control loop in automatic, apply a step change of 0.25 ”'WG to the plenum vacuum setpoint ( -5.0 ”'WG to -4.75 ”'WG).

4. While repeating Step \#3, manually adjust the gain setting until the loop (i.e., valve position) oscillates with constant amplitude.

5. Record the "ultimate" gain and the oscillation's "ultimate" period (i.e., time peak to peak).

6. Repeat Steps \#3, \#4, and \#5, but with the setpoint step change from -5 ”WG to -5.25 ”WG.

7. Record the "ultimate” gain and the oscillation's "ultimate” period (i.e., time peak to peak) for this opposing step change. Verify that the same ultimate gain and period are achieved.

8. Determine the different tuning settings for the different controller types defined in Table 6-1 of Smith using the ultimate gain and period defined in Step \#5.

9. Prepare a modeling sequence containing a short period of melter feeding followed by a normal 7X surge.

10. Perform three model runs that sequentially uses the P, PI, and PID tuning settings defined in Step \#8.

11. Record the plenum vacuum maximum deviation from setpoint during both the feeding stage and the surge stage. Also record the time it took the system to recover to normal after the melter surge.

12. Based on the recorded deviations and recovery times, determine which tuning settings performed the best.

Using the PI tuning factors developed above, perform a second tuning analysis using the

"Robbins" tuning rules as follows:

1. Determine if there are any recognizable patterns to the control response using the quarter decay tuning factors.

2. Starting with the quarter decay tuning factors defined above, follow the steps outlined in Robbins to determine the "refined" tuning factors for a PI controller. Using the same "step change" approach defined above for quarter decay tuning.

3. Perform the same modeling runs defined above, but with the Robbins tuning factors and record the deviations and recovery times.

4. Determine if the Robbins tuning approach improved the system performance over the quarter decay tuning approach. 
A.2 HLW Vessel Ventilation Pressure Control Loop

1. The HLW melter extraction fans should be manually adjusted to achieve a vacuum of -5 "WG in the melter plenum and a control air flowrate at 200 SCFM. All other air additions should be turned on as normal. The control air flowrate should be fixed and the plenum pressure control loop placed in manual. Fan speed should be fixed at this speed and the speed/flowrate control loop should placed in manual. Melter feeding should not be initiated. The vessel ventilation flowrate should be at the nominal rate. The goal is to have all system variables "fixed" except for the control loop in question.

2. Set the reset and rate settings of the vessel vent PID controller to zero.

3. With the control loop in automatic, apply a step change of 0.25 ”'WG to the vessel vent header vacuum setpoint.

4. While repeating Step \#3, manually adjust the gain setting until the loop oscillates (i.e., vessel vent pressure regulation valve position) with constant amplitude.

5. Record the "ultimate" gain and the oscillation's “ultimate” period (i.e., time peak to peak).

6. Repeat Steps \#3, \#4, and \#5, but with an opposite step change of -0.25 ”WG.

7. Record the "ultimate” gain and the oscillation's "ultimate” period (i.e., time peak to peak) for this opposing step change. Verify that the same ultimate gain and period are achieved.

8. Determine the different tuning settings for the different controller types defined in Table 6-1 of Smith using the ultimate gain and period defined in Step \#5.

9. Prepare a modeling sequence containing both the standard $2 \mathrm{X}$ and a $4 \mathrm{X}$ vessel vent offgas flowrate spikes.

10. Perform three model runs that sequentially uses the P, PI, and PID tuning settings defined in Step \#8.

11. Record the maximum pressure deviation from setpoint and recovery times during both the $2 X$ and $4 \mathrm{X}$ gas spikes.

12. Based on the recorded deviations and recovery times, determine which tuning settings performed the best.

Using the PI tuning factors developed above, perform a second tuning analysis using the "Robbins" tuning rules as follows:

1. Determine if there are any recognizable patterns to the control response using the quarter decay tuning factors.

2. Starting with the quarter decay tuning factors defined above, follow the steps outlined in Robbins to determine the "refined" tuning factors for a PI controller. Using the same "step change” approach defined above for quarter decay tuning.

3. Perform the same modeling runs defined above, but with the Robbins tuning factors and record the deviations and recovery times.

4. Determine if the Robbins tuning approach improved the system performance over the quarter decay tuning approach. 
A.3 Extraction Fan Speed Control to Regulate Control Air Flowrate (No Flowrate Averaging)

1. The HLW melter plenum vacuum should be fixed at -5 "WG and the control air flowrate fixed at 200 SCFM. The melter pressure control loop should be turned off. All other air additions should be turned on as normal. The vessel vent flowrate should be fixed and the vessel vent control valve fixed at a nominal position (i.e., vessel vent pressure control loop placed in manual). Melter feeding should also not be initiated. (NOTE: For this tuning procedure, the control air flowrate is not averaged and the fan speed controller receives the "raw" flowrate signal.)

2. Set the reset and rate settings of the extraction fan speed PID controller to zero.

3. With the control loop in automatic, apply a step change of 10 SCFM to the control air flowrate (200 SCFM to 190 SCFM).

4. While repeating Step \#3, manually adjust the gain setting until loop oscillates (i.e., fan speed) with constant amplitude.

5. Record the "ultimate” gain and the oscillation's “ultimate” period (i.e., time peak to peak).

6. Repeat Steps \#3, \#4, and \#5, but with the step change from 200 SCFM to 210 SCFM.

7. Record the "ultimate” gain and the oscillation's "ultimate” period (i.e., time peak to peak) for this opposing step change. Verify that the same ultimate gain and period are achieved.

8. Determine the different tuning settings for the different controller types defined in Table 6-1 of Smith using the ultimate gain and period defined in Step \#5.

9. Perform three model runs using the same modeling sequence defined in step \#A.9, but modified to include the normal HEME pressure drop increase before the melter surge. Use the P, PI, and PID tuning settings defined in Step \#8 for the three model runs, respectively. The melter control air and vessel ventilation pressure control loops should be in automatic and using the preferred tuning factors determined in tuning procedures $\mathrm{A}$ and $\mathrm{B}$.

10. Record the control air flowrate maximum deviation from setpoint during the feeding, HEME pressure drop increase, and the melter surge stage. Also record the time it took the system to recover to normal after the melter surge.

11. Based on the recorded deviations and recovery times, determine which tuning settings performed the best.

Using the PI tuning factors developed above, perform a second tuning analysis using the "Robbins" tuning rules as follows:

1. Determine if there are any recognizable patterns to the control response using the quarter decay tuning factors.

2. Starting with the quarter decay tuning factors defined above, follow the steps outlined in Robbins to determine the "refined" tuning factors for a PI controller. Using the same "step change" approach defined above for quarter decay tuning.

3. Perform the same modeling runs defined above, but with the Robbins tuning factors and record the deviations and recovery times.

4. Determine if the Robbins tuning approach improved the system performance over the quarter decay tuning approach. 
A.4 Extraction Fan Speed Control to Regulate Control Air Flowrate (With Flowrate Averaging)

1. The HLW melter plenum vacuum should be fixed at -5 ”WG and the control air flowrate fixed at 200 SCFM. The melter pressure control loop should be turned off. All other air additions should be turned on as normal. The vessel vent flowrate should be fixed and the vessel vent control valve fixed at a nominal position (i.e., vessel vent pressure control loop placed in manual). Melter feeding should also not be initiated. (NOTE: This tuning procedure is different than the one defined in " $\mathrm{C}$ " in that the fan speed controller will receive a "filtered" control air flowrate signal which is average using the standard control methodology.)

2. Set the reset and rate settings of the extraction fan speed PID controller to zero.

3. With the control loop in automatic, apply a step change of 10 SCFM to the control air flowrate (200 SCFM to 190 SCFM).

4. While repeating Step \#3, manually adjust the gain setting until loop oscillates (i.e., fan speed) with constant amplitude.

5. Record the "ultimate” gain and the oscillation's “ultimate” period (i.e., time peak to peak).

6. Repeat Steps \#3, \#4, and \#5, but with the step change from 200 SCFM to 210 SCFM.

7. Record the "ultimate" gain and the oscillation's "ultimate” period (i.e., time peak to peak) for this opposing step change. Verify that the same ultimate gain and period are achieved.

8. Determine the different tuning settings for the different controller types defined in Table 6-1 of Smith using the ultimate gain and period defined in Step \#5.

9. Perform three model runs using the same modeling sequence defined in step \#A.9, but modified to include the normal HEME pressure drop increase before the melter surge. Use the P, PI, and PID tuning settings defined in Step \#8 for the three model runs, respectively. The melter control air and vessel ventilation pressure control loops should be in automatic and using the preferred tuning factors determined in tuning procedures $\mathrm{A}$ and $\mathrm{B}$.

10. Record the control air flowrate maximum deviation from setpoint during the feeding, HEME pressure drop increase, and the melter surge stage. Also record the time it took the system to recover to normal after the melter surge.

11. Based on the recorded deviations and recovery times, determine which tuning settings performed the best.

12. Compare the best tuning results between procedures C and D. Determine if control air flowrate averaging is beneficial to maintaining control of the system.

Using the PI tuning factors developed above, perform a second tuning analysis using the "Robbins" tuning rules as follows:

1. Determine if there are any recognizable patterns to the control response using the quarter decay tuning factors.

2. Starting with the quarter decay tuning factors defined above, follow the steps outlined in Robbins to determine the "refined" tuning factors for a PI controller. Using the same "step change" approach defined above for quarter decay tuning.

3. Perform the same modeling runs defined above, but with the Robbins tuning factors and record the deviations and recovery times.

4. Determine if the Robbins tuning approach improved the system performance over the quarter decay tuning approach. 


\section{Appendix B: LAW Dynamic Modeling Tuning Procedural Steps}

B.1 Melter Pressure Control Loop using Control Air

1. The LAW balancing damper valves should be adjusted to achieve a vacuum of -5 ”WG in the melter plenum and a control air flowrate at 300 SCFM. The LAW extraction fans should be manually adjusted to achieve its vacuum setpoint at the offgas combination node. All other air additions should be turned on as normal. The vessel vent flowrate should be fixed and the vessel vent control valve position fixed at a nominal position (i.e., vessel vent pressure control loop placed in manual). The balancing damper position should be fixed at this position and the damper flowrate controller placed in manual. Fan speed should also be fixed at this speed and the speed/flowrate control loop should be placed in manual. Melter feeding should also not be initiated. The goal is to have all system variables "fixed" except for the control loop in question. The result should be a "flat" melter plenum vacuum with no "dynamics" occurring anywhere in the system. The control air addition and balancing damper controllers on the other LAW melter should be fixed and placed in manual.

2. Set the reset and rate settings of the melter plenum PID controller to zero.

3. With the control loop in automatic, apply a step change of 0.25 ”'WG to the plenum vacuum (5.0"WG to -4.75 ”'WG).

4. While repeating Step \#3, manually adjust the gain setting until the loop oscillates (i.e., fan speed) with constant amplitude.

5. Record the "ultimate" gain and the oscillation's "ultimate” period (i.e., time peak to peak).

6. Repeat Steps \#3, \#4, and \#5, but with the step change from -5”WG to -5.25”WG.

7. Record the "ultimate" gain and the oscillation's "ultimate" period (i.e., time peak to peak) for this opposing step change. Verify that the same ultimate gain and period are achieved.

8. Determine the different tuning settings for the different controller types defined in Table 6-1 of Smith using the ultimate gain and period defined in Step \#5.

9. Prepare a modeling sequence containing a short period of melter feeding followed by a normal 4X surge.

10. Perform three model runs that sequentially uses the P, PI, and PID tuning settings defined in Step \#8.

11. Record the plenum vacuum maximum deviation from setpoint during both the feeding stage and the surge stage. Also record the time it took the system to recover to normal after the melter surge.

12. Based on the recorded deviations and recovery times, determine which tuning settings performed the best.

Using the PI tuning factors developed above, perform a second tuning analysis using the "Robbins" tuning rules as follows:

1. Determine if there are any recognizable patterns to the control response using the quarter decay tuning factors.

2. Starting with the quarter decay tuning factors defined above, follow the steps outlined in Robbins to determine the "refined" tuning factors for a PI controller. Using the same "step change" approach defined above for quarter decay tuning.

3. Perform the same modeling runs defined above, but with the Robbins tuning factors and record the deviations and recovery times.

4. Determine if the Robbins tuning approach improved the system performance over the quarter decay tuning approach. 


\section{B.2 LAW Vessel Ventilation Pressure Control Loop}

1. The LAW melter extraction fans should be manually adjusted to achieve a vacuum of -5 ”WG in the melter plenum and a control air flowrate at 300 SCFM. All other air additions should be turned on as normal. The control air flowrate should be fixed and the plenum pressure control loop placed in manual. The balancing damper position should be fixed at this position and the damper flowrate controller placed in manual. Fan speed should also be fixed at this speed and the speed/flowrate control loop should be placed in manual. Melter feeding should not be initiated. The vessel ventilation flowrate should be at the nominal rate. The goal is to have all system variables "fixed" except for the control loop in question. The control air addition and balancing damper controllers on the other LAW melter should be fixed and placed in manual.

2. Set the reset and rate settings of the vessel vent PID controller to zero.

3. With the control loop in automatic, apply a step change of 0.25 ”'WG to the vessel vent header vacuum setpoint.

4. While repeating Step \#3, manually adjust the gain setting until the loop oscillates (i.e., vessel vent pressure regulation valve position) with constant amplitude.

5. Record the "ultimate” gain and the oscillation's “ultimate” period (i.e., time peak to peak).

6. Repeat Steps \#3, \#4, and \#5, but with an opposite step change of -0.25 ”WG.

7. Record the "ultimate” gain and the oscillation's "ultimate” period (i.e., time peak to peak) for this opposing step change. Verify that the same ultimate gain and period are achieved.

8. Determine the different tuning settings for the different controller types defined in Table 6-1 of Smith using the ultimate gain and period defined in Step \#5.

9. Prepare a modeling sequence containing both the standard $2 \mathrm{X}$ and a $4 \mathrm{X}$ vessel vent offgas flowrate spikes.

10. Perform three model runs that sequentially uses the P, PI, and PID tuning settings defined in Step \#8.

11. Record the maximum pressure deviation from setpoint and recovery times during both the $2 \mathrm{X}$ and $4 \mathrm{X}$ gas spikes.

12. Based on the recorded deviations and recovery times, determine which tuning settings performed the best.

Using the PI tuning factors developed above, perform a second tuning analysis using the "Robbins" tuning rules as follows:

1. Determine if there are any recognizable patterns to the control response using the quarter decay tuning factors.

2. Starting with the quarter decay tuning factors defined above, follow the steps outlined in Robbins to determine the "refined" tuning factors for a PI controller. Using the same "step change" approach defined above for quarter decay tuning.

3. Perform the same modeling runs defined above, but with the Robbins tuning factors and record the deviations and recovery times.

4. Determine if the Robbins tuning approach improved the system performance over the quarter decay tuning approach. 
B.3 LAW Balancing Damper Flow Control to Regulate Control Air Flowrate (No Flowrate Averaging)

5. The LAW melter plenum vacuum should be fixed at -5 "WG and the control air flowrate fixed at 300 SCFM. The melter pressure control loop should be turned off. All other air additions should be turned on as normal. The vessel vent flowrate should be fixed and the vessel vent control valve fixed at a nominal position (i.e., vessel vent pressure control loop placed in manual). Melter feeding should also not be initiated. The control air addition and balancing damper controllers on the other LAW melter should be fixed and placed in manual. (NOTE: For this tuning procedure, the control air flowrate is not averaged and the balancing damper controller receives the "raw" flowrate signal.)

6. Set the reset and rate settings of the balancing damper PID controller to zero.

7. With the control loop in automatic, apply a step change of 10 SCFM to the control air flowrate (300 SCFM to 290 SCFM).

8. While repeating Step \#3, manually adjust the gain setting until loop oscillates (i.e., valve position) with a constant amplitude.

9. Record the "ultimate” gain and the oscillation's “ultimate” period (i.e., time peak to peak).

10. Repeat Steps \#3, \#4, and \#5, but with the step change from 300 SCFM to 210 SCFM.

11. Record the "ultimate” gain and the oscillation's "ultimate” period (i.e., time peak to peak) for this opposing step change. Verify that the same ultimate gain and period are achieved.

12. Determine the different tuning settings for the different controller types defined in Table 6-1 of Smith using the ultimate gain and period defined in Step \#5.

13. Perform three model runs using the same modeling sequence defined in step \#A9, but modified to include the normal SBS pressure drop increase before the melter surge. Use the P, PI, and PID tuning settings defined in Step \#8 for the three model runs, respectively. The melter control air and vessel ventilation pressure control loops should be in automatic and using the preferred tuning factors determined in tuning procedures $\mathrm{A}$ and $\mathrm{B}$. The extraction fan speed controller should be left in manual.

14. Record the control air flowrate maximum deviation from setpoint during the feeding, SBS pressure drop increase, and the melter surge stage. Also record the time it took the system to recover to normal after the melter surge.

15. Based on the recorded deviations and recovery times, determine which tuning settings performed the best.

Using the PI tuning factors developed above, perform a second tuning analysis using the "Robbins" tuning rules as follows:

1. Determine if there are any recognizable patterns to the control response using the quarter decay tuning factors.

2. Starting with the quarter decay tuning factors defined above, follow the steps outlined in Robbins to determine the "refined" tuning factors for a PI controller. Using the same "step change" approach defined above for quarter decay tuning.

3. Perform the same modeling runs defined above, but with the Robbins tuning factors and record the deviations and recovery times.

4. Determine if the Robbins tuning approach improved the system performance over the quarter decay tuning approach. 
B.4 LAW Balancing Damper Flow Control to Regulate Control Air Flowrate (With Flowrate Averaging)

5. The LAW melter plenum vacuum should be fixed at -5 "WG and the control air flowrate fixed at 300 SCFM. The melter pressure control loop should be turned off. All other air additions should be turned on as normal. The vessel vent flowrate should be fixed and the vessel vent control valve fixed at a nominal position (i.e., vessel vent pressure control loop placed in manual). Melter feeding should also not be initiated. The control air addition and balancing damper controllers on the other LAW melter should be fixed and placed in manual. (NOTE: This tuning procedure is different than the one defined in " $\mathrm{C}$ " in that the balancing damper controller will receive a "filtered" control air flowrate signal which is average using the standard control methodology.)

6. Set the reset and rate settings of the balancing damper PID controller to zero.

7. With the control loop in automatic, apply a step change of 10 SCFM to the control air flowrate (300 SCFM to 290 SCFM).

8. While repeating Step \#3, manually adjust the gain setting until loop oscillates (i.e., valve position) with a constant amplitude.

9. Record the "ultimate” gain and the oscillation's “ultimate” period (i.e., time peak to peak).

10. Repeat Steps \#3, \#4, and \#5, but with the step change from 300 SCFM to 310 SCFM.

11. Record the "ultimate” gain and the oscillation's “ultimate” period (i.e., time peak to peak) for this opposing step change. Verify that the same ultimate gain and period are achieved.

12. Determine the different tuning settings for the different controller types defined in Table 6-1 of Smith using the ultimate gain and period defined in Step \#5.

13. Perform three model runs using the same modeling sequence defined in step \#A.9, but modified to include the normal SBS pressure drop increase before the melter surge. Use the P, PI, and PID tuning settings defined in Step \#8 for the three model runs, respectively. The melter control air and vessel ventilation pressure control loops should be in automatic and using the preferred tuning factors determined in tuning procedures $\mathrm{A}$ and $\mathrm{B}$. The extraction fan speed controller should be left in manual.

14. Record the control air flowrate maximum deviation from setpoint during the feeding, SBS pressure drop increase, and the melter surge stage. Also record the time it took the system to recover to normal after the melter surge.

15. Based on the recorded deviations and recovery times, determine which tuning settings performed the best.

16. Compare the best tuning results between procedures $C$ and $D$. Determine if control air flowrate averaging is beneficial to maintaining control of the system.

Using the PI tuning factors developed above, perform a second tuning analysis using the "Robbins" tuning rules as follows:

1. Determine if there are any recognizable patterns to the control response using the quarter decay tuning factors.

2. Starting with the quarter decay tuning factors defined above, follow the steps outlined in Robbins to determine the "refined" tuning factors for a PI controller. Using the same "step change" approach defined above for quarter decay tuning.

3. Perform the same modeling runs defined above, but with the Robbins tuning factors and record the deviations and recovery times.

4. Determine if the Robbins tuning approach improved the system performance over the quarter decay tuning approach. 
B.5 LAW Extraction Fan Speed/Pressure Control Loop

1. The LAW balancing damper valves should be adjusted to achieve a vacuum of -5 "WG in the melter plenum and a control air flowrate at 300 SCFM. All other air additions should be turned on as normal. The control air flowrate should be fixed and the plenum pressure control loop placed in manual. The balancing damper position should be fixed at this position and the damper flowrate controller placed in manual. The vessel vent flowrate should be fixed and the vessel vent control valve position fixed at a nominal position (i.e., vessel vent pressure control loop placed in manual). Melter feeding should not be initiated. The vessel ventilation flowrate should be at the nominal rate. The goal is to have all system variables "fixed" except for the control loop in question. The control air addition and balancing damper controllers on the other LAW melter should be fixed and placed in manual.

2. Set the reset and rate settings of the extraction fan speed PID controller to zero.

3. With the control loop in automatic, apply a step change of 1"WG to the common offgas node vacuum setpoint.

4. While repeating Step \#3, manually adjust the gain setting until the loop oscillates (i.e., fan speed) with a constant amplitude.

5. Record the "ultimate” gain and the oscillation's “ultimate” period (i.e., time peak to peak).

6. Repeat Steps \#3, \#4, and \#5, but with an opposite step change of -1"WG.

7. Record the "ultimate” gain and the oscillation's “ultimate” period (i.e., time peak to peak) for this opposing step change. Verify that the same ultimate gain and period are achieved.

8. Determine the different tuning settings for the different controller types defined in Table 6-1 of Smith using the ultimate gain and period defined in Step \#5.

9. Perform three model runs using the same modeling sequence defined in step \#A.9 but modified to include the normal SBS pressure drop increase before the melter surge. Use the P, PI, and PID tuning settings defined in Step \#8 for the three model runs, respectively. The melter control air, balancing damper, and vessel ventilation control loops should be in automatic and using the preferred tuning factors determined in tuning procedures $\mathrm{A}, \mathrm{B}, \mathrm{C}$, and D.

10. Perform three model runs that sequentially uses the P, PI, and PID tuning settings defined in Step \#8.

11. Record the plenum vacuum, control air flowrate, and common offgas node pressure maximum deviation from setpoint during the feeding, SBS pressure drop increase, and the melter surge stages. Also record the time it took the system to recover to normal after the melter surge.

12. Based on the recorded deviations and recovery times, determine which tuning settings performed the best.

Using the PI tuning factors developed above, perform a second tuning analysis using the

"Robbins" tuning rules as follows:

1. Determine if there are any recognizable patterns to the control response using the quarter decay tuning factors.

2. Starting with the quarter decay tuning factors defined above, follow the steps outlined in Robbins to determine the "refined" tuning factors for a PI controller. Using the same "step change" approach defined above for quarter decay tuning.

3. Perform the same modeling runs defined above, but with the Robbins tuning factors and record the deviations and recovery times.

4. Determine if the Robbins tuning approach improved the system performance over the quarter decay tuning approach. 


\section{Appendix C: PJV Dynamic Modeling Tuning Procedural Steps}

C.1 PJV Ventilation Pressure Control Loop (No Pressure Averaging)

1. The PJV extraction fans should be manually adjusted to achieve the standard vacuum setpoint upstream of the PJV HEPA preheater. The PJV ventilation offgas flowrate should be steady (i.e., no fluctuations) and at the average rate. The goal is to have all system variables "fixed" except for the control loop in question. (NOTE: For this tuning procedure, the PJV header pressure is not averaged and the fan speed controller receives the "raw" pressure signal.)

2. Set the reset and rate settings of the PJV PID controller to zero.

3. With the control loop in automatic, apply a step change of 1”WG to the PJV header vacuum setpoint.

4. While repeating Step \#3, manually adjust the gain setting until the loop oscillates (i.e., PJV extraction fan speed) with constant amplitude.

5. Record the "ultimate" gain and the oscillation's "ultimate” period (i.e., time peak to peak).

6. Repeat Steps \#3, \#4, and \#5, but with an opposite step change of -1 ”WG.

7. Record the "ultimate" gain and the oscillation's "ultimate" period (i.e., time peak to peak) for this opposing step change. Verify that the same ultimate gain and period are achieved.

8. Determine the different tuning settings for the different controller types defined in Table 6-1 of Smith using the ultimate gain and period defined in Step \#5.

9. Prepare a modeling sequence containing the standard PJV flowrate oscillation pattern combined with the step increases in offgas flowrate as more air-jets are brought on line.

10. Perform three model runs that sequentially uses the P, PI, and PID tuning settings defined in Step \#8.

11. Record the maximum pressure deviation from pressure setpoint and the recovery times when there is a significant flowrate change.

12. Based on the recorded deviations and recovery times, determine which tuning settings performed the best.

Using the PI tuning factors developed above, perform a second tuning analysis using the

"Robbins" tuning rules as follows:

1. Determine if there are any recognizable patterns to the control response using the quarter decay tuning factors.

2. Starting with the quarter decay tuning factors defined above, follow the steps outlined in Robbins to determine the "refined" tuning factors for a PI controller. Using the same "step change" approach defined above for quarter decay tuning.

3. Perform the same modeling runs defined above, but with the Robbins tuning factors and record the deviations and recovery times.

4. Determine if the Robbins tuning approach improved the system performance over the quarter decay tuning approach. 
C.2 PJV Ventilation Pressure Control Loop (With Pressure Averaging)

1. The PJV extraction fans should be manually adjusted to achieve the standard vacuum setpoint upstream of the PJV HEPA preheater. The PJV ventilation offgas flowrate should be steady (i.e., no fluctuations) and at the average rate. The goal is to have all system variables "fixed" except for the control loop in question. (NOTE: For this tuning procedure, the PJV header pressure is averaged and the fan speed controller receives the "filtered" pressure signal based on the established methodology.)

2. Set the reset and rate settings of the PJV PID controller to zero.

3. With the control loop in automatic, apply a step change of 1 ”WG to the PJV header vacuum setpoint.

4. While repeating Step \#3, manually adjust the gain setting until the loop oscillates (i.e., PJV extraction fan speed) with constant amplitude.

5. Record the "ultimate” gain and the oscillation's “ultimate” period (i.e., time peak to peak).

6. Repeat Steps \#3, \#4, and \#5, but with an opposite step change of -1”WG.

7. Record the "ultimate" gain and the oscillation's "ultimate" period (i.e., time peak to peak) for this opposing step change. Verify that the same ultimate gain and period are achieved.

8. Determine the different tuning settings for the different controller types defined in Table 6-1 of Smith using the ultimate gain and period defined in Step \#5.

9. Prepare a modeling sequence containing the standard PJV flowrate oscillation pattern combined with the step increases in offgas flowrate as more air-jets are brought on line.

10. Perform three model runs that sequentially uses the P, PI, and PID tuning settings defined in Step \#8.

11. Record the maximum pressure deviation from pressure setpoint and the recovery times when there is a significant flowrate change.

12. Based on the recorded deviations and recovery times, determine which tuning settings performed the best.

13. Compare the best tuning results between procedures A and B. Determine if pressure averaging is beneficial to maintaining control of the system.

Using the PI tuning factors developed above, perform a second tuning analysis using the "Robbins" tuning rules as follows:

1. Determine if there are any recognizable patterns to the control response using the quarter decay tuning factors.

2. Starting with the quarter decay tuning factors defined above, follow the steps outlined in Robbins to determine the "refined" tuning factors for a PI controller. Using the same "step change" approach defined above for quarter decay tuning.

3. Perform the same modeling runs defined above, but with the Robbins tuning factors and record the deviations and recovery times.

4. Determine if the Robbins tuning approach improved the system performance over the quarter decay tuning approach. 
This page intentionally left blank. 


\section{Appendix D: Process Flowsheets for Control Loop Tuning.}

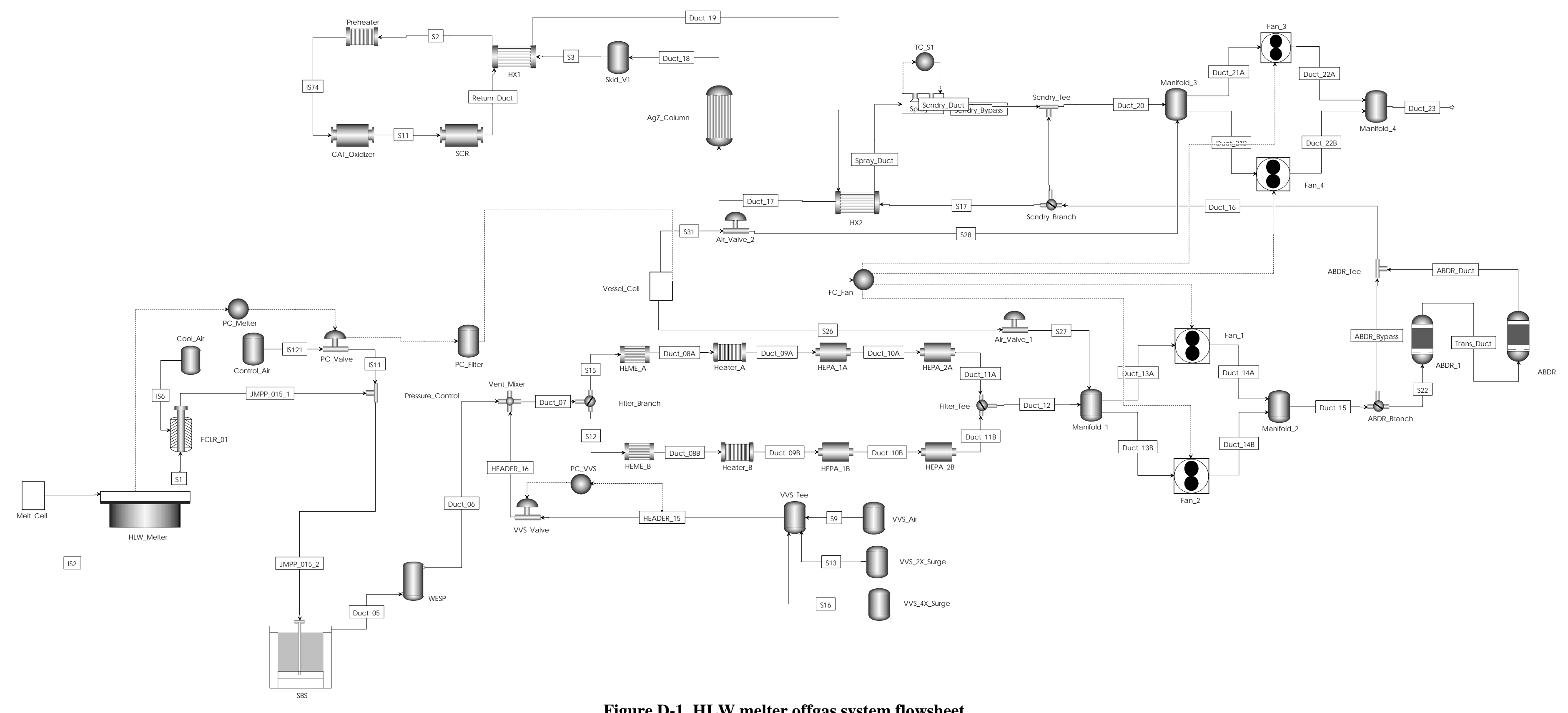

Figure D-1 HLW melter offgas system flowsheet. 


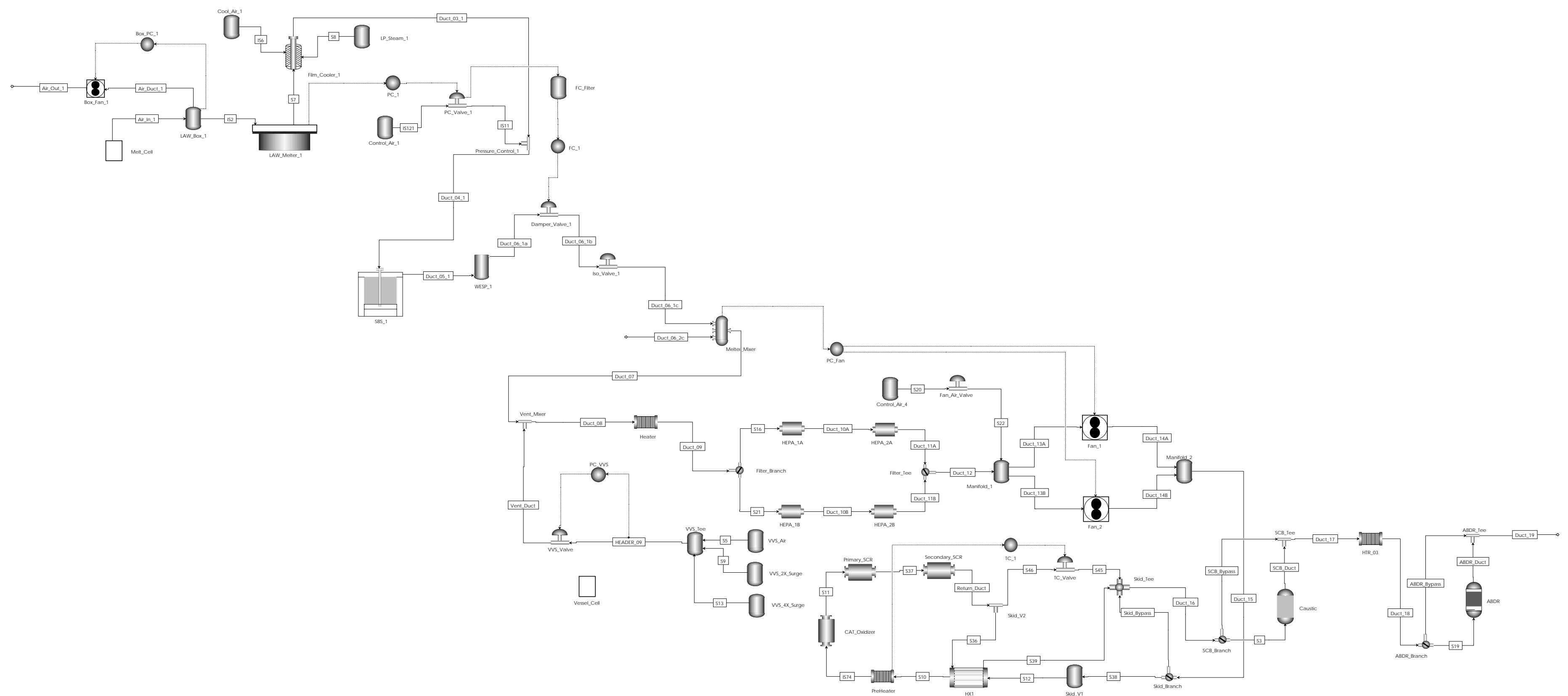

Figure D-2 LAW melter offgas system control loop tuning flowsheet. 


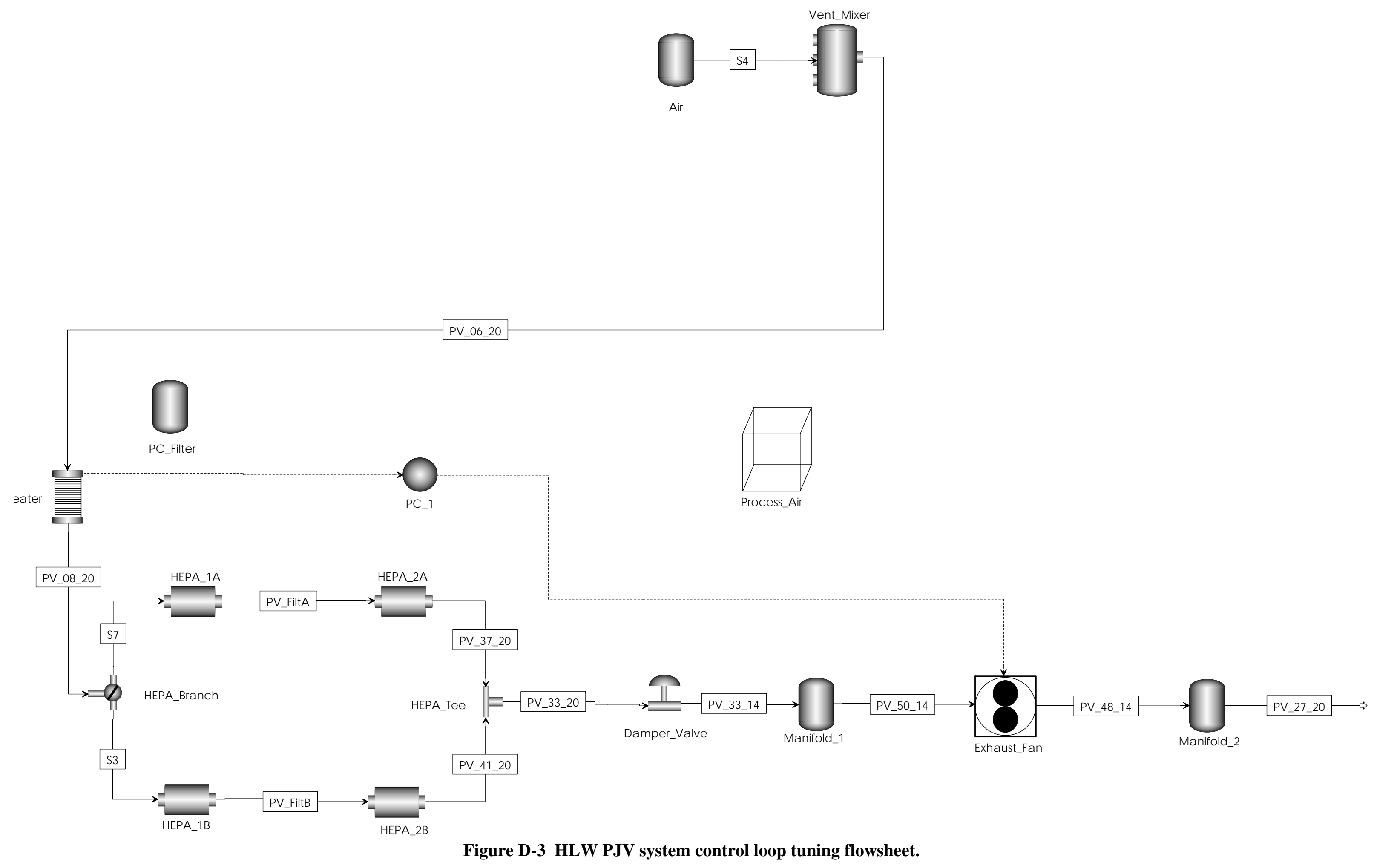

